\title{
Kappa Opioid Receptor Agonists: New Targets in the Treatment of Pain
}

\author{
Nitin Kumar
}

Student ID: 300262073

2014

A thesis submitted to Victoria University of Wellington in fulfilment of the requirements for the degree of Masters by Thesis 


\section{ABSTRACT}

Background and Purpose

Pain, although necessary for survival, can become pathological affecting an estimated 1 in 5 adults globally. It is also the most common reason people seek medical attention. Mu opioid receptor (MOPr) agonists, such as morphine, are the gold standard treatment for pain. Although these drugs have excellent analgesic properties, adverse effects such as addiction, tolerance and respiratory depression make their use problematic. An estimated 10,000 New Zealanders are addicted to prescription opiates, highlighting the need for better drugs to treat pain. Kappa opioid receptor (KOPr) agonists have analgesic properties and, unlike MOPr agonists, are also anti-addictive. Unfortunately, adverse effects such as sedation and dysphoria, have limited their therapeutic potential. The discovery of KOPr agonists that have analgesic properties without inducing adverse effects can allow for better, more efficient treatments of pain. We are the first to report the analgesic potential of novel Salvinorin $A$ (Sal A) analogues: Tetrahydropyran Salvinorin A (THP Sal A) and Mesyl Salvinorin B (Mesyl Sal B).

Experimental Approach and Compounds Tested

This study uses animal behavioural models to characterise the analgesic, anti-oedematous, sedative and hypothermic effects of a structurally new class of KOPr agonists including Sal A, THP Sal A and Mesyl Sal B. The known peripherally restricted KOPr agonist, ICI 204,448, was used to evaluate the peripherally mediated analgesic mechanisms of KOPr agonists. The tailflick and intradermal formalin test were used to assess acute central and peripheral pain processes respectively. Sedative effects were monitored via rotarod performance test; thermoregulatory effects were also recorded. 
Key Results

ICl 204,448 attenuated inflammatory pain at a dose of $1 \mathrm{mg} / \mathrm{kg}(P<0.05,30 \mathrm{~min})$ and 2 $\mathrm{mg} / \mathrm{kg}(\mathrm{P}<0.001,30-35 \mathrm{~min})$. Although it showed no centrally mediated analgesic effects, it was found to be sedative at a dose of $2 \mathrm{mg} / \mathrm{kg}(P<0.01,15-60 \mathrm{~min})$. Sal A (2 mg/kg) attenuated inflammatory pain $(P<0.01,25-35 \mathrm{~min})$ at the same dose it was sedative $(P<0.01$, 2-15 $\mathrm{min}$ ). Although it treated acute thermal pain at a non-sedative dose $(1 \mathrm{mg} / \mathrm{kg}, \mathrm{P}<0.001$, 10-15 $\mathrm{min}$ ), it has a short duration of action ( $15 \mathrm{~min}$ ). THP Sal A attenuated both thermal and inflammatory pain. Unfortunately, it was also sedative at both $1 \mathrm{mg} / \mathrm{kg}(P<0.01,15-45$ $\mathrm{min}$ ) and $2 \mathrm{mg} / \mathrm{kg}(P<0.001,15-90 \mathrm{~min})$. Mesyl Sal B significantly attenuated both central $(1 \mathrm{mg} / \mathrm{kg}, \mathrm{P}<0.01,30-60 \mathrm{~min})$ and peripheral $(2 \mathrm{mg} / \mathrm{kg}, \mathrm{P}<0.01,30 \mathrm{~min})$ pain processes. Although Mesyl Sal B was found to have a weak analgesic effect in all pain assays, it was not sedative.

\section{Conclusions and Implications}

KOPr agonists attenuate acute nociceptive and inflammatory pain. Structural modification of Sal A at the $\mathrm{C}-2$ position alters its analgesic effects in vivo. Substitution with a tetrahydropyran group greatly improves central analgesic effects; however, sedative effects were also observed. Although substitution with a mesylate group produced no sedative effects, it had reduced effects on central and peripheral pain processes. The lack of sedation by Mesyl Sal B makes it a good target for future research in pain. Its longer duration of action compared to Sal A suggests it has a better metabolic profile. The creation of more soluble KOPr compounds would allow for better dose-testing to evaluate therapeutic potential of KOPr analgesics. 
Contents

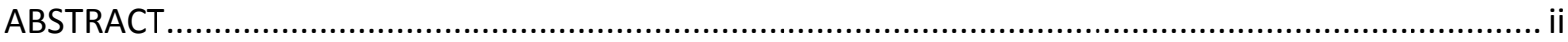

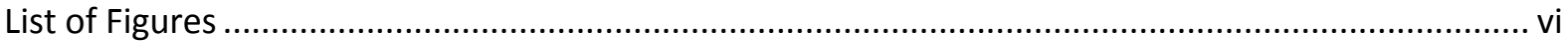

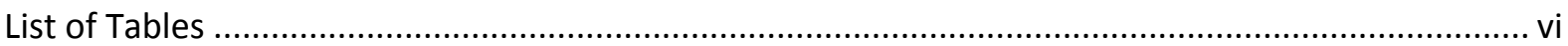

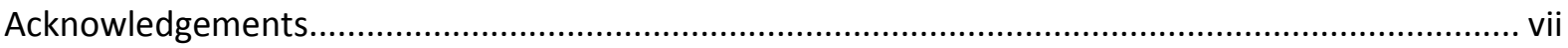

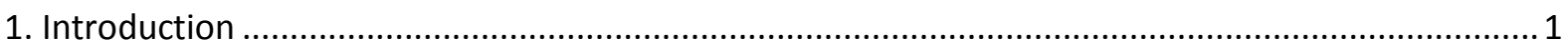

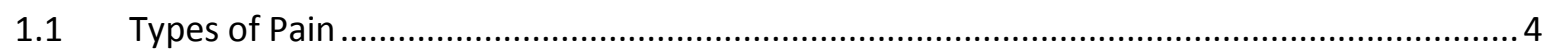

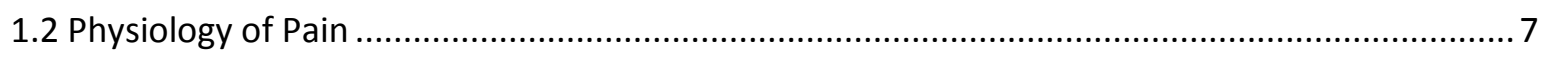

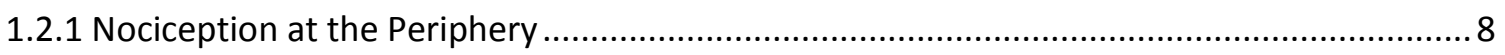

1.2.2 Nociception in the Spinal Cord and Brain ............................................................. 11

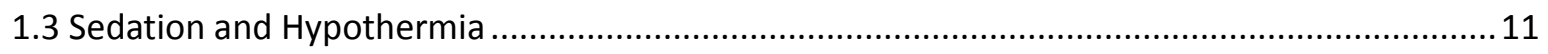

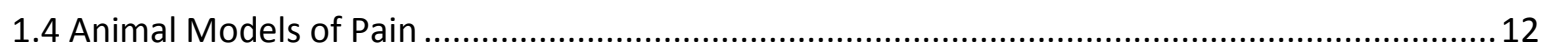

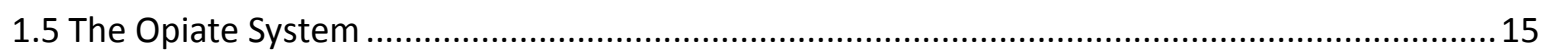

1.5.1 Kappa Opioid Receptor Agonists ................................................................... 16

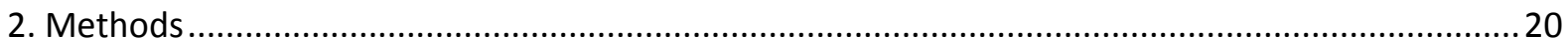

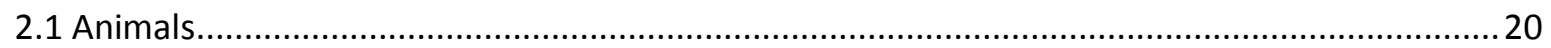

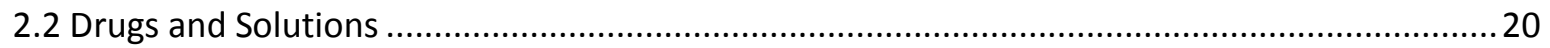

2.3 Assessment of Nociceptive Behaviour ............................................................. 21

2.3.1 Tail-Flick Test................................................................................................. 21

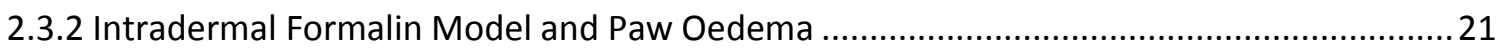

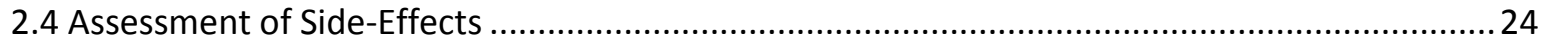

2.4.1 Motor Coordination by Rotarod Performance Assay .............................................. 24

2.4.2 Core Body Temperature Measurements ..................................................................... 24

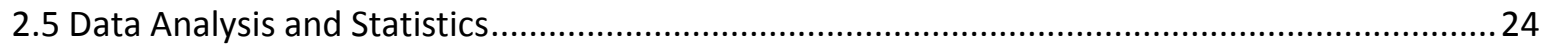

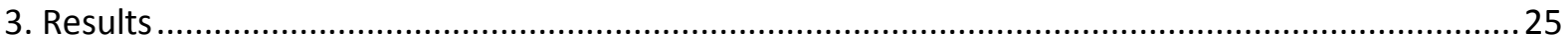

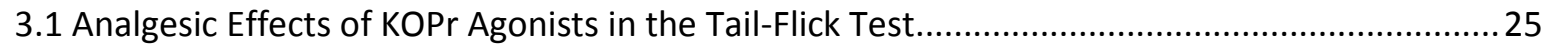

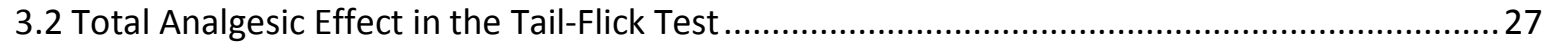

3.3 Analgesic Effects of KOPr Agonists in the Intradermal Formalin Test .................................29

3.4 Total Analgesic Effect in the Intradermal Formalin Test............................................... 31

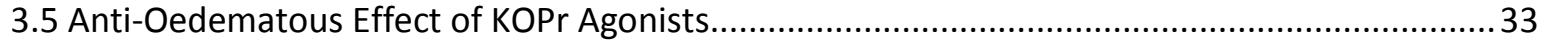

3.6. Effect of KOPr Agonists on Motor Coordination in the Rotarod Performance Test .................35

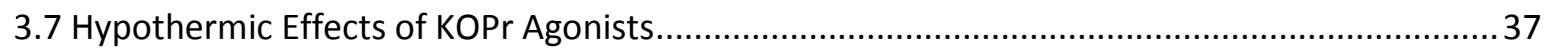

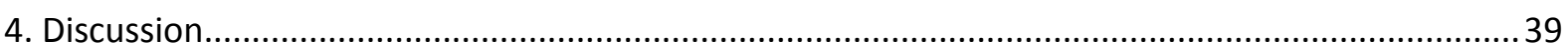

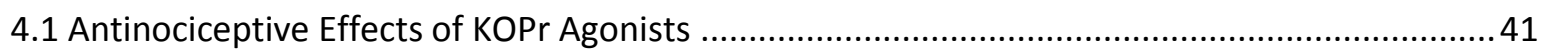




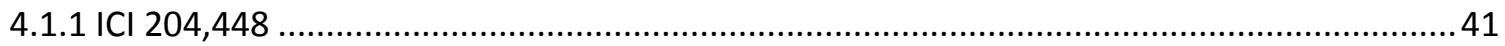

4.1.2 Tail Flick Test: Sal A, THP Sal A \& Mesyl Sal B ......................................................... 42

4.1.3 Intradermal formalin Test: Sal A, THP Sal A \& Mesyl Sal B ........................................44

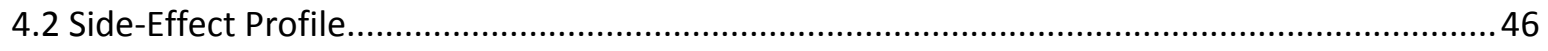

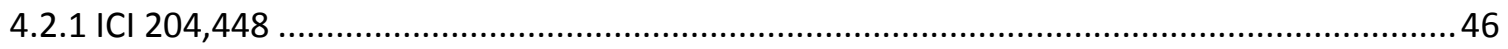

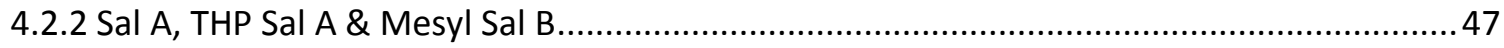

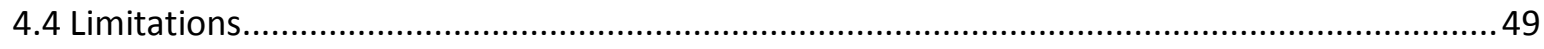

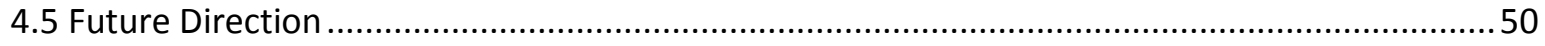

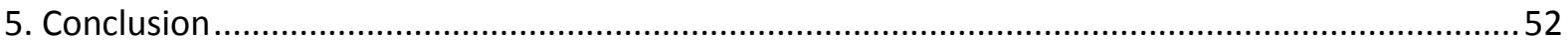

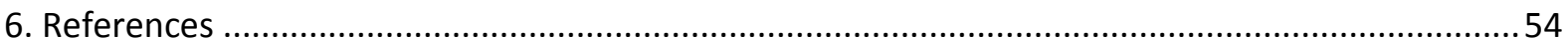




\section{List of Figures}

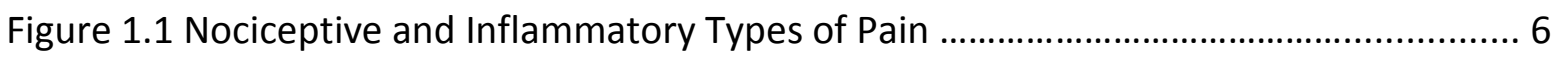

Figure 1.2 Bidirectional communication between CNS and Periphery ................................. 10

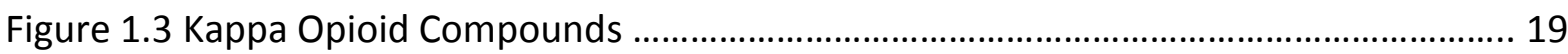

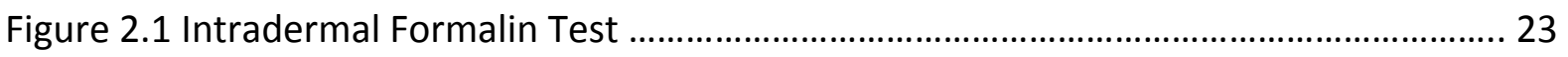

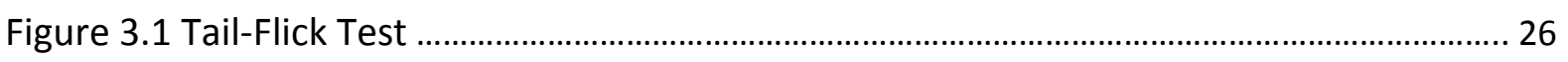

Figure 3.2 Total Analgesic Effect in the Tail-Flick Test ........................................................... 28

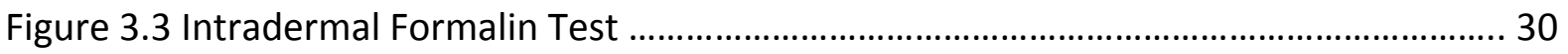

Figure 3.4 Area Under the Curve of Intradermal Formalin Test ............................................. 32

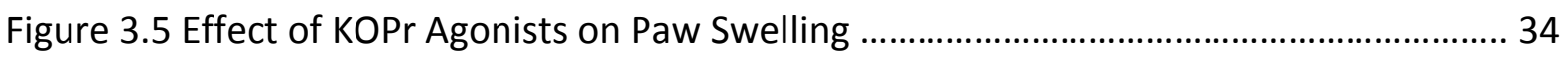

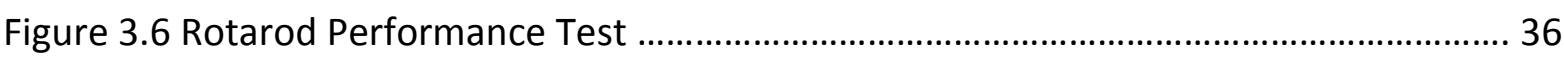

Figure 3.7 Time-Course Effects of KOPr Agonists on Rectal Temperature $\left({ }^{\circ} \mathrm{C}\right)$...................... 38

\section{List of Tables}

Table 1.1 Comparison of KOPr Agonists in Animal Behavioural Models of Pain ................... 14

Table 1.2 Comparison of Binding and Efficacy Properties between KOPr Agonists ............. 18

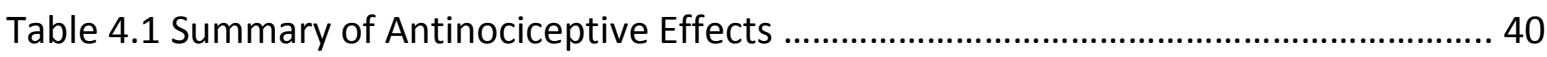

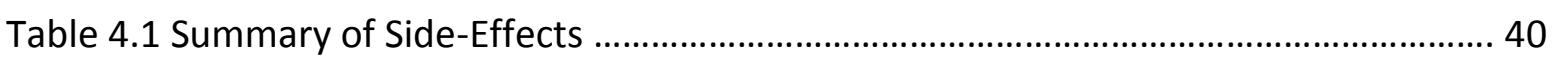




\section{Acknowledgements}

Writing this thesis was a very challenging process that would not have been accomplished without the help and support of a few very special people. I wish to convey my gratitude to all those who made this, seemingly impossible task at one time, possible. First and foremost to my supervisor, Dr. Bronwyn Kivell. Your advice and support through the entirety of my project will never be forgotten. Thank you for the effort and priority you placed over me as it was beyond your call of duty.

I like that I have learned to associate KK 601 with not only the occasional gruelling "dusk-todawn thesis write-up" scenarios, but also the very pleasant and engaging atmosphere brought on by all the lovely people in the lab. I'd like to acknowledge Kelly Paton for her input and work she did with Dr. Odette Shaw at the Malaghan Institute in processing paw tissues for inflammatory mediators. Thank you to Amy Ewald for teaching me drug preparation protocols with creative analogies; Dr. Janet Pitman for letting us use the animal facility; Craig Doney and Neville Higgison for the technical help. I owe a debt of gratitude to Patricia Stein at the Faculty of Science for her understanding and overall kindness at times of need.

Marta Machura, you were a pillar of support through my entire journey. I appreciate your input and encouragement through the months. Last and very far from least - l'd like thank my dad, Nirmal Kumar. If it wasn't for your advice, support, faith and understanding, I would be far from realising the significance of my position. 



\section{Introduction}

Pain is defined by the International Association of Pain as "an unpleasant sensory and emotional experience associated with actual or potential tissue damage" (Basbaum et al., 2009; Merskey \& Bogduk, 1994). It provides sensation of, and protection from destructive influences, such as noxious heat, cold, electrical, mechanical and chemical stimuli. Although pain is necessary for survival (Nagasako et al., 2003), it can become pathological or exist as a symptom of a pathological condition. It is estimated to affect 1 in 5 adults globally (Goldberg \& McGee, 2011), making it the most common reason people seek medical attention (Fishman, 2007). Today, the treatment of pain contributes to a global multibillion dollar industry, while, in the United States, the economic costs due to the absence of pain-related work is as high as $\$ 635$ billion per year (Gaskin \& Richard, 2012). Studies show that $50-80 \%$ of Australians suffering from pain are undertreated (Cousins, 2012), and $72.9 \%$ of Canadians waiting at pain clinics report pain as interfering with their normal work (Choiniere et al., 2010). There are a variety of pharmacological and non-pharmacological ways in which pain can be treated. Conventional pharmacological treatment by mu opioid peptide receptor (MOPr) agonists such as morphine and fentanyl remain the gold-standard for the management of acute pain in the emergency department and also in the treatment of more persistent pain (Kalso et al., 2002), particularly in cancer sufferers (Radbruch et al., 2002). Although MOPr agonists have excellent analgesic effects, adverse effects include nausea and vomiting, tolerance, addiction, constipation and respiratory depression (Madadi et al., 2013; Schug et al., 1992; Shapiro et al., 2005); making them less than ideal for long term use. Abuse of prescription opioids, such as morphine, is a major problem. The Centre of Disease Control and Prevention in the U.S. found that $73.8 \%$ of the 20,044 prescription overdose related deaths in 2008 where due to prescription opioids - an amount greater than the number of deaths due to cocaine and heroin combined (Chakravarthy et al., 2012). In Australia, the number of patients treated for poisoning by prescription opioids increased almost three-fold (from 605 patients in 1998/1999 to 1700 in 2007), while poisoning from heroin fell by similar proportions (from 1712 patients to 446), possibly suggesting a deviation of addictive behaviour from illicit opioids to prescription opioids (Huxtable et al., 2011). It is estimated that an average of one person dies every fortnight in New Zealand due 
to opiate overdose. A 2008 report by the Ministry of Health in New Zealand surveyed 97 known opiate addicts and found that $32.2 \%$ of them reported morphine as their injected drug of choice (Deering et al., 2014). There is continual reporting of increased rates of addiction every year in New Zealand, Australia, Canada and the U.S. due to prescription opioid medication (Birnbaum et al., 2011; Blanch et al., 2014; El-Guebaly, 2014; Ling et al., 2011). The burden on society due to adverse effects from conventional pain-treatment and reduction in quality of life due to undertreated pain, highlights the need for better and more efficient treatments for pain.

Another class of opioid receptors found in the human body with analgesic effects are the kappa opioid peptide receptors (KOPr). Traditional KOPr agonists such as Trans-3,4-dichloro$\mathrm{N}$-methyl-N-[2-(1-pyrrolidinyl)cyclohexyl]-benzeneacetamide $(\mathrm{U}-50,488 \mathrm{H})$, was found to have analgesic effects (Piercey et al., 1982b) without causing physical dependence (Lahti et al., 1982). KOPr agonists, such as the recently discovered Salvinorin A (Sal A), was found to have analgesic effects in animal models testing for acute and chronic pain due to inflammation (Aviello et al., 2011; Guida et al., 2012). Bremazocine, another KOPr agonist, was found to attenuate acute thermal pain (Tseng \& Collins, 1991) without causing respiratory depression (Freye et al., 1983) or addiction (Nestby et al., 1999), common adverse-effect of MOPr agonists (Contet et al., 2004; Shapiro et al., 2005). Unfortunately, side-effects such as sedation, dysphoria and hallucinations have limited the therapeutic use of KOPr agonists (Barber \& Gottschlich, 1997). Over the last 20 years, there have been considerable efforts in discovering KOPr agonists capable of producing analgesic effects with little or no side-effects. Similar to MOPr agonists (Florez et al., 1968; Oldendorf et al., 1972), many of the adverse-effects of KOPr agonists were found to be mediated via central mechanisms. As the transmission and modulation of pain mechanisms is possible via central (Mason, 1999; Urban \& Gebhart, 1999) and peripheral mechanisms (Stein et al., 2009), studies have focused on discovering KOPr agonists with peripherally restricted properties (Cunha et al., 2012; Riviere, 2004). The KOPr agonist, CR845 - currently under phase 2 clinical trials, was found to attenuate pruritus, acute and chronic pain; and was well tolerated in 300 patients receiving single or multiple doses intravenously. The therapeutic potential of CR845 is claimed to be due to its limited access to the central nervous system 
(CNS) (Nielsen et al., 2009). For recent reviews on the therapeutic potential of peripherally restricted KOPr agonists, see Stein and Küchler (2013); Kivell and Prisinzano (2010).

Although opioid pain therapy with MOPr agonists, such as morphine, has helped treat painful conditions since the 1850s (Brownstein, 1993), it does not come without serious adverse effects. The lack of selectivity towards anti-pain pathways among conventional opioid treatments to date is turning out to be a significant cause for encouraging addictive behaviour while also reducing standard of life. Studies on the opiate system point out that MOPr (Whiteside et al., 2004) and KOPr agonists (Nielsen et al., 2009; Binning et al., 2011) with limited access to the CNS allows for better selectivity for clinically relevant anti-pain mechanisms. Furthermore, KOPr agonists are anti-addictive in nature (Bruchas et al., 2010). This illustrates the therapeutic potential of KOPr agonists in the treatment of pain. 


\subsection{Types of Pain}

Pain is a complex process to study. Many classifications are predominantly based on anatomy and etiology involved in the pain experienced (Nagasako et al., 2003; Price et al., 2009). Woolf et al. (1998) criticised the etiology-based pain classification, arguing that a mechanism-based classification of pain would be more relevant, both diagnostically, and in the field of pain-research. Their classification took into account that the mechanism for the development of pain is similar across different disease states. For example, the mechanism for pain development in post-operative patients and those with inflammatory arthritis is similar in that the pain is due to the process of inflammation. Anti-inflammatory agents may thus be used to treat pain in both post-operative (Viscusi et al., 2004) and inflammatory arthritis (Stein et al., 1999). This method of classifying pain is becoming more widely accepted (Finnerup \& Jensen, 2006; O'Sullivan \& Beales, 2007; Schafer et al., 2014). It is highly relevant to the present study because it allows us to discern the mechanism of analgesic action of drugs on known animal behavioural models of pain.

Pain is known to manifest either acutely (short in duration) or chronically ( $>3$ to 6 months in humans). Acute pain in animal behavioural models can be anywhere between one hour to one week, reviewed by Le Bars et al., (2001). Woolf et al., (1998) identified three basic types of pain: nociceptive, inflammatory and pathological pain. Nociceptive pain is associated with the direct stimulation of sensory fibres following tissue injury due to noxious heat, cold, chemical and mechanical stimuli. It is responsible for the initial voluntary or reflexive withdrawal reaction from noxious stimuli and is protective in nature. It is characterised by its quick onset and short duration, and is mediated by only central processes; reviewed by Woolf (2010). Inflammation plays an important role in peripheral mechanisms of pain transmission that help alert the organism to injury. Inflammatory pain classically appears after nociceptive pain; it is longer in duration and can increase pain sensitivity (Andrew \& Greenspan, 1999). Due to its persistent nature, clinically relevant painful conditions such as post-operative pain (Smith \& Nielsen, 2006) occur as a result of inflammatory processes (Shavit et al., 2006). Pathological pain is not a symptom of a disease, but rather a diseasestate of the nervous system. It can be further classified into neuropathic pain, caused by a lesion or dysfunction of sensory pathways; and dysfunctional pain, which is present without 
any tissue damage or inflammation. The classical triad of neuropathic pain includes neurons, immune cells and glia (Scholz \& Woolf, 2007); therefore modulation of immunoregulatory pathways also present as targets for the treatment of this type of pain (Wagner et al., 1998). Nociceptive and inflammatory types of pain have been shown to be attenuated by KOPr agonists via central and peripheral mechanisms. (Aviello et al., 2011; Guida et al., 2012) Understanding the mechanisms of pain transmission has helped us create more generic treatments for pain symptoms that are commonly present alongside acute injuries and disease-states. 
A
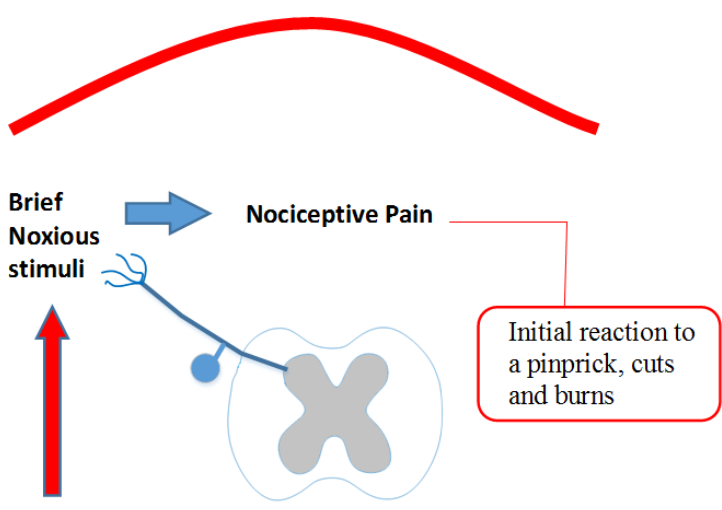

Thermal

Chemical

Centrally Mediated

Mechanical

B

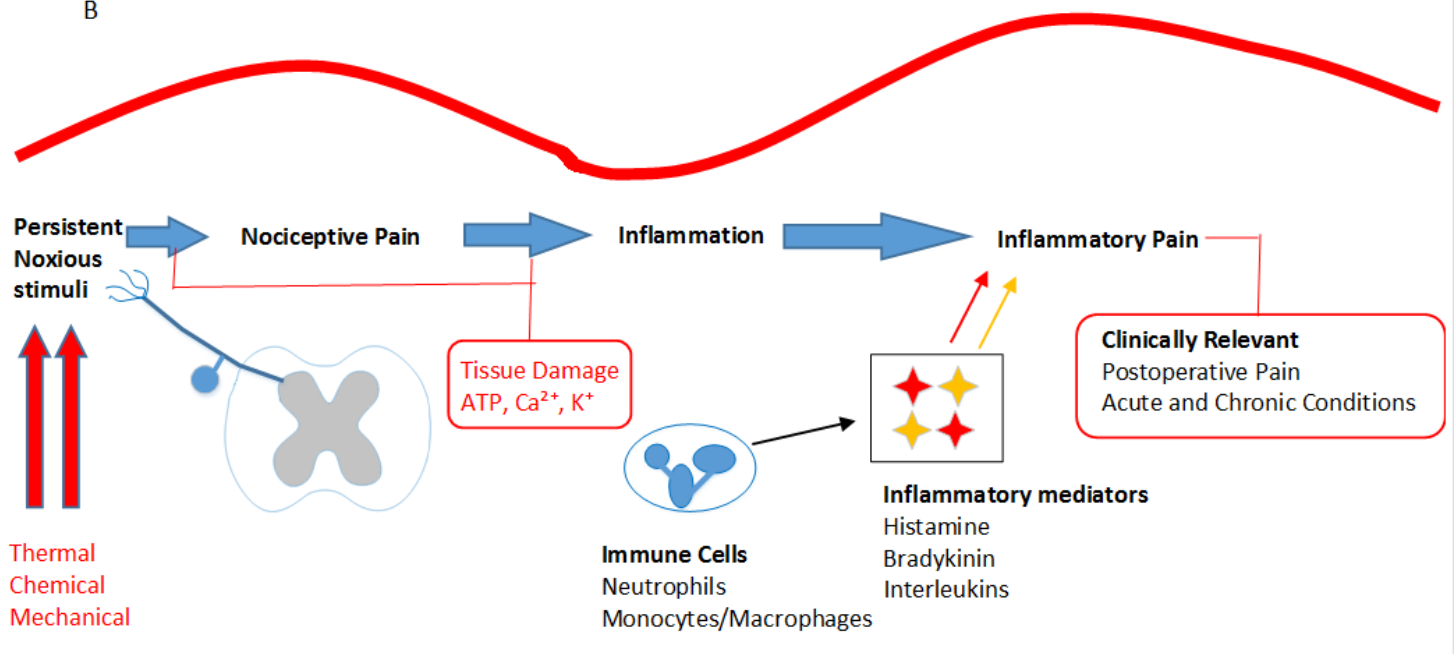

Centrally Mediated

Peripherally Mediated

Figure 1.1 Nociceptive and Inflammatory Types of Pain. (A) Nociceptive Pain is centrally mediated via spinal pathways after a direct stimulation of peripheral nociceptive neurons by noxious stimuli. This type of pain is brief, and marks the initial reaction to noxious stimuli that may be either potentially tissue damaging or nontissue damaging. (B) More persistent stimuli that potentially damage tissue causes the release of intracellular components, such as adenine triphosphate (ATP), calcium $\left(\mathrm{Ca}^{2+}\right)$ and potassium $\left(\mathrm{K}^{+}\right)$ions. This can give rise to the recruitment of inflammatory cells, such as neutrophils, monocytes/or macrophages that release proalgesic inflammatory mediators, such as histamine, bradykinin and interleukins. This process leads to the peripherally mediated and clinically relevant type of pain that exists in both acute and chronic conditions. 


\subsection{Physiology of Pain}

Nociception is the biochemical and biophysical process that is transmitted via 1 st, 2 nd and 3rd order neurons in the transmission of noxious stimuli that is interpreted by the brain as 'pain' (Basbaum et al., 2009). Pain is a complex process and its manifestation can depend on many variables, including emotional state (Villemure et al., 2003), gender (Aloisi, 2003), genetics (Cheung, 2010), previous experiences with pain (Bierman, 2011) and environmental factors (Karjalainen et al., 2013); for a recent review on the complexity of pain see Belfer (2013). Injury and inflammation of peripheral tissue stimulates the electrical activity of specialised sensory dorsal root ganglion (DRG) neurons known as nociceptors (Gold \& Gebhart, 2010; Woolf \& Ma, 2007). The reception, relay and perception of nociceptive and inflammatory pain require a three-neuron chain mechanism (Steeds, 2009). Thermal, chemical and mechanical stimuli are sensed by transducer proteins, which are ion channels/receptors on nociceptor terminals of peripheral nerves (1st order neurons). In response to noxious stimuli, they generate depolarising currents via sodium and calcium ion entry (Geffeney \& Goodman, 2012). If these currents are sufficient enough to generate an action potential, the message is relayed to the spinal cord. This process of action potential generation is referred to as transduction. Transducer proteins on peripheral nociceptor terminals allow for action potentials to reach the CNS, the perception of which is subject to modulatory mechanisms. This is done through a fine balance between intrinsic excitatory and inhibitory pain pathways in the CNS and periphery (Marchand, 2008). Pain pathways should therefore not be seen as a direct link between noxious stimulus-detecting receptors and the subsequent activation of pain networks in the brain. They are rather a complex summation of simultaneous ascending and descending influences, both centrally and peripherally. Pain is thus experienced when the summation of these influences tips in favour of excitatory nociceptive signal transmission. 


\subsubsection{Nociception at the Periphery}

Nociceptors are widely found in almost all tissue types in the human body and can be directly stimulated via acute thermal, chemical, mechanical and inflammatory stimuli (Almeida et al., 2004). The cell bodies of nociceptors are located in the dorsal root ganglion (DRG) for somatic innervations and the trigeminal ganglion for facial innervations. Both have peripheral and central axonal branches that innervate their target organ and spinal cord respectively. Nociceptors are typically characterised according to the type of stimulus they are able to detect. Noxious thermal, chemical and mechanical stimuli are detected by highthreshold nociceptors that contain transducer proteins capable of detecting these stimuli. Polymodal nociceptors are capable of detecting a variety of noxious stimuli, while silent/sleeping nociceptors activate only during certain conditions, such as that during inflammation; reviewed by Marchand (2008). These nociceptors are recognised to have two different types of axons - A $\delta$ and C-fiber axons (Lawson, 2002) - which are commonly referred to as $A \delta$ and C-fiber nociceptors.

A $\delta$ nociceptors are fast conducting myelinated sensory neurons that are associated with transmitting the initial, more rapid thermal and mechanical nociceptive pain (Georgopoulos, 1976). They are associated with sharp and well-localized pain sensations in rodents (Basbaum et al., 2009). C-fibres are a very heterogeneous group of neurons that can handle many different forms of sensory input, referred to as being polymodal in nature (Schmelz et al., 2003; Watanabe et al., 2002). These nociceptive neurons are well established as conveyers of noxious heat, chemical and mechanical stimuli in rodents, non-human primates and humans (LaMotte \& Campbell, 1978; Shir \& Seltzer, 1990; Torebjork et al., 1984). Furthermore, C-fibres have been implicated in the transmission of inflammatory pain induced by noxious chemical substances, such as formalin (Dickenson \& Sullivan, 1987). mRNA of transducer proteins of the transient-receptor-potential (TRP) family of cation channels, such as TRPV-1 and TRPA-1, have been identified on A $\delta$ and C-fibre nociceptors in rats (Kobayashi et al., 2005). TRP channels are implicated in the transduction of noxious input from thermal, chemical, mechanical and inflammatory stimuli; reviewed by Levine and Haber (2007). Noxious thermal stimuli $\left(\sim 46.5^{\circ} \mathrm{C}\right.$ to $\left.56^{\circ} \mathrm{C}\right)$ such as that used in the tail-flick test, an animal behavioural model of nociceptive pain, was found to activate TRPV-1 and -2 
ion channels (Rau et al., 2007). Formalin was identified to activate TRPA-1 ion channels (McNamara et al., 2007). A $\delta$ and C-fibre nociceptors, and their transducer proteins, are thus implicated in the transmission of nociceptive impulses from the periphery to the spinal cord, as assessed by animal behavioural models of pain.

Persistent or tissue damaging noxious stimuli, such as that produced by sunburns (Matsumura \& Ananthaswamy, 2004) or intradermal administration of chemical toxins (Murray et al., 1988; Aceto et al., 1990) can initiate inflammatory processes. Tissue injury can compromise the integrity of the plasma membrane, resulting in the release of intracellular substances, such as adenine triphosphate and potassium ions. Intracellular components can either directly activate nociceptors to produce pain or cause the release of cytokines and chemokines that serve to attract leukocytes, such as neutrophils, to the area of injury (Kataoka et al., 2014). The release of vasoactive amines and peptides, such as histamine, serotonin, bradykinin, substance $P$ and calcitonin-gene-related peptide, via nociceptors and mast cell degranulation (Basbaum et al., 2009) contribute to increased vasodilation and permeability of blood vessels, and causes inflammatory pain (Ottosson \& Edvinsson, 1997). This is accompanied by oedema formation that is triggered by vasoactive mediators that elicit an exudative response composed of plasma proteins and leukocytes. Excessive accumulation of interstitial fluid is generally viewed as detrimental to tissue function because oedema formation increases the diffusion distance for oxygen and other nutrients, compromising cellular metabolism in the swollen tissue (Jerome et al., 1994). The physiological effects of persistent noxious stimuli are manifested as pain and swelling in the injured area. These effects can be measured and quantified in animal behavioural models of pain, including the intradermal formalin test in rodents (Hunskaar \& Hole, 1987). 


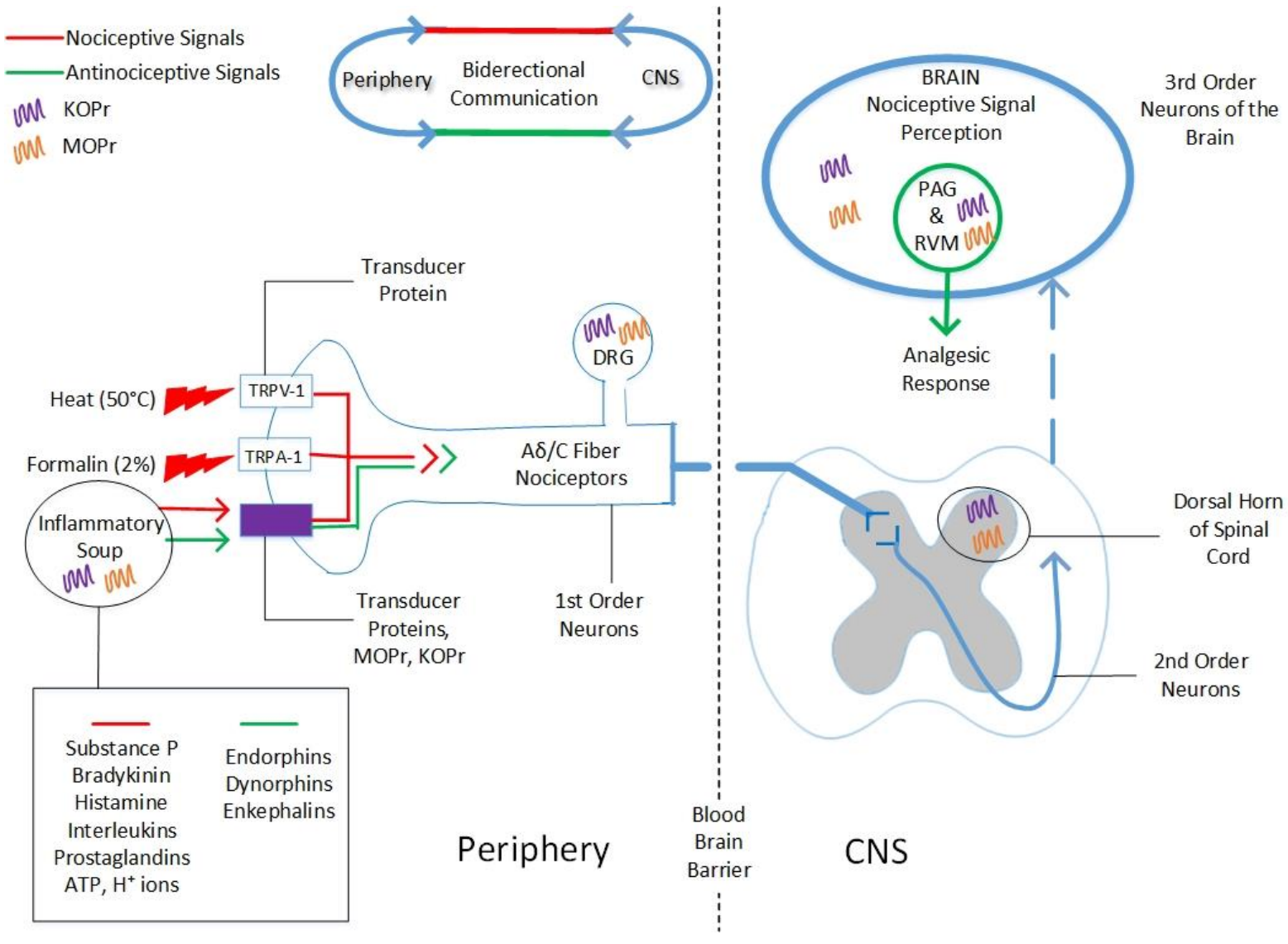

Figure 1.2 Bidirectional Communication between the CNS and Periphery. Brief or persistent noxious heat, chemical and inflammatory stimuli can activate Transient Receptor Potential family of ion channels, such as TRPV-1 and TRPA-1 on $1^{\text {st }}$ order neurons. This gives rise to the centrally mediated nociceptive pain that is transmitted via $2^{\text {nd }}$ and $3^{\text {rd }}$ order neurons and perceived in the brain as pain. In response to this, areas in the brain, such as the Periaqueductal Grey (PAG) and Rostroventral Medulla (RVM) contribute to the descending modulation of nociceptive processes. Noxious stimuli that are potentially tissue damaging can give rise to inflammatory processes and the congregation of molecules, such as substance $\mathrm{P}$, bradykinin, endorphins and dynorphins. The resulting "inflammatory soup" allows for both nociceptive and antinociceptive impulses to be transmitted via peripheral $1^{\text {st }}$ order neurons. This, along with nociceptive and antinociceptive mechanisms of the spinal cord and brain allow for bidirectional communication between the periphery and the central nervous system (CNS). Mu opioid peptide and kappa opioid peptide receptors (MOPr \& KOPr) have been identified in these crucial areas of pain transmission, perception and modulation in $1^{\text {st }}, 2^{\text {nd }}$ and $3^{\text {rd }}$ order neurons. 


\subsubsection{Nociception in the Spinal Cord and Brain}

Regulation of nociceptive signals in the spinal cord is a complex process requiring the integration of peripheral and supraspinal controls (Maier, 2003). A $\delta$ and C-fibre nociceptors from the periphery predominantly terminate in the dorsal horn of the spinal cord (Woolf \& Fitzgerald, 1986). The spinal cord relays nociceptive signals from the periphery to the brain, while being capable of facilitating and inhibiting these signals via ascending or descending spinal tracts. This allows for bidirectional communication between supraspinal centres and the periphery (Leak et al., 1988; Porreca et al., 2002) (Figure 1.2). Nociceptive specific neuronal cells in the dorsal horn synapse with $A \delta$ and C-fibre terminals, creating action potentials upon noxious peripheral stimulation (Cervero et al., 1976). Established mechanisms of nociceptive signal transmission in the spinal cord include those involving glutamatergic receptors (Hartmann et al., 2004; Chaplan et al., 1997) and the neurokinin receptor agonist - substance $\mathrm{P}$ (Abbadie et al., 1996). In vivo pain-related studies on rodents, such as the tail-flick test and intradermal formalin model, have implicated these spinal processes in the production of thermal and inflammatory mediated nociceptive mechanisms (Baamonde et al., 2011; Lutfy et al., 1997; Malmberg \& Yaksh, 1993; McCarson, 1999; Willis, 2001). FMRI studies of the human brain show different brain-regions are responsible for pain anticipation, perception and relief. The nucleus accumbens, mid-cingulate and anterior insula corresponds to pain anticipation; the anterior cingulated, mid and posterior insula, and the dorsal striatum for pain perception; and finally the locus coeruleus (Tsuruoka \& Willis Jr, 1996) periaqeductal grey (PAG) and rostroventral medulla (RVM) (Ploghaus et al., 1999) area were found to be involved in pain relief.

\subsection{Sedation and Hypothermia}

Sedation is one of the most common side-effects of opioid analgesics (McCaughan \& Miaskowski, 2001).The process of opioid induced sedation, or sedation in general, remains elusive. Studies with anaesthetics were shown to cause sedation via modulation of gamma aminobutyric acid (GABA) receptors in the CNS (Nelson et al., 2002). There is also evidence of reduced dopamine levels in the mouse brain to give rise to sedative effects (Chiara et al., 
1976). In the clinic opioid induced sedation is measured by determining alertness, attention, information processing and motor skills (Devlin et al., 1999; Sessler et al., 2002). The subjective nature of these responses and the elusive mechanism of sedation make it hard to translate into animal models. Motor coordination is relatively less subjective and easier to monitor. Hence, motor coordination is frequently used in animal behavioural models, such as the rotarod performance test, to assess opioid induced sedative effects (Hayes et al., 1985; Rogers et al., 1992).

Impulses from warm and cold stimuli travel via $A \delta$ and $\mathrm{C}$-fiber afferents to reach the hypothalamus, which in turn regulates processes such as vasodilation, vasoconstriction, shivering and non-shivering thermogenesis that modulate core-body temperatures (Rev by Andrea Kurz, 2008). A reduction in core body temperature is referred to as hypothermia, and an increase as hyperthermia. These effects can be monitored by a simple measurement of rectal body temperature with the use of a rectal probe.

\subsection{Animal Models of Pain}

There are many animal behavioural models relevant to the study of pain in humans (Le Bars et al., 2001). However, no single model on its own is good enough to be representative of nociceptive processes. As pain is a very complex process, studies use multiple animal pain models to discern the antinociceptive potential of analgesics. The principle rationale behind the use of such models is that the sources and mechanisms of brief nociceptive pain differ significantly from those of persistent inflammatory pain (Dubuisson \& Dennis, 1977a; Aceto et al., 1990). In this study we focus on animal models representing acute pain, such as that produced by brief thermal, chemical and inflammatory stimuli.

Assessment of the centrally mediated effect of analgesics is commonly assessed by the tailflick or hot-plate test, where a brief $(<10-15 \mathrm{~s})$ thermal stimulus $\left(50-55^{\circ} \mathrm{C}\right)$ is applied to either the tail or the paw to illicit a withdrawal response. While the tail-flick test is useful in assessing nociceptive process in the spinal cord (Basbaum \& Fields, 1984; Bjorkman, 1995); the hot-plate test is used for the assessment of supraspinal processes (Casey et al., 1996; F Porreca et al., 1984). Autoradiographic localization of opioid receptors in the rat spinal cord found KOPr binding sites to be highly concentrated in the superficial layers of the dorsal 
horn in the spinal cord (Gouardères et al., 1985), where many A $\delta$ and C-fiber nociceptors terminate. The same study identified the lumbar-sacral portion of the spinal cord to be enriched with KOPr compared to the thoracic or cervical segments. The lumbar-sacral spinal segment is responsible for receiving sensory input from the tail of rodents (Bonnot et al., 2002). While there are a variety of tail-flick assays that use different sources of thermal stimuli on the tail, such as radiant heat, light and hot-water; the latter was found to be more representative of acute thermal pain, reviewed by Le Bars et al., 2001. This is because rapid tail-immersion into a hot-water bath of $50-55^{\circ} \mathrm{C}$ was found to immediately trigger thermal transducer proteins, such as TRPV-1, as opposed to the slower heat conduction/transduction methods via radiant heat. The hot water tail-flick assay was thus chosen for this study to assess the cenrally mediated analgesic effects of KOPr agonists on acute nociceptive (thermal) pain.

The assessment of peripheral mechanisms of pain is carried out by inducing inflammation via intradermal administration of substances such as formalin, carageenan, capcasin or complete Freud's adjuvant. Each substance has a characteristic duration of action (Aceto et al., 1990) that is used to model different disease states. Substances such as carageenan or complete Freud's adjuvant are more commonly used to model arthritic conditions due to long lasting inflammatory responses (Committee on Recognition and Alleviation of Pain in Laboratory Animals, 2009). Formalin induces acute responses to pain due to inflammation. This is good in modelling relevant clinical conditions that give rise to acute inflammatory pain, such as post-operative pain or acute injuries. Using formalin concentrations of $>1 \%$ has been found to trigger both nociceptive and inflammatory types of pain (Rosland et al., 1990) that present as a biphasic pain-response (Shibata et al., 1989). This early phase (phase 1) represents central processes of nociceptive pain transmission; the late phase (phase 2) represents peripheral mechanisms of inflammatory pain (Tjølsen et al., 1992) (Fig 1.1). This model has been used extensively to investigate the central and peripheral mechanisms of analgesia of KOPr agonists (Binder et al., 2001; Dubuisson \& Dennis, 1977b; Lamb et al., 2012). 
Table 1.1. Comparison of KOPr agonists on animal behavioural models of pain.

\begin{tabular}{|c|c|c|c|c|c|c|c|}
\hline \multirow{2}{*}{$\begin{array}{c}\text { Behavioural } \\
\text { Model }\end{array}$} & \multirow[t]{2}{*}{ Acute Stimulus } & \multirow{2}{*}{$\begin{array}{l}\text { Physiological } \\
\text { Effect Tested }\end{array}$} & \multicolumn{4}{|c|}{ KOPr Agonist } & \multirow{2}{*}{$\begin{array}{c}\text { MOPr Agonist } \\
\text { Morphine }\end{array}$} \\
\hline & & & Dynorphin & $\begin{array}{c}\text { U- } \\
504,448 \mathrm{H}\end{array}$ & $\begin{array}{c}\text { Salvinorin } \\
\text { A }\end{array}$ & $\mathrm{ICl} 204,448$ & \\
\hline Tail-flick & Thermal & $\begin{array}{l}\text { Spinally } \\
\text { mediated } \\
\text { thermal } \\
\text { response time }\end{array}$ & $\begin{array}{c}+ \\
(\text { Han \& Xie, } \\
1987 ;)\end{array}$ & $\begin{array}{c}+ \\
\text { (Piercey et } \\
\text { al., 1982a) }\end{array}$ & $\begin{array}{c}+ \\
\text { ( McCurdy et } \\
\text { al., 2006) }\end{array}$ & nd & $\begin{array}{c}+ \\
\text { (Abbott et al., } \\
\text { 1982) }\end{array}$ \\
\hline Hot-plate & & $\begin{array}{l}\text { Supraspinally } \\
\text { mediated } \\
\text { thermal } \\
\text { response time }\end{array}$ & $\begin{array}{c}\quad+ \\
\text { (Baumeister } \\
\text { et al., 1987) }\end{array}$ & $\begin{array}{c}\quad+ \\
\text { (F. Porreca } \\
\text { et al., 1984) }\end{array}$ & $\begin{array}{c}+ \\
\text { (McCurdy et } \\
\text { al., 2006) }\end{array}$ & nd & $\begin{array}{c}+ \\
\text { (Hunskaar et al., } \\
1986)\end{array}$ \\
\hline $\begin{array}{l}\text { Intradermal } \\
\text { formalin test } \\
\text { (Phase 1) }\end{array}$ & Chemical & $\begin{array}{l}\text { Central pain } \\
\text { mechanisms }\end{array}$ & $\begin{array}{c}+ \\
\text { (Tan-No et } \\
\text { al., 1996) }\end{array}$ & $\begin{array}{c}+ \\
\text { (Pelissier et } \\
\text { al., 1990) }\end{array}$ & $\begin{array}{c}+ \\
\text { (Aviello et } \\
\text { al., 2011) }\end{array}$ & $\begin{array}{l}- \\
\text { A Barber et } \\
\text { al., (1994) }\end{array}$ & $\begin{array}{c}+ \\
\text { (Abbott et al., } \\
\text { 1982) }\end{array}$ \\
\hline $\begin{array}{l}\text { Intradermal } \\
\text { formalin test } \\
\text { (Phase 2) }\end{array}$ & Inflammatory & $\begin{array}{l}\text { Peripheral pain } \\
\text { mechanisms }\end{array}$ & $\begin{array}{c}+ \\
\text { (Ossipov et } \\
\text { al., 1996) }\end{array}$ & $\begin{array}{c}\quad+ \\
\text { (Idänpään- } \\
\text { Heikkilä et } \\
\text { al., 1994) }\end{array}$ & $\begin{array}{c}+ \\
\text { (Aviello et } \\
\text { al., 2011) }\end{array}$ & $\begin{array}{c}t \\
\text { A Barber et } \\
\text { al., (1994) }\end{array}$ & $\begin{array}{c}+ \\
\text { Abbott et al., } \\
\text { 1982) }\end{array}$ \\
\hline Temperature & nil & $\begin{array}{l}\text { Rectal } \\
\text { temperature }\end{array}$ & $\begin{array}{c}\downarrow \\
\text { (Handler et } \\
\text { al., 1992) }\end{array}$ & $\begin{array}{c}\qquad \\
\text { (Bhargava, } \\
\text { et al., 1989) }\end{array}$ & $\begin{array}{c}\downarrow \\
\text { (Ansonoff et } \\
\text { al., 2006) }\end{array}$ & $\begin{array}{c}\downarrow \\
\text { (S. M. Rawls, } \\
\text { Ding, Gray, \& } \\
\text { Cowan, } \\
\text { 2005) }\end{array}$ & $\begin{array}{c}\uparrow \\
\text { (Low dose) } \\
\text { (Cox et al., 1976) } \\
\downarrow \\
\text { (High dose) } \\
\text { (Warwick \& Craig } \\
\text { Schnell, 1976) }\end{array}$ \\
\hline Rotarod & nil & $\begin{array}{l}\text { Sedation/motor } \\
\text { coordination }\end{array}$ & $\begin{array}{c}+ \\
\text { (Stevens \& } \\
\text { Yaksh, 1986) }\end{array}$ & $\begin{array}{c}+ \\
\text { (Hayes et al., } \\
\text { 1985) }\end{array}$ & nd & $\begin{array}{c}- \\
\text { (Rogers et } \\
\text { al., 1992) }\end{array}$ & $\begin{array}{c}+ \\
\text { (Cartmell et al., } \\
\text { 1991) }\end{array}$ \\
\hline
\end{tabular}

${ }^{+}$, Effect present; ${ }^{-}$, Effect absent; nd, not determined; $\uparrow$, Hyperthermia; $\downarrow$, Hypothermia 


\subsection{The Opiate System}

KOPr, MOPr and delta opioid peptide receptors are the three main opioid receptors identified (Wood et al., 1982). These G-protein coupled opioid receptors have been demonstrated to show 63-73\% homology (Pogozheva et al., 2008). They are capable of forming homo and/or heterodimers, which was found to modulate receptor function (Jordan \& Devi, 1999). Although opiate receptors differ in anatomical distribution and behavioural properties; reviewed in Benarroch (2012), studies have found considerable overlap between KOPr and MOPr immunoreactivity, and mRNA in anatomical locations implicated in the modulation of pain. These areas include the PAG and RVM, supraspinally (Gutstein et al., 1998), superficial dorsal horn of the spinal cord (Mansour et al., 1994), DRG of peripheral nerves (Ji et al., 1995; Werz et al., 1987) and leukocytes (L. F. Chuang et al., 1995; T. K. Chuang et al., 1995) (Fig. 1.1). Dynorphins and endorphins, the respective endogenous ligands of KOPr and MOPr, are also expressed in these locations (Basbaum \& Fields, 1984; Cabot et al., 1997; Cabot et al., 2001; Hassan et al., 1992; Mousa et al., 2001).

Despite these similarities, studies using KOPr and MOPr knockout models have found considerable differences in the perception of thermal, chemical and inflammatory pain. For example, MOPr knockouts showed significant reduction in noxious chemical pain perception, as assessed by abdominal constriction assays in mice (Sora et al., 1999). KOPr knockouts however, showed significantly increased sensitivity to pain by noxious chemical stimuli in the same assay but not in the intradermal formalin test (Simonin et al., 1998). Furthermore, immunohistochemistry techniques have revealed differential distribution of KOPr and MOPr in the rat gastrointestinal tract (Bangnol et al.,1997); suggesting a possible reason for the inhibition of intestinal transit by morphine but not by KOPr agonists such as $\mathrm{U}-50,499 \mathrm{H}$ (Shook et al., 1989). This illustrates that KOPr and MOPr systems share biochemical and anatomical differences and similarities that add to their unique analgesic and side-effect profiles. 


\subsubsection{Kappa Opioid Receptor Agonists}

$\mathrm{KOPr}$ agonists are able to attenuate nociceptive processes via central and peripheral mechanisms. Studies with U-50,488H found serotonergic (Vonvoigtlander et al., 1984) and GABAergic pathways (Nemmani \& Mogil, 2003) to have a role in KOPr induced analgesic effects against thermal stimuli. KOPr agonists, such as bremazocine, GR89,696 (Caudle et al., 1994; Eliav, 1999; Ho et al., 1997), dynorphin-A, U-69,593 and U-50,488H (Chang et al., 1989; Randic et al., 1995; Xin et al., 1997) were found to attenuate nociceptive processes via modulation of NMDA, AMPA and substance P related biochemcial processes in the CNS. Sal $A$ and $\mathrm{U}-50,488 \mathrm{H}$ were found to attenuate peripheral pain processes as assessed by the abdominal constriction test (Craft et al., 1995; Labuz et al., 2007; McCurdy et al., 2006) and intradermal formalin test (Hong \& Abbott, 1995; Aviello et al., 2011). Aside from central and peripheral antinociceptive effects, KOPr stimulation is also known to play a role in motor coordination (Ukai et al., 1984), temperature regulation (Cavicchini et al., 1988); addictive, dysphoric and stress-related behaviour, reviewed by Bruchas et al. (2010); pruritis (Kumagai et al., 2010); cardiovascular and respiratory function (Hassen et al., 1984); neuroprotection (Zeynalov et al., 2006); and angiogenesis (Yamamizu et al., 2014).

Adverse-effects of KOPr agonists, such as dysphoria and hallucinations, are known to manifest via central pathways. Therefore restricting KOPr agonists to act in the periphery (like CR-845) increases their therapeutic potential in the treatment of pain. Another, more recently employed rationale for improving the therapeutic potential of KOPr agonists, is the identification of functionally selective KOPr agonists. Functional selectivity refers to the ability of a ligand to be biased towards a particular intracellular pathway it activates, such as pathways mediating analgesia over dysphoria. For example, U-69,593 based triazole and isoquinolinone probes with KOPr affinity, were found to selectively prefer G-protein coupled pathways over $\beta$-arrestin-2 recruitment. This attenuated dysphoric behaviour while maintaining analgesic potential to thermal stimuli in the mouse tail-flick test (Zhou et al., 2013). The discovery of KOPr agonists that are peripherally restricted in the targets they stimulate, or functionally selective towards antinociceptive pathways, may improve therapeutic potential in the treatment of pain. 
This study focuses on four KOPr agonists: the known peripherally restricted compound, S-N[2-(N-methyl-3,4-dichlorophenylacetamido)-2-(3-carboxyphenyl) ethyl]pyrrolidine, ICI 204,448; the non-nitrogenous diterpene, Sal A, and its novel analogues: Tetrahydropyran Salvinorin A (THP Sal A) and Mesyl Salvinorin B (Mesyl Sal B). ICI 204,448 and Sal A have been shown previously to have analgesic effects in behavioural models of pain (Table 1.1). THP Sal A is a novel compound and has not been assessed by behavioural pain models prior to this study. In vivo and in vitro studies on Mesyl Sal B have recently been performed by our laboratory (Simonson et al., 2014). In this study I showed that Mesyl Sal B had central analgesic effects. The source and structures of these compounds are shown in Figure 1.3. KOPr binding and efficacy properties are outlined in Table 1.2. 
Table 1.2. Comparison of binding and efficacy properties between KOPr agonists

\begin{tabular}{|c|c|c|c|}
\hline $\begin{array}{l}\text { Radioactive KOPr } \\
\text { ligand }\end{array}$ & {$\left[{ }^{3} \mathrm{H}\right]$ Bremazocine } & {$\left[{ }^{3} \mathrm{H}\right] \mathrm{U}-69,593$} & {$\left[{ }^{125} I\right]$ OXY } \\
\hline ICI 204,448 & $\mathrm{IC}_{50}=33.2 \pm 14.7 \mathrm{nM}$ & & \\
\hline Sal A & & $\begin{array}{l}\mathrm{K}_{\mathrm{i}}=4 \pm 1 \mathrm{nM} \\
\mathrm{EC}_{50}=46 \pm 8 \mathrm{nM}\end{array}$ & $\begin{array}{l}\mathrm{K}_{\mathrm{i}}=1.9 \pm 0.2 \mathrm{nM} \\
\mathrm{EC}_{50}=40 \pm 10 \mathrm{nM}\end{array}$ \\
\hline THP Sal A & & $\begin{array}{l}\mathrm{K}_{\mathrm{i}}=6.21 \pm 0.4 \mathrm{nM} \\
\mathrm{EC}_{50}=60 \pm 6 \mathrm{nM}\end{array}$ & \\
\hline Mesyl Sal B & & & $\begin{array}{l}\mathrm{K}_{\mathrm{i}}=2.3 \pm 0.1 \mathrm{nM} \\
\mathrm{EC}_{50}=30 \pm 5 \mathrm{nM}\end{array}$ \\
\hline
\end{tabular}

$I C_{50}$, Inhibitory concentration (binding potency) $\mathrm{EC}_{50}$, Effective concentration (binding potency); $\mathrm{K}_{\mathrm{i}}$, binding affinity to $\mathrm{KOPr}$ 
ICI 199,441<smiles></smiles>

\section{Salvia Divinorum}

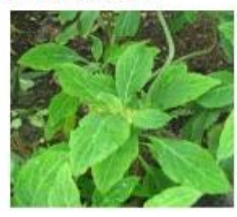

$\mathrm{ICl} 204,448$<smiles>COc1cccc([C@H](NC(=O)Cc2ccc(Cl)c(Cl)c2)N2CCCC2)c1</smiles>

\section{Tetrahydropyran \\ Salvinorin A}

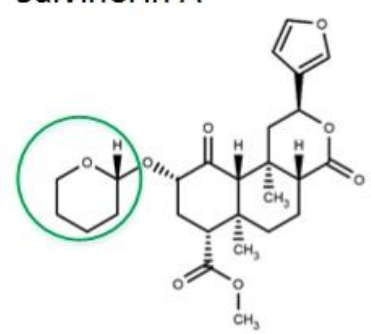

Mesyl Salvinorin B

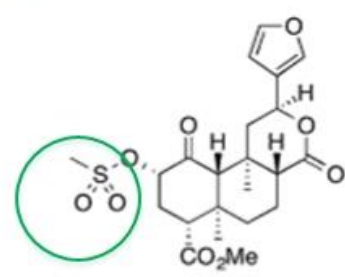

Figure 1.3 Kappa Opioid Compounds. ICI 204,448, the known peripherally restricted kappa opioid peptide (KOPr) agonist, is derived from ICI 199,441 by a modification to its central phenyl ring at the 3-position with a carboxymethyl ether. Salvinorin A is extracted from the Mexican sage, Salvia Divinorum. Substitution of the acetate group on the C-2 terminal of Salvinorin A with a tetrohydropyran moiety results in Tetrahydropyran Salvinorin A; substitution with a mesylate group results in Mesyl Salvinorin B. 


\section{Methods}

\subsection{Animals}

Adult male B6-SJL protein tyrosine phosphatase receptor type $c$ allele a (ptprca) mice weighing 23-30 g were bred within the animal facilities of Malaghan Institute of Medical Research and Victoria University of Wellington. All in vivo experiments were approved by the Victoria University Animal Ethics Committee and carried out in accordance with their guidelines for animal care. Animals were housed within, Victoria University of Wellington animal facility, in a room maintained at $21{ }^{\circ} \mathrm{C}$ with an alternating 12 -hour light/dark cycle (7am-7pm). Food and water were available ad libitum. All tests were conducted in the light phase.

\subsection{Drugs and Solutions}

Salvinorin A was isolated from Salvia divinorum leaves as previously described by Giroud et al. (2000) and purified by chromatography (courtesy of Thomas E. Prisinzano, University of Kansas, USA). Tetrahydropyran Salvinorin A and Mesyl Salvinorin B were synthesised from Salvinorin A (courtesy of Thomas E. Prisinzano, University of Kansas, USA). ICI 204,448 was purchased from TOCRIS.

Vehicle solutions were trialled to measure the solubility of KOPr agonists without mediating sedative effects. Preliminary tests were conducted with vehicle, 75\% Dimethyl sulfoxide (DMSO) and $25 \%$ of $10 \times$ phosphate buffered saline (PBS) solution $\left(\mathrm{NaCl}, \mathrm{KCl}, \mathrm{Na}_{2} \mathrm{HPO}_{4}, \mathrm{KH}_{2} \mathrm{PO}_{4}\right.$, distilled water, adjusted to $\mathrm{pH}$ 7.4). Sedation was observed in mice after this vehicle was delivered, IP, and affected initial results with Sal $A$. This seemed to be correlated with increased DMSO concentrations. Since this study was the first to report the analgesic effects of novel Sal A analogues, a vehicle capable of fully dissolving our KOPr agonists had not been reported. We based our study on the vehicle used to dissolve Sal A by McCurdy et al., (2006). They used $90 \%$ propylene glycol and 10\% DMSO. We found full dissolution of all KOPr agonists with $80 \%$ propylene glycol and $20 \%$ DMSO (dissolving at a concentration of 2 $\mathrm{mg} / \mathrm{ml}$ ). The resulting solution was made up to dosages of 1 or $2 \mathrm{mg} / \mathrm{kg}$ for 23-30 g mice 
using $10 \times$ PBS solution. The resulting vehicle was 80:20, PG:DMSO, with PBS corrected to mouse weight. Drug solutions were stored at $2^{\circ} \mathrm{C}$ and used within 8 days. All KOPr agonists ( 1 and $2 \mathrm{mg} / \mathrm{kg}$ ) were given IP (200 $\mu \mathrm{l})$ via 29 gauge syringes (BD, Auckland, NZ).

\subsection{Assessment of Nociceptive Behaviour}

\subsubsection{Tail-Flick Test}

The tail-flick test was performed according to methods of Horan et al., (1992). Mice were restrained in custom made restrainers (School of Biological Sciences Workshop, Victoria University of Wellington), which permitted free tail motion, and allowed to habituate for 10 min. Following this, vehicle or drug was administered IP, and mice placed back in the restrainer. The distal $2 \mathrm{~cm}$ of the tail was submerged into a $50^{\circ} \mathrm{C}\left( \pm 1^{\circ} \mathrm{C}\right)$ hot-water bath. The time it took for mice to withdrawal their tails was recorded by a stopwatch. Baseline tailwithdrawal latencies for each mouse were recorded on 3 separate occasions ( 3 min apart) before experimenting and averaged. Mice with baseline latencies between 1-4 s were chosen for experimentation. A cut-off of $10 \mathrm{~s}$ was used to minimise tissue damage. KOPr agonists were administered IP and tail-withdrawal latencies recorded at 1, 5, 10, 15, 30, 45, 60, 90 and $120 \mathrm{~min}$. The maximum possible analgesic effect (MPE) was calculated according to previously published protocols (Horan et al., 1992; Martin, Tsou, \& Walker, 1998), using the following formula:

$\% \mathrm{MPE}=100 \times$ (Test Latency - Control Latency)

(10 - Control Latency)

\subsubsection{Intradermal Formalin Model and Paw Oedema}

The intradermal formalin model was carried out according to the methods of Hunskaar and Hole (1987). Testing apparatus is illustrated in Fig. 2.1. Mice were allowed to habituate to the test environment for 15 min before testing was carried out. Mice were given KOPr agonist or vehicle, IP, and placed back into the test chamber for $5 \mathrm{~min}$. The height of the 
hind paw of the mouse was measured by 0-150 mm digital callipers (Whitworth, Inspec Inc., Michigan, USA) and $20 \mu \mathrm{l}$ of formalin (2\%) injected intradermally into the dorsal surface of the right paw. Mouse pain behaviour was then recorded via digital cameras (Bosch, Stuttgart, Germany) for $60 \mathrm{~min}$. Paw height was measured again at $60 \mathrm{~min}$ ( $\pm 10 \mathrm{~min}$ ) to determine change in oedema formation. Assessment of pain behaviour was based on protocols developed by Dennis and Dubuisson (1977), using weight bearing score criteria. A score of 0 to 3 was given according to the following behavioural outcomes: 0 - full weight bearing where the mouse walks normally (no pain), 1 - partial weight bearing where the mouse is limping but able to sustain part of its weight (mild pain), 2 - no weight bearing where the mouse paw is raised (moderate pain), 3 - paw flinching and licking. Pain behaviour scores were assigned at $5 \mathrm{~s}$ intervals for $60 \mathrm{~min}$ by an observer blinded to the treatment groups. Additionally, time-dependent oedema formation was assessed at 10, 20, $30,40,50$ and 60 min post intradermal formalin. Following pain behavioural recording and paw measurements, mice were euthanized by asphyxiation with $\mathrm{CO}_{2}$ and the right hind paw excised for tissue processing to determine the presence of inflammatory markers by other researchers in Dr Kivell's laborarory. 
Recording and display unit

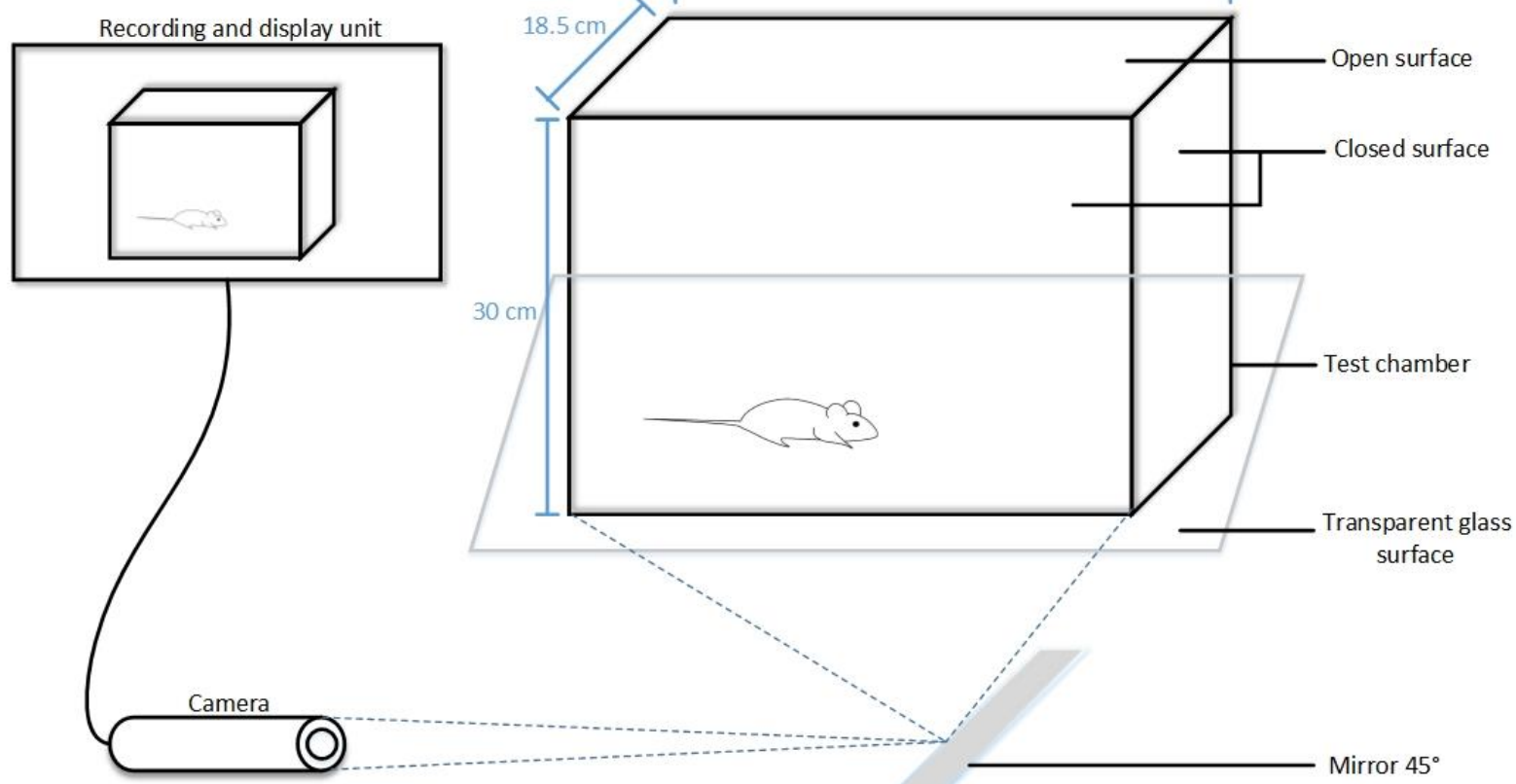

Figure 2.1 Intradermal Formalin Test. Nociceptive behaviour of mice were assessed by recording pain behaviour by administration of intradermal formalin ( $2 \%)$. Mice were kept in a wooden box ( $27.5 \times 18.5 \times 30)$ with an open top and bottom surface, placed on a transparent glass surface. Pain behaviour was recorded with a help of a mirror, kept at an angle of $45^{\circ}$ below the mouse, and a camera positioned perpendicular to it. 


\subsection{Assessment of Side-Effects}

\subsubsection{Motor Coordination by Rotarod Performance Assay}

This test was carried out according to the methods of Joanna L. Stanley et al. (2005). Mice were trained to run on a rotarod (Harvard Apparatus, Massachusetts, U.S.) (dimension: 60 $\mathrm{mm}$ width, $30 \mathrm{~mm}$ diameter) at $10 \mathrm{rpm}$ for $120 \mathrm{~s}$. Mice unable to successfully complete 2 out of 3 consecutive trials without falling were excluded from the study. Able mice were administered $200 \mu \mathrm{L}$ of either vehicle or KOPr agonist (IP) and immediately placed on the rotarod. The time at which they fell off the rod was recorded. This test procedure was carried out at $0,15,30,45,60,75$ and 90 min intervals.

\subsubsection{Core Body Temperature Measurements}

Baseline core body temperatures of mice were measured via rectal probe (Acorn series, Singapore). The probe was inserted $2 \mathrm{~cm}$ into the anal canal of mice and held in place until temperatures stabilised (not more than $10 \mathrm{~s}$ ). After IP administration of KOPr agonist or vehicle, core body temperatures were measured at $10 \mathrm{~min}$ intervals for $60 \mathrm{~min}$. Mice were housed in separate cages during the experiment.

\subsection{Data Analysis and Statistics}

Data was analysed using Prism v5.0c (GraphPad Prism Software Inc., La Jolla, CA, USA) and Microsoft Excel (Microsoft Corp., Redmond, WA, USA). Two-way Repeated Measures ANOVA followed by Bonferroni post-tests were used for analysing significance compared to controls in the tail-flick test, intradermal formalin model, rotarod test and core body temperature measurements. Two-way ANOVA followed by Dunnet's Multiple Comparison test was performed to compare treatments to controls for measurements of oedema. Oneway ANOVA followed by Dunnet's Multiple Comparison test was used to assess significance compared to controls for oedema formation following $60 \mathrm{~min}$ formalin exposure. Results were considered significant when $\mathrm{P} \leq 0.05$. 


\section{Results}

\subsection{Analgesic Effects of KOPr Agonists in the Tail-Flick Test}

The hot water tail-flick test was used to assess the centrally mediated duration of analgesic effects of KOPr agonists. The dose dependent (1 and $2 \mathrm{mg} / \mathrm{kg}$ ) analgesic effect of $\mathrm{ICl}$ 204,448 , Sal A, THP Sal A and Mesyl Sal B towards nociceptive thermal $\left(50^{\circ} \mathrm{C}\right)$ pain are shown in Figure 3.1. The peripherally restricted KOPr agonist, ICl 204,448, did not increase tail-withdrawal latencies at either 1 or $2 \mathrm{mg} / \mathrm{kg}$ (Figure $3.1 \mathrm{~A}$ ). Sal A (1 mg/kg) significantly increased tail-withdrawal latencies at $5(P<0.05), 10$ and $15 \mathrm{~min}(P<0.001)$ following IP administration; Sal A (2 mg/kg) was significant at $5(P<0.05)$ and $10 \mathrm{~min}(\mathrm{P}<0.01)$ (Figure 3.1 B).

THP Sal A did not have significant analgesic effects at $1 \mathrm{mg} / \mathrm{kg}$. At $2 \mathrm{mg} / \mathrm{kg}$ however, it significantly attenuated acute thermal stimuli at 5, 10, $15 \mathrm{~min}(\mathrm{P}<0.01)$ and $30 \mathrm{~min}(\mathrm{P}<0.05)$ time-points (Figure $3.1 \mathrm{C}$ ). Mesyl Sal B (1 mg/kg) significantly increased tail-withdrawal latencies at $15(P<0.05), 30,45,60(P<0.01)$ and $90 \mathrm{~min}(P<0.05)$ time-points; however at 2 $\mathrm{mg} / \mathrm{kg}$, it was only significant at $60 \mathrm{~min}(\mathrm{P}<0.05)$. 
A

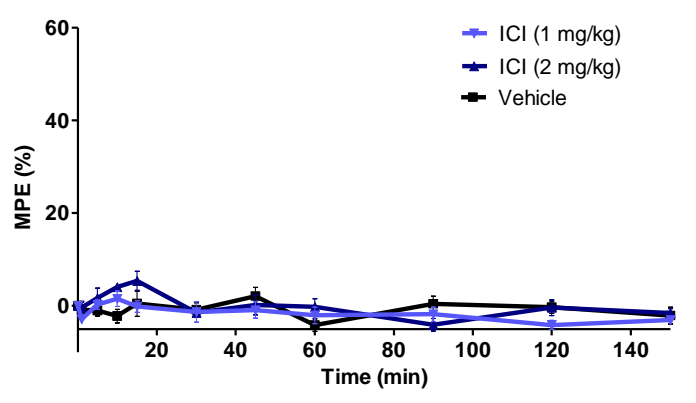

C

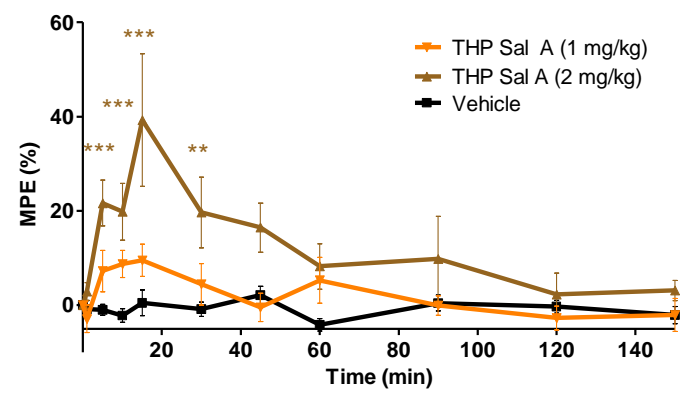

B

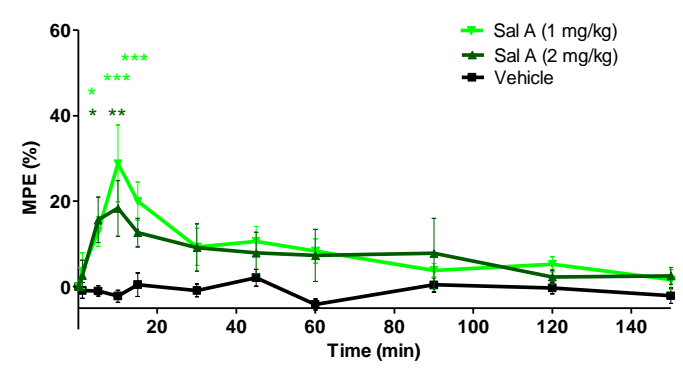

D

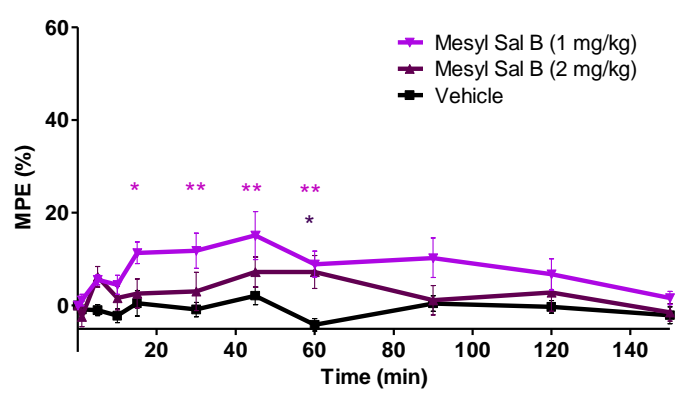

Fig. 3.1 Tail-Flick Test showing dose related ( 1 and $2 \mathrm{mg} / \mathrm{kg}$, IP) and time-course effects of KOPr agonists on tail-flick latencies to acute thermal $\left(50^{\circ} \mathrm{C}\right)$ stimuli. Vehicle ( $\left.n=9\right)$ (A) Salvinorin A ( $\left.n=5-9\right)$ (B) ICI 204,448 ( $\left.n=6\right)$ (C) Tetrahydropyran Salvinorin A ( $n=6$ ) (D) Mesyl Salvinorin B ( $n=6-8)$. Percentage of maximum possible effect (\%MPE) at each time-point was calculated based on pre-drug latencies and results expressed as mean \pm SEM. Two-way Repeated Measures ANOVA found increased tail-withdrawal latencies due to Sal A $[F(2,200)=9.39$, $P=0.0013]$; Mesyl Sal B $[F(2,200)=8.66, P=0.0020]$; THP Sal A $[F(2,180)=7.29, P<0.0048]$ but not ICI $204,448[F(2,180)=0.86, P=0.4390]$. Bonferroni post-test were done to compared KOPr agonist treated mice with vehicle, $* \mathrm{P}<0.05, * * \mathrm{P}<0.01, * * * \mathrm{P}<0.001$. 
3.2 Total Analgesic Effect in the Tail-Flick Test

Total analgesic effect of KOPr agonists, every $30 \mathrm{~min}$ in the tail-flick test, was evaluated using area under the curve (AUC) based on tail-withdrawal latencies. ICI 204,448 was not found to have any analgesic effect. Sal A (1 mg/kg) had a significant analgesic effect for the first $30 \mathrm{~min}(P<0.001)$. Similarly, THP Sal A $(2 \mathrm{mg} / \mathrm{kg})$ significantly increased withdrawal latencies within $30 \mathrm{~min}(\mathrm{P}<0.001)$. There was no analgesic effect by Sal A and THP Sal A beyond this point. Mesyl Sal B (2 mg/kg) had a significant overall analgesic effect 30-120 min $(\mathrm{P}<0.05)$ post IP administration. 
A

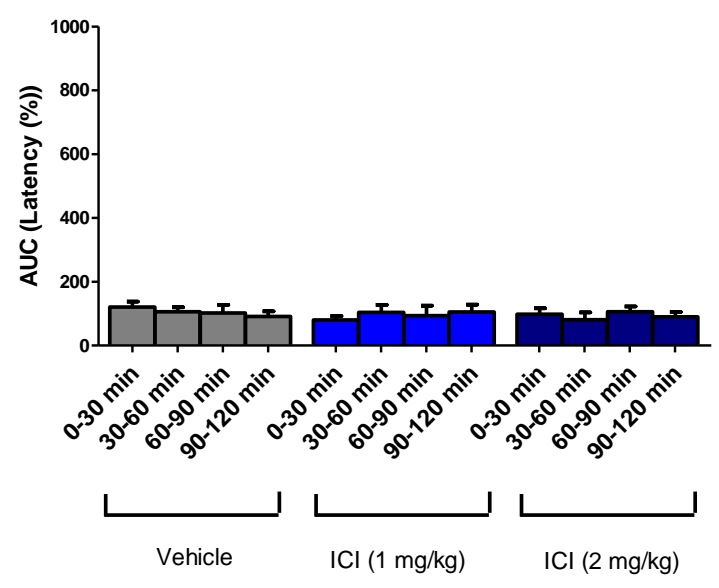

C

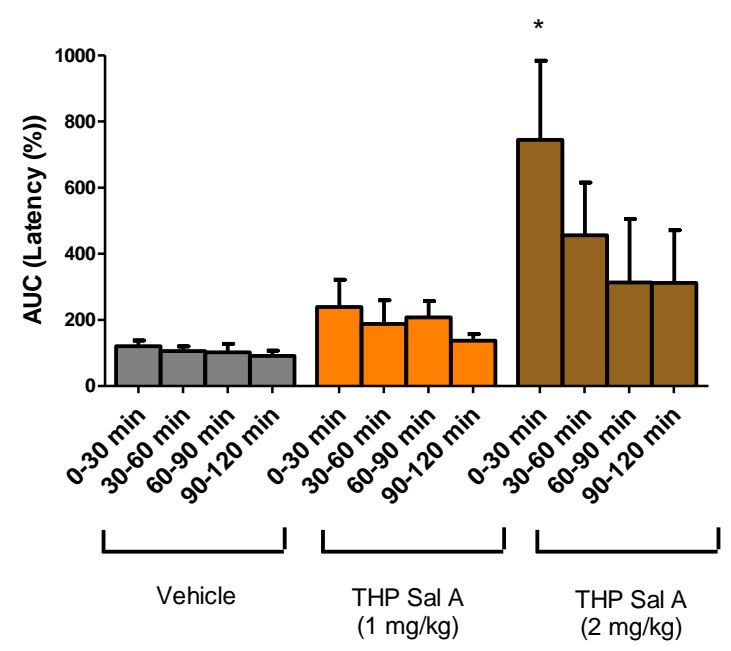

B

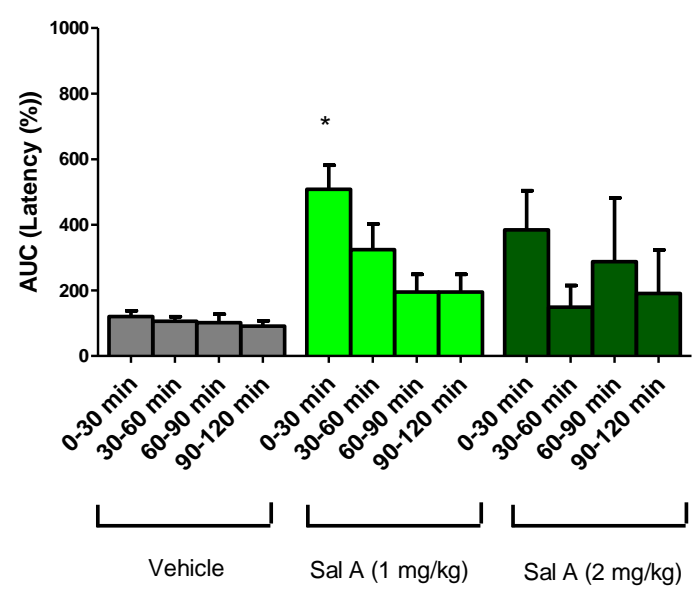

D

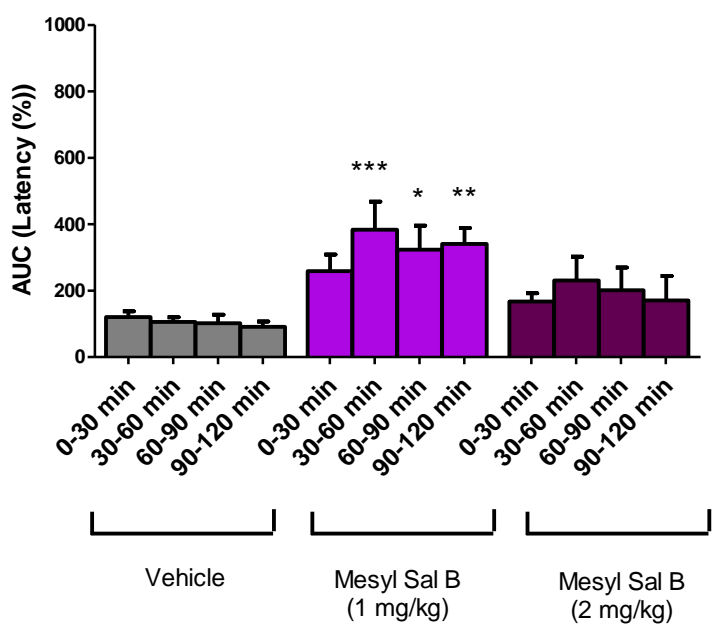

Figure 3.2 Total Analgesic Effect in the Tail-Flick Test shows the overall analgesic effects of KOPr agonists (1 and $2 \mathrm{mg} / \mathrm{kg}$ ) on tail-withdrawal latencies every $30 \mathrm{~min}$. (A) ICI 204,448 (B) Salvinorin A (C) Tetrahydropyran Salvinorin A (D) Mesyl Salvinorin B. One-way ANOVA followed by Dunnett's test to compare with vehicle. $* \mathrm{P}<0.05,{ }^{* * P}<0.01, * * * \mathrm{P}<0.001$ 
3.3 Analgesic Effects of KOPr Agonists in the Intradermal Formalin Test

The intradermal formalin test was used to assess the analgesic effects of KOPr agonists on formalin-induced phase 1 (0-10 $\mathrm{min})$ and phase 2 pain (20-60 $\mathrm{min})$ (Fig. 3.3). Analgesic effects of ICl 204,448, Sal A, THP Sal A and Mesyl Sal B were compared to positive pain controls (vehicle IP followed by intradermal formalin). Positive pain controls, compared to negative pain controls, showed significant pain scores at 5, 10, 25, 30, 35, 40, 45, 50, 55 and $60 \mathrm{~min}(\mathrm{P}<0.001)$ post intradermal formalin administration. $\mathrm{ICl} 204,448$ did not have an effect on phase 1 pain; however it reduced phase 2 pain at $30 \mathrm{~min}$ with $1 \mathrm{mg} / \mathrm{kg}(P<0.05)$ and 25-35 min with $2 \mathrm{mg} / \mathrm{kg}(\mathrm{P}<0.001)$ (Fig. $3.3 \mathrm{~A})$. Sal A $(1 \mathrm{mg} / \mathrm{kg})$ did not significantly reduce either phase 1 or 2 pain, however it showed an insignificant trend of reducing phase 2 pain. Sal A $(2 \mathrm{mg} / \mathrm{kg})$ significantly attenuated phase 1 pain at $5-10 \mathrm{~min}(P<0.001)$, and phase 2 pain at $25-35$ min $(P<0.01)$, (Fig. 3.3 B).

THP Sal A ( $1 \mathrm{mg} / \mathrm{kg})$ reduced phase 1 pain at $10 \mathrm{~min}(\mathrm{P}<0.01)$ and phase 2 pain at 40,45 and $60 \mathrm{~min}(P<0.05)$. At $2 \mathrm{mg} / \mathrm{kg}$, it attenuated phase 1 pain at $5 \mathrm{~min}(P<0.001)$ and phase 2 pain at 25-40 min ( $\mathrm{P}<0.001)$ (Fig. $3.3 \mathrm{C})$. Mesyl Sal B $(1 \mathrm{mg} / \mathrm{kg})$ significantly reduced phase 1 pain at $10 \mathrm{~min}(\mathrm{P}<0.05)$ and phase 2 pain at $60 \mathrm{~min}(\mathrm{P}<0.05)$. At $2 \mathrm{mg} / \mathrm{kg}$, it only reduced phase 2 pain at $30 \mathrm{~min}(\mathrm{P}<0.01)$ (Fig. $3.3 \mathrm{D})$. 

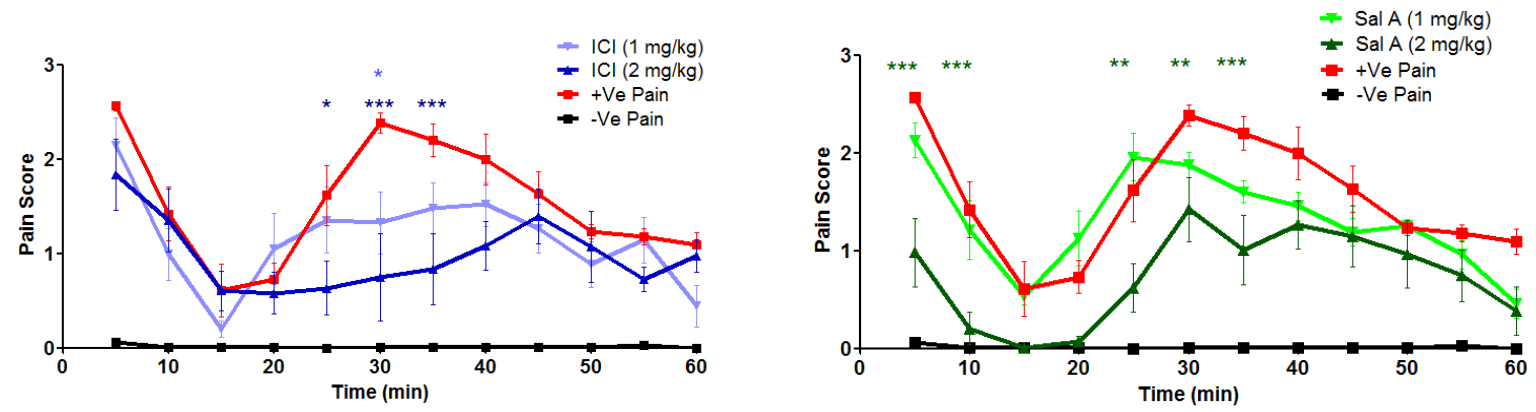

C

D
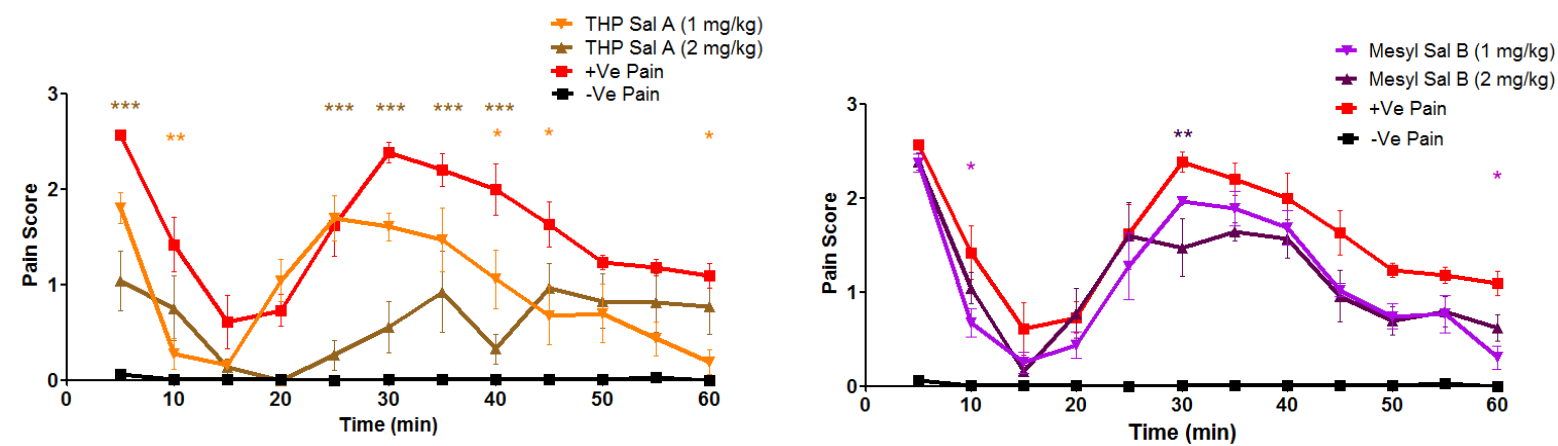

Fig. 3.2 Intradermal Formalin Test showing dose related (1 and $2 \mathrm{mg} / \mathrm{kg}, \mathrm{IP}$ ) and time-course of analgesic effects of KOPr agonists on phase 1 (0-10 min) and phase 2 pain (20-60 min). Results are mean \pm SEM of nociceptive behaviour scores, determined every $5 \min$ ( $n=6$ for each group). (A) ICl 204,448; (B) Salvinorin A; (C) Tetrahydropyran Salvinorin A (D) Mesyl Salvinorin B. Two-way Repeated Measures ANOVA revealed a timedependent analgesic action for Sal A $[F(11,220)=15, P<0.0001] ; I C I 204,448[F(11,220)=11.37, P<0.0001]$; Mesyl Sal B $[F(11,220)=33.22, \mathrm{P}<0.0001]$; THP Sal A $[F(11,220)=17.89, P<0.0001]$. Bonferonni post-test compared to +VE Pain, ${ }^{*} \mathrm{P}<0.05,{ }^{*} \mathrm{P}<0.01, * * * \mathrm{P}<0.001$; $-\mathrm{VE}$ Pain, vehicle treated mice with intradermal PBS; +VE Pain, vehicle treated mice with intradermal Formalin (2\%) 
3.4 Total Analgesic Effect in the Intradermal Formalin Test

Total analgesic effect of KOPr agonists on phase 1 and phase 2 pain was evaluated separately by area under the curve (AUC), based on pain behaviour scores. ICI 204,448 was not found to have any overall analgesic effect at either phase 1 or 2 of the intradermal formalin test. Sal A $(2 \mathrm{mg} / \mathrm{kg})$ significantly attenuated phase $1(P<0.001)$ and Phase 2 pain $(P<0.001)$; at $1 \mathrm{mg} / \mathrm{kg}$ it was only found to attenuate phase 2 pain $(P<0.05)$. THP Sal $A$ significantly reduced phase 1 pain at 1 and $2 \mathrm{mg} / \mathrm{kg}(P<0.01)$; at $2 \mathrm{mg} / \mathrm{kg}$ it was further able to significantly attenuate phase 2 pain $(P<0.01)$. Mesyl Sal B was only able to significantly attenuate phase 1 pain at $1 \mathrm{mg} / \mathrm{kg}(P<0.01)$. 
A

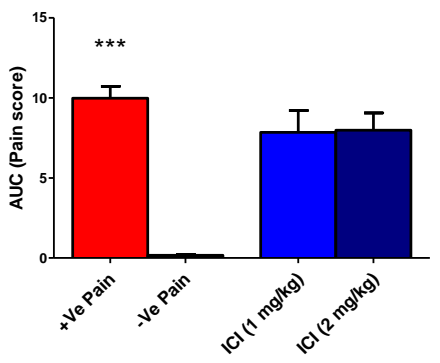

Phase 1

B

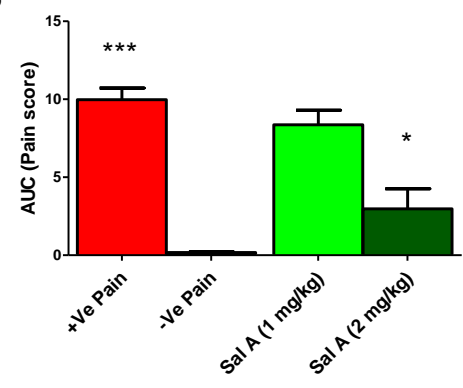

C

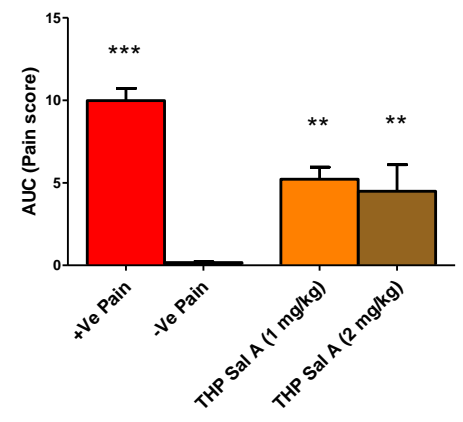

D

Phase 1

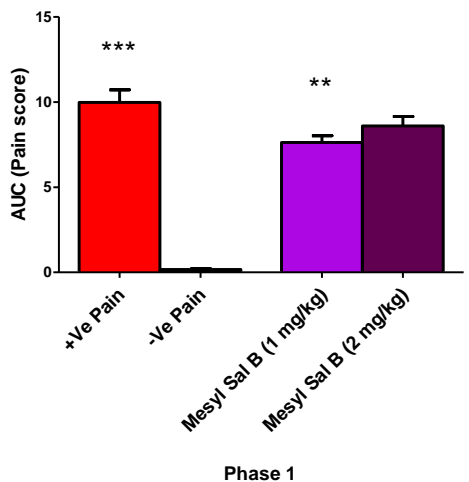

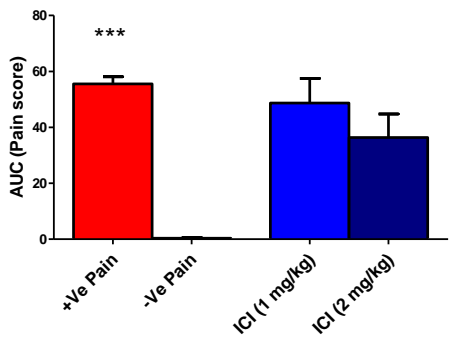

Phase 2

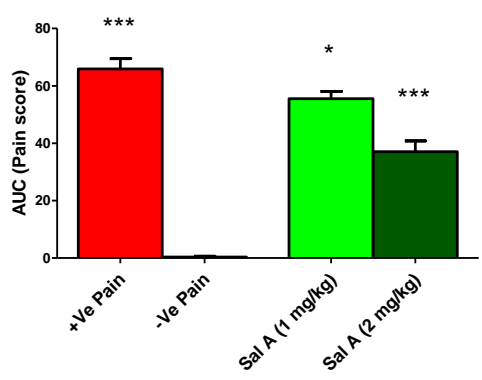

Phase 2

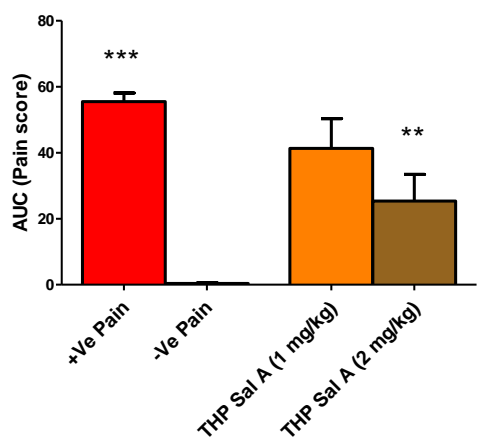

Phase 2

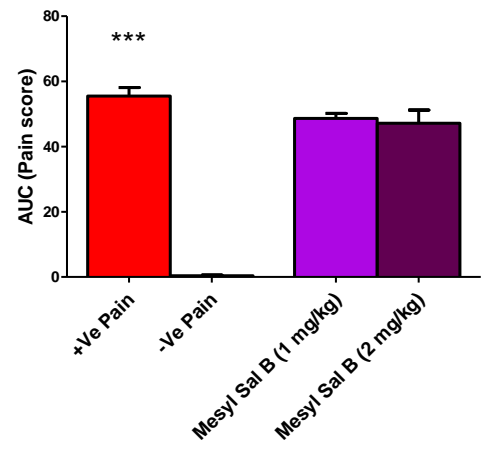

Phase 2

Figure 3.4 Total Analgesic Effect in the Intradermal Formalin Test shows the overall analgesic effects of KOPr agonists on phase 1 (left panel) and phase 2 pain (right panel). (A) ICI 204,448 (B) Salvinorin A (C) Tetrahydropyran Salvinorin A (D) Mesyl Salvinorin B. One-way ANOVA followed by Dunnett's test to compare with +Ve pain control. ${ }^{*} \mathrm{P}<0.05$; ${ }^{*} \mathrm{P}<0.01 ;{ }^{* * *} \mathrm{P}<0.001$. - Ve Pain, vehicle treated mice with intradermal $\mathrm{PBS}$; +Ve Pain, vehicle treated mice with intradermal formalin (2\%). 


\subsection{Anti-Oedematous Effect of KOPr Agonists}

Paw swelling $(\mathrm{mm})$ was evaluated before and after the intradermal formalin tests. Mice administered vehicle (PBS) intradermally into the hind paw showed a 53.1\% decrease (37.99 to 68.20 of $95 \% \mathrm{Cl}, \mathrm{P}<0.001)$ in paw swelling compared to mice administered formalin $(2 \%)$. Significant reduction of paw swelling was seen at a dose of $2 \mathrm{mg} / \mathrm{kg}$ with $\mathrm{ICl} 204,448$ (15.78\%, 1.806 to 29.74 of $95 \% \mathrm{Cl}, \mathrm{P}<0.05)$ and Sal $\mathrm{A}(13.54 \%, 0.2112$ to 26.87 of $95 \% \mathrm{Cl}$, $\mathrm{P}<0.05$ ) (Figure 3.5 A, B). Although THP Sal A and Mesyl Sal B showed insignificant trends in attenuating oedema, the effect was not considered significant (Figure 3.5 B, C). THP Sal A (1 $\mathrm{mg} / \mathrm{kg}$ ) reduced paw swelling by $15.01 \%(-2.891$ to 32.92 of $95 \% \mathrm{Cl}, \mathrm{P}>0.05)$. Mesyl Sal $\mathrm{B}$ reduced paw swelling at $1 \mathrm{mg} / \mathrm{kg}(15.21 \%,-3.812$ to 34.23 of $95 \% \mathrm{Cl}, \mathrm{P}>0.05)$ and $2 \mathrm{mg} / \mathrm{kg}$ (17.5\%, -1.516 to 36.52 of $95 \% \mathrm{Cl}, \mathrm{P}>0.05)$.

Salvinorin A and $\mathrm{ICl} 204,448$ (2 mg/ $\mathrm{kg}$ ) were further evaluated for time-course antioedematous effects (Firgure 3.5 E). There was significant paw swelling in mice administered intradermal formalin compared to vehicle in the footpad from $10-20 \mathrm{~min}(\mathrm{P}<0.05)$ and 30-60 $\min (\mathrm{P}<0.001)$. Sal A significantly reduced swelling from $30-60 \mathrm{~min}(23.97$ to $25.51 \%$, $\mathrm{P}<0.05)$; ICl 204,448 attenuated swelling at $30 \mathrm{~min}$ (25.23\%, $\mathrm{P}<0.05)$. Two-way ANOVA tests revealed significant overall anti-oedematous effects $[F(2,42)=29.97, P<0.0004]$ that was significantly time-dependent $[F(6,42)=12.18, P<0.0001]$. Bonferonni post-tests were done to compare against controls. 
A

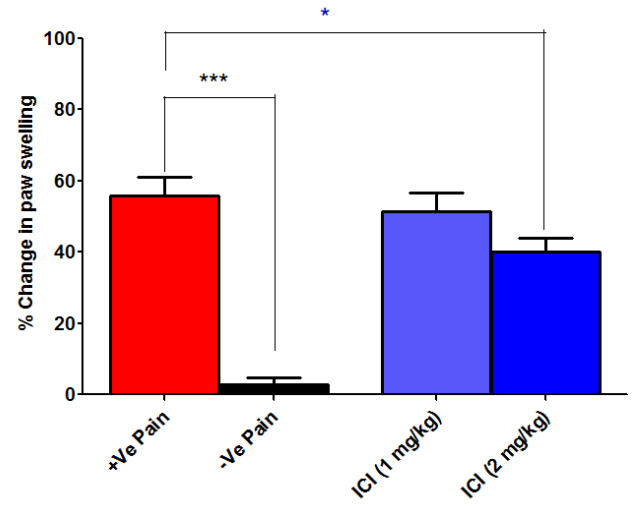

C

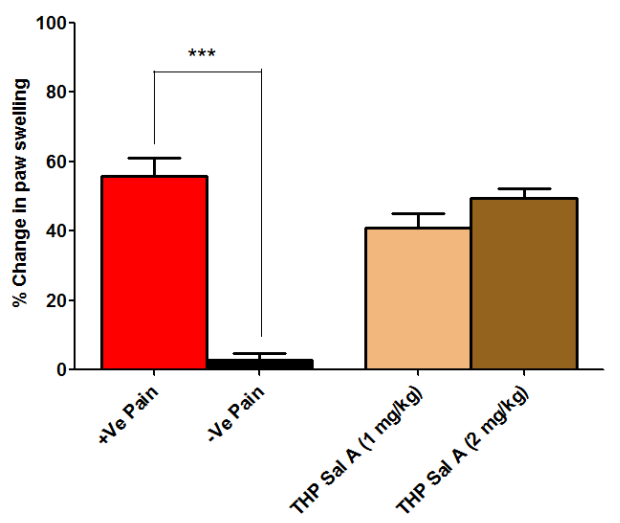

B

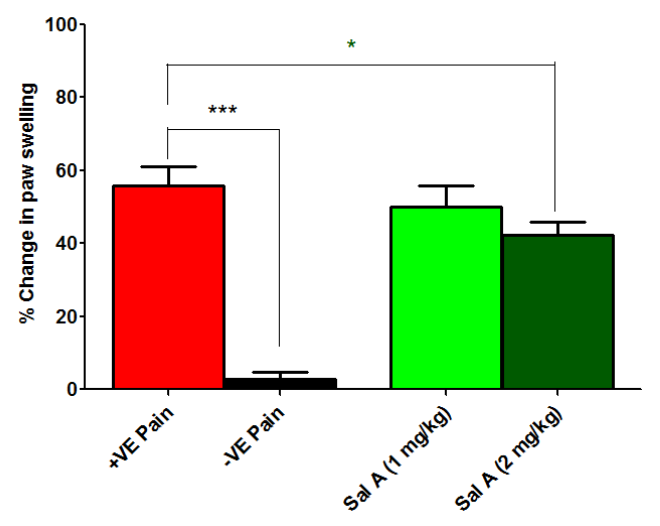

D

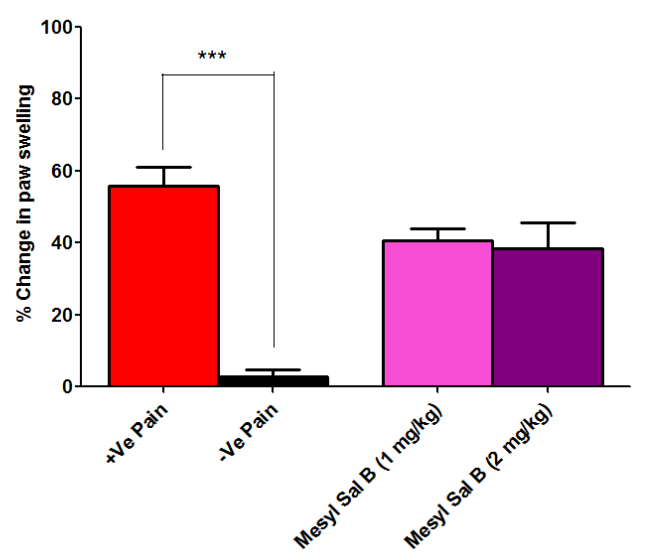

$\mathbf{E}$

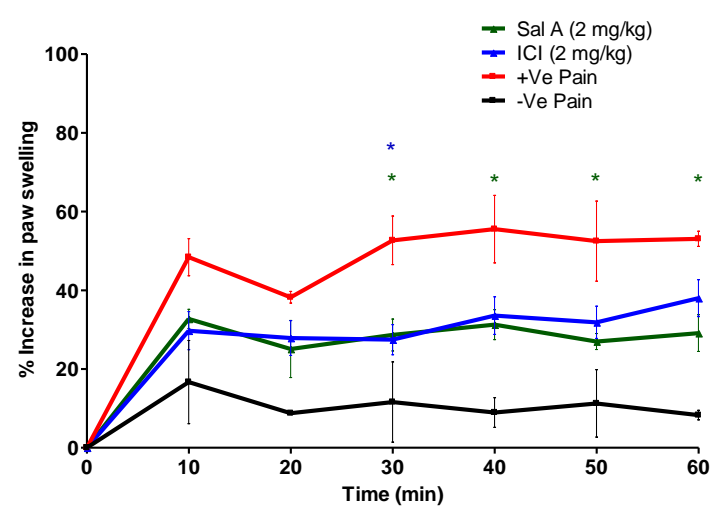

Fig. 3.5 Effect of KOPr agonists on paw swelling. Dose dependent ( 1 and $2 \mathrm{mg} / \mathrm{kg}$; IP) effect of KOPr agonists on formalin (2\%) induced paw swelling. Results are mean \pm SEM of percentage change in paw height for each group. +VE Pain (2\% Formalin, $n=17$ ), -VE Pain (PBS, $n=12$ ) (A) Salvinorin A (B) ICI 204,448 (C) Tetrahydropyran Salvinorin A (D) Mesyl Salvinorin B. One-way ANOVA followed by Dunnet's Test to compare against +Ve Pain. (E) Results are mean \pm SEM of percentage change in paw height every 10 min for $n=6$ for each group. +VE Pain (2\% Formalin, $n=2$ ), -VE Pain (PBS, $n=2$ ). Two-way ANOVA followed by Dunnet's Test to compare against +Ve Pain, ${ }^{*} P<0.05,{ }^{* * * P}<0.001$. $-V e$ Pain, vehicle treated mice with intradermal $P B S ;+V e$ Pain, vehicle treated mice with intradermal formalin (2\%). 
3.6. Effect of KOPr Agonists on Motor Coordination in the Rotarod Performance Test

KOPr agonist ( 1 and $2 \mathrm{mg} / \mathrm{kg}$ ) effect on motor coordination was assessed based on the latencies of mice to fall off the rotarod (Figure 3.6). ICl 204,448 (1 mg/kg) did not affect motor coordination; however at $2 \mathrm{mg} / \mathrm{kg}$, showed significant motor impairment 15-60 min $(P<0.01)$ post IP administration (Fig. 3.6 A). Sal A $(1 \mathrm{mg} / \mathrm{kg}$ ) had no significant effect on falloff latencies; at $2 \mathrm{mg} / \mathrm{kg}$ it showed significant motor impairment from 2-15 min $(P<0.01)$ (Figure $3.6 \mathrm{~B})$. THP Sal A (1 mg/kg) caused significant motor impairment 15-45 min ( $<<0.01)$; at $2 \mathrm{mg} / \mathrm{kg}$, it showed significant sedation within 2 min of IP drug administration $(P<0.05)$ and from 15-90 min after $(P<0.001 ; n=4)$ (Fig. 3.6 C). Mesyl Sal B did not cause motor impairment at 1 or $2 \mathrm{mg} / \mathrm{kg}$ (Fig. $3.5 \mathrm{C}$ ). 
A

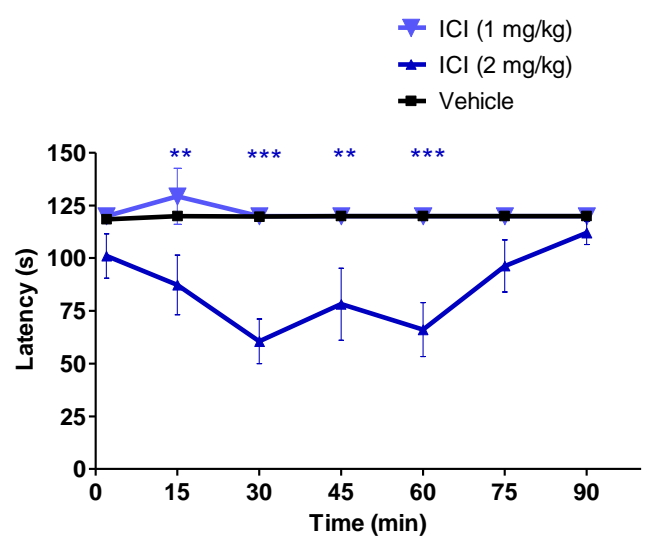

C

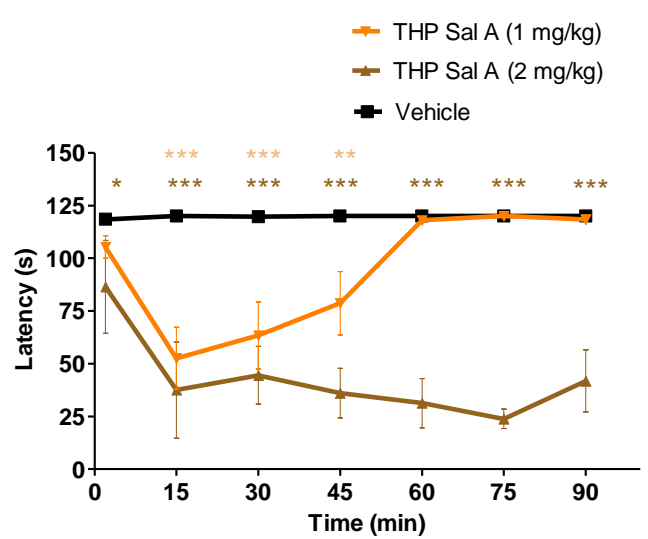

B

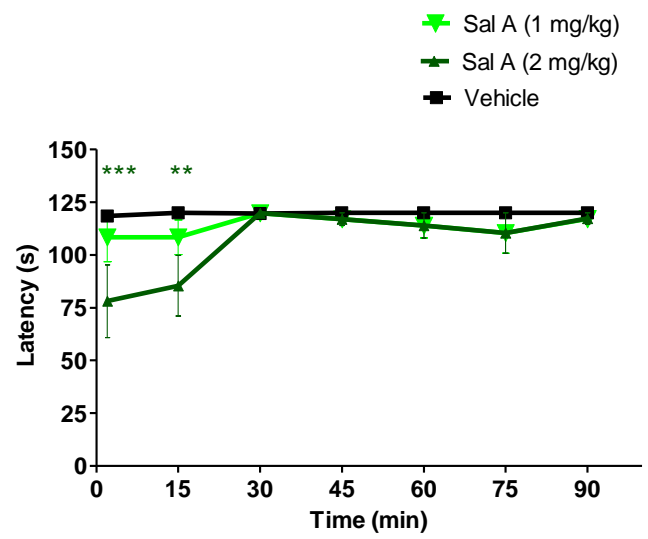

D

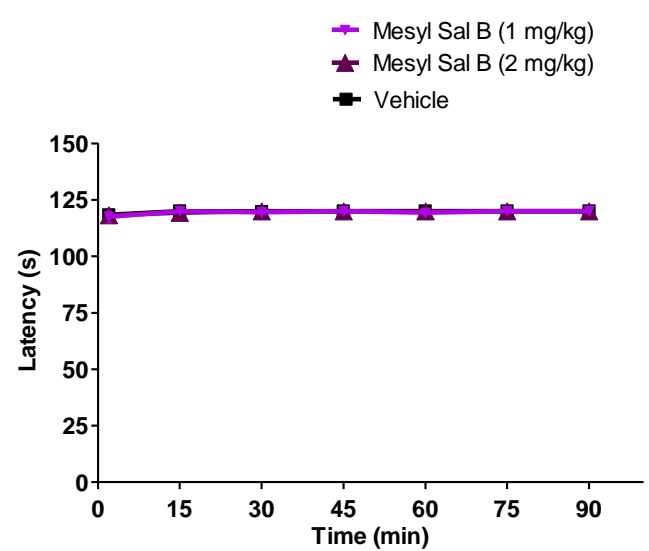

Fig. 3.6 Rotarod Performance Test showing dose-related ( 1 and $2 \mathrm{mg} / \mathrm{kg} ; \mathrm{IP}$ ) and time-course effect of KOPr agonists on motor coordination. Results are mean \pm SEM of fall-off latencies of mice ( $n=4$ to 7 per group) (A) Salvinorin A (B) ICI 204, 448 (C) Tetrahydropyran Salvinorin A (D) Mesyl Salvinorin B. Two-way ANOVA Repeated Measures revealed sedative effects for Sal A $[F(2,108)=6.79, P<0.0063] ; \operatorname{ICl} 204,448$ [F $(2,102)=$ 23.52, $\mathrm{P}<0.0001]$; THP Sal A $[F(2,84)=35.66, \mathrm{P}<0.0001]$ but not Mesyl Sal $B[F(2,96)=0.23, P<0.7986]$. Bonferonni post-test to compare to vehicle, ${ }^{*} \mathrm{P}<0.05,{ }^{* *} \mathrm{P}<0.01,{ }^{* * *} \mathrm{P}<0.001$ 


\subsection{Hypothermic Effects of KOPr Agonists}

The effect of KOPr agonists on core body temperature was examined using a rectal probe. No compound produced significant changes in body temperature except Sal A ( $2 \mathrm{mg} / \mathrm{kg}$ ) at 20 and $40 \mathrm{~min}(P<0.05)$. Two-way ANOVA revealed a significant hypothermic effect by Sal $A$ $[F(2,54)=25.14, P<0.0001]$, although this effect was not consistent through the experiment $[\mathrm{F}(12,54)=1.17, \mathrm{P}<0.3259] . \mathrm{ICl} 204,448(2 \mathrm{mg} / \mathrm{kg})$ did not show a significant effect on body temperature $[F(2,66)=2.73, P<0.1091]$ although there was a trending interaction between hypothermic effect and time $[\mathrm{F}(12,66)=1.71, \mathrm{P}<0.0855$; Fig. $3.6 \mathrm{~B}]$. Mesyl Sal B $[F(2,66)=1.69, P<0.2299]$ and THP Sal A $[F(2,30)=0.25, P<0.0 .7895]$ did not show any significant effect in temperature change. 
A

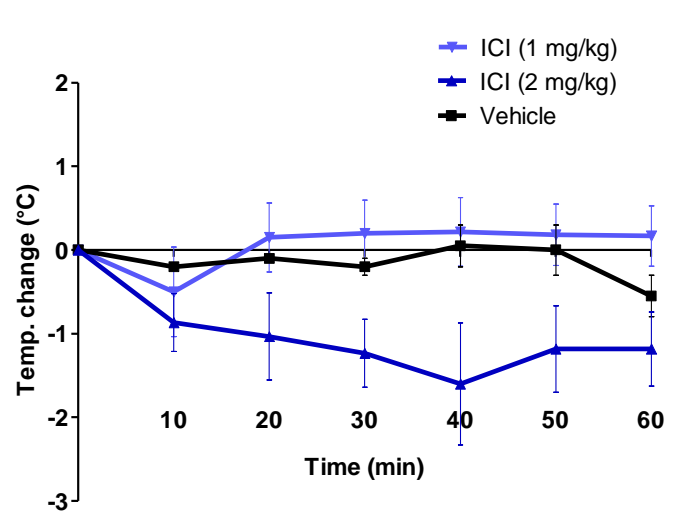

C

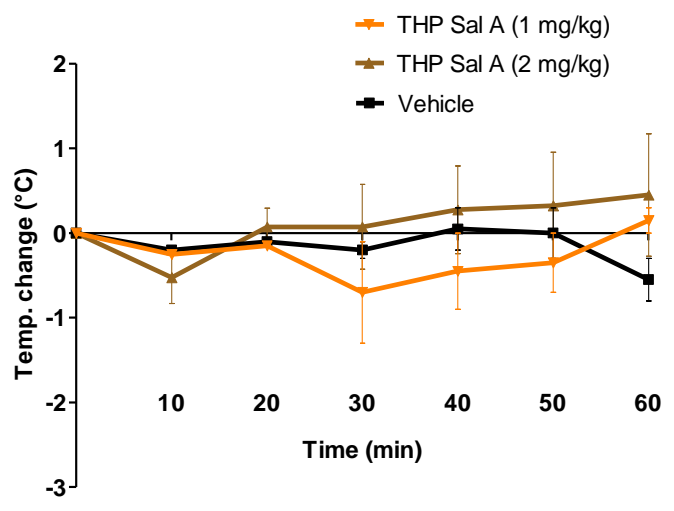

B

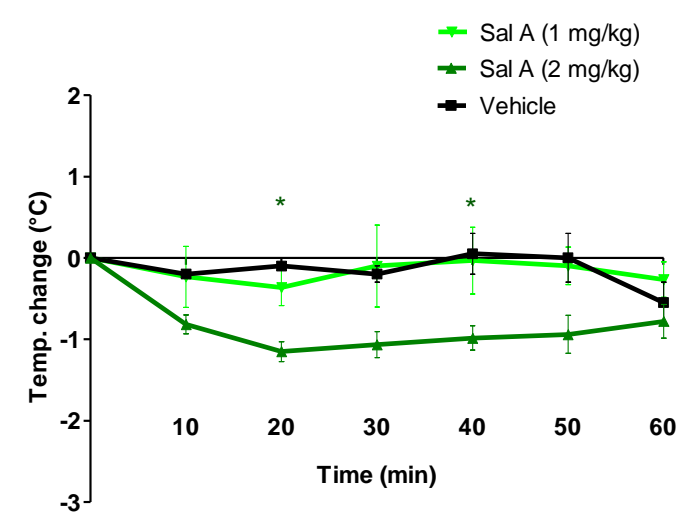

D

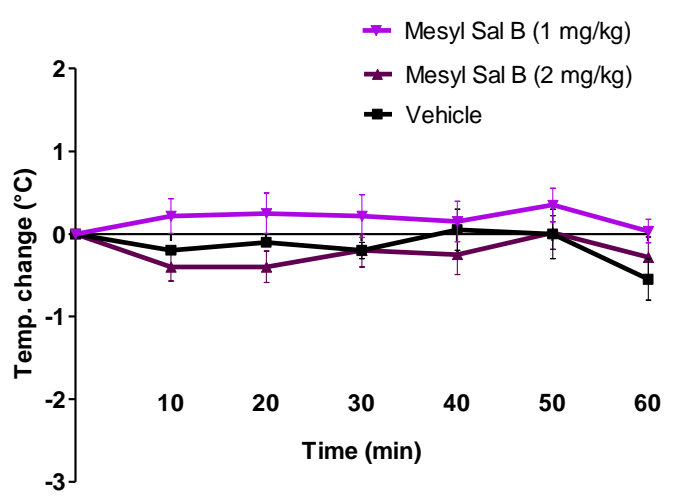

Fig. 3.7 Time-Course Effect of KOPr Agonists on Rectal Temperature $\left({ }^{\circ} \mathrm{C}\right)$. Results are mean \pm SEM of change in core body temperature in mice; Vehicle (PBS) (A) Salvinorin A (B) ICI 204, 448 (C) Tetrahydropyran Salvinorin A (D) Mesyl Salvinorin B. Two-way ANOVA Repeated Measures followed by Bonferonni post-test, ${ }^{*} \mathrm{P}<0.05$. 


\section{Discussion}

KOPr agonists, like MOPr agonists, have analgesic properties. However, centrally mediated side-effects such as sedation, dysphoria and hallucinations restrict them from being used therapeutically as analgesics. There are a variety of ways in which the therapeutic analgesic potential of opioid compounds may be exploited. Previous studies have shown that targeting both KOPr (by U-69,593) and MOPr (by fentanyl) may reduce abuse potential in rhesus monkeys, without reducing analgesic effects relative to selective MOPr agonists given alone (Neguset al., 2008). Other ways in which the therapeutic potential of KOPr agonists have been re-evaluated recently include the development KOPr agonists that are restricted in their ability to cross the blood brain barrier. Restricting KOPr agonist action to the periphery has been shown to reduce the predominantly centrally mediated side-effects. Examples of this include the KOPr agonist CR-845 (Arendt-Nielsen et al., 2009), ICI 204,448 (Barber et al., 1994), FE 200665 and FE 200666 (Rivière, 2004). A further strategy is to evaluate the functionally selective nature of KOPr agonists for antinociceptive pathways over pathways activating side-effects (Rives et al., 2012; Zhou et al., 2013). Recently, Sal A analogues have been shown to have fewer side effects in preclinical models as a consequence of functionally selective mechanisms (Fichna et al., 2009; Lamb et al., 2012).

In the present study we evaluate the analgesic properties of a known KOPr agonist with predominantly peripheral effects, ICl 204,448. In addition, we evaluate Sal A and its novel analogues THP Sal A and Mesyl Sal B using pre-clinical models of acute pain. Although the analgesic actions of these novel analogues have not been reported previously, we have recently shown that Mesyl Sal B has a longer duration of action compared to Sal $A$ in the tail-flick test (Simonson et al 2014). 
Table 4.1 Summary of Anitnociceptive Effects

\begin{tabular}{|c|c|c|c|c|c|}
\hline \multicolumn{2}{|c|}{$\begin{array}{l}\text { KOPr Agonist } \\
\text { (1 and/or } 2 \mathrm{mg} / \mathrm{kg} \text { ) }\end{array}$} & $\mathrm{ICl} 204,448$ & Sal A & THP Sal A & Mesyl Sal B \\
\hline \multicolumn{2}{|c|}{$\begin{array}{l}\text { Time of effect in } \\
\text { tail-flick test (min) }\end{array}$} & nil & $5-15$ & $5-15$ & $\begin{array}{c}15,25-30,40-45 \\
90\end{array}$ \\
\hline \multirow{2}{*}{$\begin{array}{l}\text { Time of } \\
\text { effect in } \\
\text { intradermal } \\
\text { formalin test } \\
\text { (min) }\end{array}$} & Phase 1 & & $5-10$ & 10 & 10 \\
\hline & Phase 2 & $25-35$ & $25-35$ & $25-60$ & 30,45 \\
\hline
\end{tabular}

Table 4.2 Summary of Side-Effects

\begin{tabular}{|l|c|c|c|c|}
\hline $\begin{array}{l}\text { KOPr Agonist } \\
(1 \text { and/or } 2 \mathrm{mg} / \mathrm{kg})\end{array}$ & $\mathrm{ICl} 204,448$ & Sal A & THP Sal A & Mesyl Sal B \\
\hline $\begin{array}{l}\text { Time of effect in } \\
\text { rotarod test (min) }\end{array}$ & $25-35$ & $2-15$ & $2-90$ & Nil \\
\hline $\begin{array}{l}\text { Time of hypothermic } \\
\text { effect }\end{array}$ & Nil & 20,40 & Nil & Nil \\
\hline
\end{tabular}




\subsection{Antinociceptive Effects of KOPr Agonists}

\subsubsection{ICI 204,448}

There is evidence to support that $\mathrm{ICI} 204,448$ has limited entry into the CNS. Initial ex vivo studies on mice, 30 min after subcutaneous (SC) administration of $\mathrm{ICl} 204,448$ (50 mg/kg), estimated to accumulate in brain tissue at a concentration of $435 \mathrm{pg} / \mathrm{mg}$. The estimation was based on ex vivo and in vitro $\left[{ }^{3} \mathrm{H}\right]$-bremazocine displacement curves in treated and untreated mice, giving it a CNS penetration index of 8.7 (compared to 328.1 of $\mathrm{U} 50,488 \mathrm{H}$ ) (Shaw et al., 1989). This has resulted in studies using this compound for evaluating peripheral effects of KOPr agonists (Inan \& Cowan, 2004; Trigub et al., 2014). Salas et al. (2007) showed that ICl 204,448 had a dose-dependent analgesic effect in rat models of neuropathic pain after SC, intrathecal and PAG administration. The analgesic effect due to SC administration were partially blocked by a broad opioid receptor antagonist (naloxone) delivered SC but not intrathecally. This suggests that ICI 204,448 is capable of producing analgesia by KOPr selective mechanisms both centrally and peripherally; it shows exclusive peripheral mechanisms of analgesic action following systemic delivery.

To the best of our knowledge, the analgesic effects of $\mathrm{ICI} 204,448$ have not been determined utilising the tail-flick test. Figures 3.1 A \& 3.2 A show that ICI 204,448 does not have potential in attenuating central processes of pain transmission as assessed by the tail-flick test. This supports results from other studies showing ICI 204,448 has limited effects in the CNS following systemic administration. In addition, we found ICI 204,448 attenuated phase 2, but not phase 1 pain in the intradermal formalin test. However, this analgesic effect was short-lived and only significant at $30 \mathrm{~min}$ with $1 \mathrm{mg} / \mathrm{kg}$, and 25-35 min with $2 \mathrm{mg} / \mathrm{kg}$ (Figure 3.3 A). Barber et al., (1994) constructed a bell-shaped dose response curve with ICl 204,448 $(0.003-30 \mathrm{mg} / \mathrm{kg})$ in mice and concluded that it could attenuate phase 1 nociceptive pain at an inhibitory dose $\left(I_{50}\right)$ of $18.9 \mathrm{mg} / \mathrm{kg}$ (lower limit $7.3 \mathrm{mg} / \mathrm{kg}$ ) and phase 2 inflammatory pain at an $I_{50}$ of $12.6 \mathrm{mg} / \mathrm{kg}$ (lower limit $8.4 \mathrm{mg} / \mathrm{kg}$ ) using the intradermal formalin (3\%) model. Pain induced by the abdominal constriction test, a model of inflammatory pain, was reduced by an $I D_{50}$ of $1.9 \mathrm{mg} / \mathrm{kg}$ (lower limit $0.6 \mathrm{mg} / \mathrm{kg}$ ), suggesting better potential in attenuating inflammatory pain over nociceptive pain. Our study was consistent with these 
results in observing prevalent analgesic effects during phase 2 pain, as opposed to phase 1 and thermal nociceptive pain, at 1 and $2 \mathrm{mg} / \mathrm{kg}$ (Figure $3.1 \mathrm{~A}, 3.3 \mathrm{~A}$ ). The overall analgesic effect was assessed by area under the curve (AUC) of tail-withdrawal latencies in the tailflick test, and behavioural pain scores in the intradermal formalin test (Figure 3.2 A, 3.4 A). These results show that $\mathrm{ICI} 204,448$ does not modulate nociceptive pain (thermal and phase 1 pain) or phase 2 inflammatory pain (Figure 3.2 A, 3.4 A), suggesting limited analgesic potential at 1 and $2 \mathrm{mg} / \mathrm{kg}$.

The attenuation of phase 2 pain between $25-35 \mathrm{~min}$ by ICl 204,448 (2 mg/kg) (Figure $3.2 \mathrm{~A}$ ) correlates with its capacity to significantly reduce oedema formation at 30 min (Figure 3.6). This suggests that ICI 204,448 has an onset of action in the modulation of peripheral inflammatory processes $\sim 30$ min post IP administration. Barber et al. (1994) used a 30 min pretreament time as opposed to 5 min by this study. Since phase 2 pain only manifests 15 20 min after intradermal formalin administration, a pretreatment time of 30 min would require ICI 204,448 to be active $45-50$ min after formalin administration. At this time-point the phase 2 analgesic effect of ICI 204,448, in the intradermal formalin test, was found to have subsided (Figure 3.3 A). This may explain the higher doses required to attenuate phase 2 pain by Barber et al., (1994). Our study also found ICI 204,448 (2 mg/kg) significantly reduced paw oedema at $60 \mathrm{~min}$ following the intradermal formalin test. Flow cytometry results (Unpublished data, 2013), done by a colleague in the Kivell lab, found ICI 204,448 (1 and $2 \mathrm{mg} / \mathrm{kg}$ ) significantly attenuated neutrophil migration induced by intradermal formalin. These results suggest ICI 204,448 has potential for attenuating nociceptive processes, oedema and inflammatory cell recruitment as a result of inflammation due to tissue damage. However, at a dose of 1 and $2 \mathrm{mg} / \mathrm{kg}$, there is limited potential for it to be an effective analgesic. The therapeutic potential of this compound was further evaluated with the rotarod performance test (discussed below, section 4.2.1).

\subsubsection{Tail Flick Test: Sal A, THP Sal A \& Mesyl Sal B}

Unlike ICl 204,448, Sal A is known for its central (Grilli et al., 2009; Imanshahidi \& Hosseinzadeh, 2006); and peripheral analgesic effects (Gabriella Aviello et al., 2011) via KOPr selective mechanisms. We found Sal A (1 and $2 \mathrm{mg} / \mathrm{kg}$ ) significantly increased tail- 
withdrawal latencies 5 to $15 \mathrm{~min}$ post IP administration (Figure $3.1 \mathrm{~B}$ ). This suggests a rapid onset and short duration of central action towards thermal stimuli. Studies utilising tail-flick tests with systemic administration (SC) of Sal A found it had a short-acting ( $20 \mathrm{~min}$ ) and dose-dependent (1-4 mg/kg) effect on tail-withdrawal latencies in mice (McCurdy, 2006). Our results were consistent with these findings. However, we found that Sal $A$ at $1 \mathrm{mg} / \mathrm{kg}$ increased tail-withdrawal latencies compared to vehicle treated mice by $28.8 \%$, compared to $18.3 \%$ at $2 \mathrm{mg} / \mathrm{kg}$ (Figure $3.1 \mathrm{~B}$ ). McCurdy et al. (2006) found the opposite dose-related effects with Sal A ( $2>1 \mathrm{mg} / \mathrm{kg}$ ); they did however find lower doses better attenuated acute thermal, chemical and inflammatory stimuli in mouse behavioural pain models, including the tail-flick test $(2>4 \mathrm{mg} / \mathrm{kg})$, hot-plate test $(1>2 \mathrm{mg} / \mathrm{kg})$ and in abdominal constriction assays $(0.5>2 \mathrm{mg} / \mathrm{kg})$.

THP Sal A showed a similar pattern of attenuating nociceptive pain in the tail-flick test as Sal A (Figure $3.1 \mathrm{~B}, \mathrm{C}$ ). It had a rapid onset $(5 \mathrm{~min}$ ) and short duration of central action (30 $\mathrm{min})$ at $2 \mathrm{mg} / \mathrm{kg}$. Despite similarities, its dose-related effects were contrary to Sal A, attenuating pain only at $2 \mathrm{mg} / \mathrm{kg}$ and not at $1 \mathrm{mg} / \mathrm{kg}$ (Sal A: $1>2 \mathrm{mg} / \mathrm{kg}$ ). AUC indicated better potential in attenuating thermal nociceptive pain than Sal $A$ within the first $30 \mathrm{~min}$ of IP administration (Figure $3.2 \mathrm{~B}, \mathrm{C}$ ). It's therefore possible that THP Sal A is rapidly converted into a metabolite that is incapable of producing analgesia, similar to Sal $A$ ( $t 1 / 2=\sim 8 \mathrm{~min}$ in non-human primate brains) (Hooker et al., 2008). The therapeutic potential of THP Sal A was further evaluated for sedative and thermoregulatory effects (discussed below, section 4.2.2).

In contrast to THP Sal A, Mesyl Sal B (1 mg/kg) was found to have a later onset (15 $\mathrm{min}$ ) and longer duration of action (60 min) than Sal A and THP Sal A in the tail-flick test (Figure $3.1 \mathrm{~B}$, C, D). AUC analysis revealed significant analgesic effects, $30-120 \mathrm{~min}$ at $1 \mathrm{mg} / \mathrm{kg}$ but not at 2 $\mathrm{mg} / \mathrm{kg}$. Its overall potential in reducing thermal pain at $1 \mathrm{mg} / \mathrm{kg}$ was lower than Sal $A$ within the first 30 min, but greater than Sal A and THP Sal A from 30-120 min (Figure 3.2 B, C, D). This suggests that Mesyl Sal B may have a better metabolic profile than Sal A and THP Sal A due to its more sustained analgesic effects. However, its overall potential in treating nociceptive thermal pain is compromised. Future experiments in determining the analgesic potential of Mesyl Sal B at higher and lower doses would better elucidate its dosedependent central mechanisms of producing analgesia. 


\subsubsection{Intradermal formalin Test: Sal A, THP Sal A \& Mesyl Sal B}

Time-course analysis on formalin induced pain behaviour showed that Sal A $(2 \mathrm{mg} / \mathrm{kg})$ significantly attenuated phase 1 (at 5-10 $\mathrm{min}$ ) and phase 2 pain (at 25-35 min) (Figure $3.2 \mathrm{~B}$ ). At $1 \mathrm{mg} / \mathrm{kg}$, no significant analgesic effects were observed at any single time-point. However, AUC analysis found Sal A to significantly attenuate phase 2 pain at $1 \mathrm{mg} / \mathrm{kg}$ and both phase 1 and 2 pain at $2 \mathrm{mg} / \mathrm{kg}$ (Figure $3.4 \mathrm{~B}$ ). Sal A also attenuated formalin induced oedema from 30 to $60 \mathrm{~min}$ at $2 \mathrm{mg} / \mathrm{kg}$ (Figure $3.5 \mathrm{~B}$; 3.6). Aviello et al., (2012) found systemic delivery (IP) of Sal A (1-2 mg/ $\mathrm{kg}$ ) significantly reduced phase 1 and 2 pain in a dosedependent and antagonist (NorBNI) sensitive manner. This suggests $\mathrm{KOPr}$ selective mechanisms in the attenuation of formalin induced nociceptive and inflammatory pain. The same study reported Sal A $(0.5-2 \mathrm{mg} / \mathrm{kg})$ to significantly attenuate paw oedema, induced by carageenan and lipopolysaccharide. The antioedematous effect was found to be greatest at the lowest administered dose $(0.5 \mathrm{mg} / \mathrm{kg}, 2-6$ hours).

Studies within our laboratory, investigating inflammatory processes using flow cytometry and histological techniques on paw tissue, were carried out $60 \mathrm{~min}$ ( $\pm 15 \mathrm{~min}$ ) after intradermal formalin administration (Unpublished data, 2013). Results from this analysis showed significant attenuation of neutrophils in paw tissue of Sal A (2 mg/ $/ \mathrm{kg})$ treated mice compared to controls. Indeed, Sal A has been shown to modulate pain-related inflammatory processes, such as reducing tumour necrosis factor $\alpha$, interleukins and nitrite levels in lipopolysaccharide induced intraperitoneal mouse macrophages in vitro (Aviello et al., 2011). Guida et al. (2012) showed that a $2 \mathrm{mg} / \mathrm{kg}$ repeated treatment with Sal A (IP) attenuated inflammatory processes within the CNS by reducing spinal astrocytes, microglia and interleukin-10 in spinal tissue between 3-7 days. This suggests that Sal A has analgesic and anti-inflammatory properties at both central and peripheral sites. There are however discrepencies between specific does-related effects with administering Sal A IP, as shown by results with this study and those done by McCurdy et al., (2006) and Aviello et al., (2011). Conversely, studies employing intrathecal or intracerebroventricular administration of Sal A have not reported these dose-related discrepancies (John et al. 2005; Ansonoff et al., 2006). It is speculated that these differences are due to different peripheral or central target 
preferences by different drug dosages, although further studies are needed to clarify this unintuitive effect.

THP Sal A was found to have a similar pattern in attenuating phase 1 and 2 pain as Sal $A$ (Figure 3.3 B, C). Time-course analysis of formalin induced pain found it to reduce phase 1 pain at both 1 and $2 \mathrm{mg} / \mathrm{kg}$ (Figure $3.3 \mathrm{C} ; 3.4 \mathrm{C}$ ). Similarly, phase 2 pain was reduced at 1 $\mathrm{mg} / \mathrm{kg}$ (at 40, 45, $60 \mathrm{~min}$ ) and $2 \mathrm{mg} / \mathrm{kg}$ (25-45 min). However, AUC analysis showed THP Sal A to reduce phase 2 pain at only $2 \mathrm{mg} / \mathrm{kg}$ (Figure $3.4 \mathrm{C}$ ). These results suggest that, compared to Sal A, THP Sal A has similar potential in reducing chemically induced nociceptive pain; it may have a similar half-life in the CNS as Sal A. THP Sal A has a longer duration of action in reducing inflammatory pain.

Time-course analysis of formalin induced pain found Mesyl Sal B to attenuate both phase 1 (1 mg/kg, $10 \mathrm{~min}$ ) and phase 2 pain ( $1 \mathrm{mg} / \mathrm{kg}, 60 \mathrm{~min} ; 2 \mathrm{mg} / \mathrm{kg}, 30 \mathrm{~min}$ ) (Figure $3.3 \mathrm{D}$ ). This suggests potential for Mesyl Sal B in attenuating both nociceptive and inflammatory pain. However, AUC analysis assessing overall analgesic effects did not find Mesyl Sal B to attenuate phase 1 or 2 pain at either 1 or $2 \mathrm{mg} / \mathrm{kg}$. This shows that although Mesyl Sal B has analgesic potential through CNS and peripheral targets, it is weaker in comparison to Sal A and THP Sal A. Just as in the tail-flick test, it would be worth assessing higher doses of Mesyl Sal $B$ in the intradermal formalin model to further evaluate its dose-related analgesic potential in the CNS and periphery. 
4.2 Side-Effect Profile

\subsubsection{ICI 204,448}

As far as we know, ICl 204,448 has not been tested for sedative effects in mice using the rotarod performance test. We found ICI 204,448 to be significantly sedative (33-50\% \pm SEM with $\mathrm{n}=7$ ) from $15-60 \mathrm{~min}$ at a dose of $2 \mathrm{mg} / \mathrm{kg}$, as assessed by the rotarod performance test. Studies using rotarod and elevated plus maze tests on rats however, found no locomotor effects post SC (Barber et al., 1994) or intragastric (Alexeeva et al., 2012) administration (30 min pretreatment time), respectively. It was only found to be sedative at a dose of $52 \mathrm{mg} / \mathrm{kg}$ (SC) in the platform sedation test in mice (Kumar et al., 2005); at 30 $\mathrm{mg} / \mathrm{kg}(\mathrm{SC}$ ), it neither prolonged hexobarbitone-induced sleeping time in mice (A. Barber et al., 1994) nor was it active in the rotarod performance test in rats (Rogers et al., 1992). It was however, found to produce a concentration-dependent displacement of $\left({ }^{3} \mathrm{H}\right)$ bremazocine from guinea-pig cerebellum membranes after SC administration (30 min pretreatment time) (A. Barber et al., 1994). This suggests that systemic delivery of $\mathrm{ICl}$ 204,448 may stimulate KOPr in the cerebellum, a crucial region in the mediation for motor coordination (Morton \& Bastian, 2004), although in vivo results in rodents have not been suggestive of sedative effects. We are the first to report sedative effects of $I C I 204,448$ at a dose of $2 \mathrm{mg} / \mathrm{kg}$ in mice using the rotarod performance test. Although this effect may be a consequence of centrally penetrative effects of $\mathrm{ICI} 204,448$, there is a chance of it being mediated via peripheral mechanisms. KOPr expression and dynorphins have been detected in the inner ear of guinea pigs (Jongkamonwiwat et al., 2006). The vestibular system of the inner ear is known to contribute to balance and sense of spatial orientation. It is therefore possible that these locomotor effects are a consequence of KOPr activity in these peripheral regions, although more studies are needed in elucidating these effects.

We did not find any hypothermic effects with $\mathrm{ICl} 204,448$ at $1 \mathrm{mg} / \mathrm{kg}$, although a hypothermic trend, however insignificant, can be noticed at $2 \mathrm{mg} / \mathrm{kg}$ (Figure $3.6 \mathrm{~A}$ ). $\mathrm{ICl}$ 204,448 has been suggested to produce hypothermia via peripheral mechanisms. Rawls et al 
(2005) showed that ICI 204,448 (SC) produced significant hypothermia at doses $\geq 5 \mathrm{mg} / \mathrm{kg}$ in cold exposed $\left(5^{\circ} \mathrm{C}\right)$ rats but not in rats exposed to warmer temperatures $\left(20-30^{\circ} \mathrm{C}\right)$. The hypothermic effect was attenuated by intracerebroventricular administration of the KOPr selective antagonist, NorBNI, making it unlikely to be caused by KOPr activity it the CNS. This suggests peripheral mechanisms of hypothermia.

ICI 204,448, although known to be peripherally restricted, can penetrate the CNS at high doses. As most studies employ 30 min pretreatment times, the level of central penetration in vivo is not known before this time-point. As peripheral mechanisms of KOPr-dependent sedation have not been fully elucidated, studies using this compound as a positive control for suggesting peripherally mediated effects (Inan et al., 2004; Trigub et al., 2014) may need further evidence. This may be achieved by imaging techniques (de Lange \& Danhof, 2002) or coadministration with intrathecal or intracerebroventricular NorBNI. Although ICI 204,448 shows therapeutic potential of having analgesic and anti-inflammatory effects without causing sedation at $1 \mathrm{mg} / \mathrm{kg}$, these effects are short-lived. Peripherally restricted properties of KOPr agonists, such as CR-845, may prove to be more effective in the treatment of pain, although this study did not find $\mathrm{ICI} 204,448$ to be an effective analgesic.

\subsubsection{Sal A, THP Sal A \& Mesyl Sal B}

Results from the rotarod performance test with Sal A in this study were consistent with results from the tail-flick test (Figure $3.1 \mathrm{~B} ; 3.7 \mathrm{~B}$ ). It was found have a fast onset ( $33.6 \%$ $\pm 29 \%$ within $2 \mathrm{~min}$ ) and short-acting (2-15 $\mathrm{min}$ ) sedative effect in mice at a dose of $2 \mathrm{mg} / \mathrm{kg}$ (Fig. $3.3 \mathrm{~B}$ ); this effect was not observed at a dose of $1 \mathrm{mg} / \mathrm{kg}$. Sal A has been shown to induce sedation and dysphoria in rodents, humans and non-human primates (Butelman et al., 2004; Chavkin et al., 2004; Fantegrossi et al., 2005). PET scans in primates using $\left[{ }^{11} \mathrm{C}\right]$-Sal A, found that it rapidly crossed the blood-brain-barrier and reached $3.3 \%$ of the injected dose within $40 \mathrm{~s}$, and cleared to half of its peak by $8 \mathrm{~min}$ (Hooker et al., 2008). Persistent radioactive carbon concentrations were found in the spine; its highest level in the brain was observed in the cerebellum - a critical area for balance and locomotion (Morton \& Bastian, 2004). Fantegrossi et al. (2005) found Sal A $(0.5-2 \mathrm{mg} / \mathrm{kg})$ to cause significant sedation and 
decreased motor coordination within the first $5 \mathrm{~min}$ of IP administration $(5 \mathrm{~min}$ pretreatment time). It was shown to do this in a KOPr selective manner in the inverted screen task in mice, a behavioural model for assessing sedation and muscle strength. These results suggest that, like the central antinociceptive effects of Sal $A$, the sedative effects have a fast onset and brief duration of action. Furthermore, Sal A (1-3.2 mg/kg) was found to decrease dopamine levels in the brain (Carlezon et al., 2006; Zhang et al., Ho, \& Kreek, 2005) in a KOPr selective manner. As decreased extracellular dopamine has been linked to sedative effects in mice (Chiara et al., 1976), interplay between $\operatorname{KOPr}$ and dopamine mechanisms may be responsible for the sedative nature of this KOPr agonist.

THP Sal A ( $2 \mathrm{mg} / \mathrm{kg})$ had similar potential in being sedative as Sal A ( 30\%, \pm SEM with $\mathrm{n}=4)$, having a fast onset of action within $2 \mathrm{~min}$. It was sedative at both $1 \mathrm{mg} / \mathrm{kg}$ (15-45 $\mathrm{min}$ ) and 2 $\mathrm{mg} / \mathrm{kg}(2-90 \mathrm{~min}$ ). Although its duration of central action in the tail-flick test was similar to Sal A (30 min), it had a longer sedative effect than Sal A (Figure 3.7 B, C). This suggests that if these effects are in fact centrally mediated, then it may be due to differential KOPr stimulation in the CNS by THP Sal A. In contrast, Mesyl Sal B was not sedative at either 1 or 2 $\mathrm{mg} / \mathrm{kg}$, suggesting better therapeutic potential in treating pain. Although Mesyl Sal B had central effects in the tail-flick test (Figure 3.1 D), it did not cause sedation. Unless these sedative effects are peripherally mediated, this suggests differential stimulation of KOPr in the CNS, by Mesyl Sal B, to produce analgesia without sedation/locomotor dysfunction.

We found Sal $A$ to be significantly hypothermic $\left(P<0.05,-1^{\circ} \mathrm{C}, \pm S E M\right.$ with $\left.n=6\right)$ at $2 \mathrm{mg} / \mathrm{kg}, 20$ and 40 min post IP administration (Fig. 3.6 B). Ansonoff et al., 2006 used KOPr knockout mice to show Sal A had reduced potential in producing hypothermia in these models; Sal Ainduced hypothermia in wild-type mice lasted for 75-120 min post intracerebroventricular administration $(50 \mu \mathrm{g})$. Wang et al. (2008) found that IP administration of high-dose Sal A $(10 \mathrm{mg} / \mathrm{kg})$ in rats had no hypothermic effects, although this study used a pretreatment time of $30 \mathrm{~min}$. A significant part of Sal A action may have subsided after $30 \mathrm{~min}$. As studies on Sal A have found it to have a very short half-life in the CNS ( 8 min in non-human primates) (Hooker et al., 2008), whether the hypothermic effect of Sal A in our study was due to central or peripheral mechanisms is, like ICI 204,448, yet to be determined. In contrast, THP 
Sal A and Mesyl Sal B were not found to cause significant irregularities in thermoregulation at 1 and $2 \mathrm{mg} / \mathrm{kg}$.

\subsection{Limitations}

It was recently reported that male human experimenters/observers, such as that used by this study, may contribute to significant alterations to nociceptive and thermoregulatory mechanisms in rodents as opposed to female human experimenters/observers (Sorge et al., 2014). These effects were suggested to be due to increased levels of stress-induced androgens from exposure to male observers, since these effects were not replicated in castrated rodents, cats and dogs. Nociceptive processes, assessed by the tail-flick test in mice (sample size > 1000), revealed male observers to significantly increase mean base-line tail-flick latencies. Assessment of male-induced analgesia in the intradermal formalin test (1\%) showed phase 1 pain was attenuated by minimal olfactory stimuli, such as a shirt that was previously worn by a male. Phase 2 pain was also reported to be attenuated by male observers entering the room 20 min post intradermal formalin injection. High dose formalin concentrations (5\%) however was shown to require both visual and olfactory stimuli to attenuate phase 1 pain. Furthermore, the study also found male observers to induce significant hyperthermia in mice, 15-30 min after exposure.

This study accounted for modulatory visual and audio stimuli by using a wooden box and white noise, respectively, to curtail exposure to confounding factors; alterations due to olfactory stimuli however, were not accounted for. The use of positive and negative controls may have standardised many of these effects as all tests were done by one male experimenter. It is however possible that the central and peripheral analgesic effects of KOPr agonists may have been potentiated by the stress-induced "male-observer" effect, whereas the hypothermic effect may have been attenuated by the same effect. The same study found that habituation to male T-shirts fully attenuated male observer inducer analgesic response within 30-60 min post-exposure. However the effect was not reduced with mice exposed to a male observer for 1 hour in a day or $30 \mathrm{~min} /$ day for 5 days, followed 
by pain-assays the following day. These results mimic the scenario of mice exposed to male care-takers herein the case with this study.

Apart from stress induced by the male-observer effect, there may have been significant stress induced analgesia in the tail-flick test due to the $10 \mathrm{~min}$ habituation period in the mouse-restrainers before experimentation. Mouse restrainers were found to contain urine (diuresis is a stress-response) after acclimatisation, which was wiped with only paper towels rather than ethanol or virkon to reduce alterations in pain-behaviour by inhaled substances. This stress induced effect may have been magnified by olfactory and visual cues by the male experimenter handling the transparent Plexiglas restrainers. Another limitation we experienced was the capacity for KOPr agonists (especially THP Sal A) to fully dissolve in the vehicle (PBS, PG, DMSO) at doses higher than $2 \mathrm{mg} / \mathrm{kg}$. This limited our ability to test for behavioural effects at higher doses.

\subsection{Future Direction}

Mesyl Sal B displayed weak analgesic effects at $2 \mathrm{mg} / \mathrm{kg}$ without causing sedation or hypothermia. Further studies with larger doses would help determine the effective dose at which this compound is capable of producing maximum analgesic effects without sideeffects. In contrast, THP Sal A, attenuated nociceptive and inflammatory pain at $1 \mathrm{mg} / \mathrm{kg}$. However, sedative effects were also seen. Further dose-response tests with Mesyl Sal B and THP Sal A would allow for better evaluation of therapeutic potential in treating pain.

In order to understand the cellular mechanisms of action of each KOPr agonist, investigations into KOPr signalling pathways are needed. The recruitment of proteins, such as beta-arrestin-2, have been implicated in the production of dysphoric effects of $\mathrm{KOPr}$ agonists. Pain behavioural tests followed by mass spectrometry studies to locate target proteins regulated by THP Sal A and Mesyl Sal B may help in the detection proteins that would permit or inhibit functionally selective mechanisms of analgesia. The assessment of further C-2 substituted Sal A analogues in vivo with combined proteomic studies may help in the determination of specific pathways of analgesia, while also adding to the database of KOPr agonists with therapeutic potential in treating pain. 
ICI 204,448 has been used as a positive control by studies testing the peripherally restricted effects of KOPr agonists. Although sedation is still a rather elusive process, it is widely recognised to be mediated by CNS functions. The sedative effect of ICI 204,448 suggests peripheral mechanisms involved in the modulation of motor coordination, such as those in the vestibular apparatus of the ear. Conversely, ICl 204,448 was also found to activate KOPr in the cerebellum of guinea pigs, suggesting centrally penetrative effects. Without further studies in determining the cause of $\mathrm{ICl} 204,448$ induced sedation, it may be necessary to use intrathecal or intracerebroventricular antagonist (NorBNI) challenge to claim peripherally restricted mechanisms of action.

Recently, TOLL-like receptors (TLR) have been gaining popularity in the modulation of pain transmission (Lan et al., 2010; Nicotra et al., 2012) and itch (Liu et al., 2012) via immune pathways. Almost all identified TLR subtypes have been found to be expressed on neutrophils and shown to be involved in mediating chemotaxis (Hayashi et al., 2003). In vitro, in vivo and in silico techniques exploring opioid influence on TLR-4 signalling have suggested TLR-4 signalling activation can occur from MOPr agonists such as morphine (Hutchinson et al., 2010). Blocking TLR signalling pathways was found to potentiate morphine analgesia, suggesting interaction between the opiate system and TLR in the modulation of pain behaviour. As far as we know, there have been no studies done on KOPr interaction with TLR. It is possible that the peripheral antinociceptive mechanisms of KOPr are mediated via TLR pathways. ICI 204,448, having antipruritic (Inan et al., 2004) and antiinflammatory potential, may be a good compound to test this interaction by coadministration with TLR antagonists.

KOPr have been shown to interact with other opiate and non-opiate receptors, giving rise to a variety of physiological and behavioural effects. TRP channels have been implicated in the transmission of noxious heat and chemical stimuli, such as those used in the tail-flick and intradermal formalin model. Local administration of KOPr agonists, such as U-50,488, have been documented to attenuate pain caused by the TRPV-1 agonist, capsaicin (Ko et al., 2000). Capsaicin induces nociceptive processes by activating C-fibers and stimulating release of substance P and CGRP from peripheral nociceptors (Holzer 1991; Winter et al. 1995; Caterina et al., 1997; Kilo et al. 1997). Substance $P$ plays an important role in the transmission of nociceptive signals (McCarson et al., 1999). KOPr stimulation can reduce 
nociceptor excitability (Russell et al. 1987; Haley et al. 1990; Andreev et al. 1994) and release of substance $P$ from peripheral nociceptors (Yonehara et al. 1992). Studies investigating substance $\mathrm{P}$ receptor (NK-1) internalisation in the dorsal horn due to Sal $\mathrm{A}$ and ICI 204,448, in the Kivell lab (Unpublished results, 2013), did not notice any effects; however tests with substance $P$ release from peripheral nociceptors were not carried out. Icilin, a TRPA-1 agonist (Rawls et al., 2007), can induce a "wet-dog" shaking behaviour in rodents an effect found to be attenuated by KOPr agonists such as $\mathrm{U}-50,488$ and Nalfurafine (Werkheiser et al., 2007). This suggests a relationship between KOPr and TRP channels exists in the regulation of animal behaviours including pain. Studies using confocal microscopy to analyse neuronal cells expressing GFP-tagged KOPr and TRPV-1 or TRPA-1 channels after KOPr agonist administration may help elucidate the relationship between these receptor and ion channel systems. In vivo tests with systemic coadministration of KOPr agonists with TRPV-1 antagonists, such as capsaizocin, or TRPA-1 antagonists, such as A 967079, may also help determine the level of overall interaction of these receptors and ion channels in behavioural models of pain.

\section{Conclusion}

KOPr agonists show potential in attenuating acute nociceptive and inflammatory pain. Modification of the C-2 terminal of the central phenyl ring of Sal A alters its analgesic potential in vivo, giving rise to a different onset and duration of action. Substitution with a tetrahydropyran group greatly improves central analgesic effects; however, sedative effects were also observed. Substitution at the C-2 position with a mesylate group showed no sedative effects but reduced central and peripheral analgesic effects. The lack of sedation by Mesyl Sal B makes it a good target for future research in pain. Development of more soluble KOPr agonists may permit further dose-testing for better evaluation of therapeutic potential. This potential may be exploited with the discovery of compounds that have limited entry into the CNS, such as ICl 204,448 and CR-845; or by identifying compounds that exclusively target pathways giving rise to analgesic effects. 


\section{References}

Abbadie, C., Brown, J. L., Mantyh, P. W., \& Basbaum, A. I. (1996). Spinal cord substance P receptor immunoreactivity increases in both inflammatory and nerve injury models of persistent pain. Neuroscience, 70(1), 201-209. doi: 10.1016/0306-4522(95)00343-H

Abbott, F. V., Melzack, R., \& Leber, B. F. (1982). Morphine analgesia and tolerance in the tail-flick and formalin tests: Dose-response relationships. Pharmacology Biochemistry and Behavior, 17(6), 1213-1219. doi: http://dx.doi.org/10.1016/0091-3057(82)90123-X

Alexeeva, E. V., Nazarova, G. A., \& Sudakov, S. K. (2012). Effects of peripheral mu, delta, and Kappaopioid receptor agonists on the levels of anxiety and motor activity of rats. Bulletin of Experimental Biology and Medicine, 153(5), 720-721.

Almeida, T. F., Roizenblatt, S., \& Tufik, S. (2004). Afferent pain pathways: a neuroanatomical review. Brain Research, 1000(1-2), 40-56. doi: http://dx.doi.org/10.1016/i.brainres.2003.10.073

Aloisi, A. M. (2003). Gonadal hormones and sex differences in pain reactivity. Clinical Journal of Pain, 19(3), 168-174.

Andrew, D., \& Greenspan, J. D. (1999). Mechanical and heat sensitization of cutaneous nociceptors after peripheral inflammation in the rat. Journal of Neurophysiology, 82(5), 2649-2656.

Ansonoff, M. A., Zhang, J., Czyzyk, T., Rothman, R. B., Stewart, J., Xu, H., . . Pintar, J. E. (2006). Antinociceptive and Hypothermic Effects of Salvinorin A Are Abolished in a Novel Strain of KOpioid Receptor-1 Knockout Mice. Journal of Pharmacology and Experimental Therapeutics, 318(2), 641-648. doi: 10.1124/jpet.106.101998

Arendt-Nielsen, L., Olesen, A. E., Staahl, C., Menzaghi, F., Kell, S., Wong, G. Y., \& Drewes, A. M. (2009). Analgesic efficacy of peripheral kappa-opioid receptor agonist CR665 compared to oxycodone in a multi-modal, multi-tissue experimental human pain model: selective effect on visceral pain. Anesthesiology, 111(3), 616-624. doi: 10.1097/ALN.0b013e3181af6356

Aviello, G., Borrelli, F., Guida, F., Romano, B., Lewellyn, K., Chiaro, M. D., . . Capasso, R. (2011). Ultrapotent effects of salvinorin A, a hallucinogenic compound from Salvia divinorum, on LPS-stimulated murine macrophages and its anti-inflammatory action in vivo. Journal of Molecular Medicine, 89(9), 891-902. doi: 10.1007/s00109-011-0752-4 
Baamonde, A., Hidalgo, A., \& Menéndez, L. (2011). Involvement of glutamate NMDA and AMPA receptors, glial cells and IL-1 $\beta$ in the spinal hyperalgesia evoked by the chemokine CCL2 in mice. Neuroscience Letters, 502(3), 178-181. doi: http://dx.doi.org/10.1016/j.neulet.2011.07.038

Bagnol, D., Mansour, A., Akil, H., \& Watson, S. J. (1997). Cellular localization and distribution of the cloned mu and kappa opioid receptors in rat gastrointestinal tract. Neuroscience, 81(2), 579591.

Barber, A., Bartoszyk, G. D., Bender, H. M., Gottschlich, R., Greiner, H. E., Harting, J., ... et al. (1994). A pharmacological profile of the novel, peripherally-selective kappa-opioid receptor agonist, EMD 61753. British Journal of Pharmacology, 113(4), 1317-1327.

Barber, A., Bartoszyk, G. d., Bender, H. m., Gottschlich, R., Greiner, H. e., Harting, J., . . Seyfried, C. a. (1994). A pharmacological profile of the novel, peripherally-selective k-opioid receptor agonist, EMD 61753. British Journal of Pharmacology, 113(4), 1317-1327. doi: 10.1111/j.1476-5381.1994.tb17142.x

Barber, A., \& Gottschlich, R. (1997). Novel developments with selective, non-peptidic kappa-opioid receptor agonists. Expert Opinion on Investigational Drugs, 6(10), 1351-1368. doi: 10.1517/13543784.6.10.1351

Basbaum, A. I., Bautista, D. M., Scherrer, G., \& Julius, D. (2009). Cellular and molecular mechanisms of pain. Cell, 139(2), 267-284. doi: 10.1016/j.cell.2009.09.028

Basbaum, A. I., \& Fields, H. L. (1984). Endogenous pain control systems: brainstem spinal pathways and endorphin circuitry. Annual Review of Neuroscience, 7, 309-338. doi: 10.1146/annurev.ne.07.030184.001521

Baumeister, A. A., Hawkins, M. F., Anticich, T. G., Moore, L. L., \& Higgins, T. D. (1987). Bilateral intranigral microinjection of morphine and opioid peptides produces antinociception in rats. Brain Research, 411(1), 183-186. doi: http://dx.doi.org/10.1016/0006-8993(87)90698-6

Belfer, I. (2013). Nature and nurture of human pain. Scientifica (Cairo), 2013, 415279. doi: $10.1155 / 2013 / 415279$

Benarroch, E. E. (2012). Endogenous opioid systems: current concepts and clinical correlations. Neurology, 79(8), 807-814. doi: 10.1212/WNL.0b013e3182662098

Bhargava, H. N., Ramarao, P., \& Gulati, A. (1989). Effects of morphine in rats treated chronically with U-50,488 H, a к opioid receptor agonist. European Journal of Pharmacology, 162(2), 257-264. doi: http://dx.doi.org/10.1016/0014-2999(89)90288-4 
Bierman, A. (2011). Pain and depression in late life: mastery as mediator and moderator. Journals of Gerontology. Series B: Psychological Sciences and Social Sciences, 66(5), 595-604. doi: 10.1093/geronb/gbr070

Binder, W., Machelska, H., Mousa, S., Schmitt, T., Rivière, P. J. M., Junien, J.-L., . . Schäfer, M. (2001). Analgesic and Antiinflammatory Effects of Two Novel k-Opioid Peptides. Anesthesiology, 94(6), 1034-1044.

Binning, A. R., Przesmycki, K., Sowinski, P., Morrison, L. M., Smith, T. W., Marcus, P., ... Dahan, A. (2011). A randomised controlled trial on the efficacy and side-effect profile (nausea/vomiting/sedation) of morphine-6-glucuronide versus morphine for post-operative pain relief after major abdominal surgery. European Journal of Pain (London, England), 15(4), 402-408. doi: 10.1016/j.ejpain.2010.09.007

Birnbaum, H. G., White, A. G., Schiller, M., Waldman, T., Cleveland, J. M., \& Roland, C. L. (2011). Societal costs of prescription opioid abuse, dependence, and misuse in the United States. Pain Medicine, 12(4), 657-667. doi: 10.1111/j.1526-4637.2011.01075.x

Bjorkman, R. (1995). Central antinociceptive effects of non-steroidal anti-inflammatory drugs and paracetamol. Experimental studies in the rat. Acta Anaesthesiologica Scandinavica. Supplementum, 103, 1-44.

Blanch, B., Pearson, S., \& Haber, P. S. (2014). An overview of the patterns of prescription opioid use, costs and related harms in Australia. British Journal of Clinical Pharmacology. doi: 10.1111/bcp.12446

Bonnot, A., Whelan, P. J., Mentis, G. Z., \& O'Donovan, M. J. (2002). Spatiotemporal pattern of motoneuron activation in the rostral lumbar and the sacral segments during locomotor-like activity in the neonatal mouse spinal cord. Journal of Neuroscience, 22(3), RC203.

Brownstein, M. J. (1993). A brief history of opiates, opioid peptides, and opioid receptors. Proceedings of the National Academy of Sciences of the United States of America, 90(12), 5391-5393.

Bruchas, M. R., Land, B. B., \& Chavkin, C. (2010). The dynorphin/kappa opioid system as a modulator of stress-induced and pro-addictive behaviors. Brain Research, 1314, 44-55. doi: 10.1016/j.brainres.2009.08.062

Butelman, E., Harris, T., \& Kreek, M. (2004). The plant-derived hallucinogen, salvinorin A, produces Kopioid agonist-like discriminative effects in rhesus monkeys. Psychopharmacology, 172(2), 220-224. doi: 10.1007/s00213-003-1638-0 
Cabot, P. J., Carter, L., Gaiddon, C., Zhang, Q., Schafer, M., Loeffler, J. P., \& Stein, C. (1997). Immune cell-derived beta-endorphin. Production, release, and control of inflammatory pain in rats. Journal of Clinical Investigation, 100(1), 142-148. doi: 10.1172/JCI119506

Cabot, P. J., Carter, L., Schafer, M., \& Stein, C. (2001). Methionine-enkephalin-and Dynorphin Arelease from immune cells and control of inflammatory pain. Pain, 93(3), 207-212.

Caram-Salas, N. L., Reyes-García, G., Bartoszyk, G. D., Araiza-Saldaña, C. I., Ambriz-Tututi, M., RochaGonzález, H. I., ... Granados-Soto, V. (2007). Subcutaneous, intrathecal and periaqueductal grey administration of asimadoline and $\mathrm{ICI}-204448$ reduces tactile allodynia in the rat. European Journal of Pharmacology, 573(1-3), 75-83. doi: http://dx.doi.org/10.1016/i.ejphar.2007.06.034

Carlezon, W. A., Jr., Beguin, C., DiNieri, J. A., Baumann, M. H., Richards, M. R., Todtenkopf, M. S., . . Cohen, B. M. (2006). Depressive-like effects of the kappa-opioid receptor agonist salvinorin A on behavior and neurochemistry in rats. Journal of Pharmacology and Experimental Therapeutics, 316(1), 440-447. doi: 10.1124/jpet.105.092304

Cartmell, S. M., Gelgor, L., \& Mitchell, D. (1991). A revised rotarod procedure for measuring the effect of antinociceptive drugs on motor function in the rat. Journal of Pharmacological Methods, 26(2), 149-159. doi: http://dx.doi.org/10.1016/0160-5402(91)90063-B

Casey, K. L., Minoshima, S., Morrow, T. J., \& Koeppe, R. A. (1996). Comparison of human cerebral activation pattern during cutaneous warmth, heat pain, and deep cold pain (Vol. 76).

Caudle, R. M., Chavkin, C., \& Dubner, R. (1994). Kappa 2 opioid receptors inhibit NMDA receptormediated synaptic currents in guinea pig CA3 pyramidal cells. Journal of Neuroscience, 14(9), 5580-5589.

Cavicchini, E., Candeletti, S., \& Ferri, S. (1988). Effects of dynorphins on body temperature of rats. Pharmacological Research Communications, 20(7), 603-604.

Cervero, F., Iggo, A., \& Ogawa, H. (1976). Nociceptor-driven dorsal horn neurones in the lumbar spinal cord of the cat. Pain, 2(1), 5-24. doi: http://dx.doi.org/10.1016/0304-3959(76)90042-7

Chakravarthy, B., Shah, S., \& Lotfipour, S. (2012). Prescription drug monitoring programs and other interventions to combat prescription opioid abuse. Western Journal of Emergency Medicine, 13(5), 422-425. doi: 10.5811/westjem.2012.7.12936

Chang, H. M., Berde, C. B., Holz, G. G. t., Steward, G. F., \& Kream, R. M. (1989). Sufentanil, morphine, met-enkephalin, and kappa-agonist $(\mathrm{U}-50,488 \mathrm{H})$ inhibit substance $\mathrm{P}$ release from primary sensory neurons: a model for presynaptic spinal opioid actions. Anesthesiology, 70(4), 672677. 
Chaplan, S. R., Malmberg, A. B., \& Yaksh, T. L. (1997). Efficacy of spinal NMDA receptor antagonism in formalin hyperalgesia and nerve injury evoked allodynia in the rat. Journal of Pharmacology and Experimental Therapeutics, 280(2), 829-838.

Chavkin, C., Sud, S., Jin, W., Stewart, J., Zjawiony, J. K., Siebert, D. J., . . Roth, B. L. (2004). Salvinorin A, an Active Component of the Hallucinogenic Sage Salvia divinorum Is a Highly Efficacious KOpioid Receptor Agonist: Structural and Functional Considerations. Journal of Pharmacology and Experimental Therapeutics, 308(3), 1197-1203. doi: 10.1124/jpet.103.059394

Cheung, K. M. (2010). The relationship between disc degeneration, low back pain, and human pain genetics. Spine J, 10(11), 958-960. doi: 10.1016/j.spinee.2010.09.011

Choiniere, M., Dion, D., Peng, P., Banner, R., Barton, P. M., Boulanger, A., ... Ware, M. (2010). The Canadian STOP-PAIN project - Part 1: Who are the patients on the waitlists of multidisciplinary pain treatment facilities? Canadian Journal of Anaesthesia, 57(6), 539-548. doi: 10.1007/s12630-010-9305-5

Chuang, L. F., Chuang, T. K., Killam, K. F., Jr., Qiu, Q., Wang, X. R., Lin, J. J., . . et al. (1995). Expression of kappa opioid receptors in human and monkey lymphocytes. Biochemical and Biophysical Research Communications, 209(3), 1003-1010.

Chuang, T. K., Killam, K. F., Jr., Chuang, L. F., Kung, H. F., Sheng, W. S., Chao, C. C., . . Chuang, R. Y. (1995). Mu opioid receptor gene expression in immune cells. Biochemical and Biophysical Research Communications, 216(3), 922-930. doi: 10.1006/bbrc.1995.2709

Committee on Recognition and Alleviation of Pain in Laboratory Animals, N. R. C. (2009). Washington (DC).

Contet, C., Kieffer, B. L., \& Befort, K. (2004). Mu opioid receptor: a gateway to drug addiction. Current Opinion in Neurobiology, 14(3), 370-378. doi: 10.1016/j.conb.2004.05.005

Cousins, M. J. (2012). Unrelieved pain: a major health care priority. Medical Journal of Australia, 196(6), 373-374.

Cox, B., Ary, M., Chesarek, W., \& Lomax, P. (1976). Morphine hyperthermia in the rat: An action of the central thermostats. European Journal of Pharmacology, 36(1), 33-39. doi: http://dx.doi.org/10.1016/0014-2999(76)90253-3

Cunha, T. M., Souza, G. R., Domingues, A. C., Carreira, E. U., Lotufo, C. M., Funez, M. I., . . Ferreira, S. H. (2012). Stimulation of peripheral kappa opioid receptors inhibits inflammatory hyperalgesia via activation of the PI3Kgamma/AKT/nNOS/NO signaling pathway. Mol Pain, 8, 10. doi: $10.1186 / 1744-8069-8-10$ 
de Lange, E. M., \& Danhof, M. (2002). Considerations in the Use of Cerebrospinal Fluid Pharmacokinetics to Predict Brain Target Concentrations in the Clinical Setting. Clinical Pharmacokinetics, 41(10), 691-703. doi: 10.2165/00003088-200241100-00001

Deering, D., Sellman, J. D., \& Adamson, S. (2014). Opioid substitution treatment in New Zealand: a 40 year perspective. New Zealand Medical Journal, 127(1397), 57-66.

Devlin, J. W., Boleski, G., Mlynarek, M., Nerenz, D. R., Peterson, E., Jankowski, M., . . Zarowitz, B. J. (1999). Motor Activity Assessment Scale: a valid and reliable sedation scale for use with mechanically ventilated patients in an adult surgical intensive care unit. Critical Care Medicine, 27(7), 1271-1275.

Di Chiara, G., Porceddu, M. L., Vargiu, L., Argiolas, A., \& Gessa, G. L. (1976). Evidence for dopamine receptors mediating sedation in the mouse brain. Nature, 264(5586), 564-567. doi: $10.1038 / 264564 \mathrm{a} 0$

Dickenson, A. H., \& Sullivan, A. F. (1987). Peripheral origins and central modulation of subcutaneous formalin-induced activity of rat dorsal horn neurones. Neuroscience Letters, 83(1-2), 207211.

Dubuisson, D., \& Dennis, S. G. (1977a). The formalin test: a quantitative study of the analgesic effects of morphine, meperidine, and brain stem stimulation in rats and cats. Pain, 4(2), 161-174.

Dubuisson, D., \& Dennis, S. G. (1977b). The formalin test: a quantitative study of the analgesic effects of morphine, meperidine, and brain stem stimulation in rats and cats. Pain, 4(2), 161 174.

El-Guebaly, N. (2014). A canadian perspective on addiction treatment. Substance Abuse, 35(3), 298303. doi: $10.1080 / 08897077.2014 .923362$

Eliav, E., Herzberg, U., \& Caudle, R. M. (1999). The kappa opioid agonist GR89 696 blocks hyperalgesia and allodynia in rat models of peripheral neuritis and neuropathy. Pain, 79(23), 255-264. doi: http://dx.doi.org/10.1016/S0304-3959(98)00177-8

Fantegrossi, W. E., Kugle, K. M., Valdes, L. J. I., Koreeda, M., \& Woods, J. H. (2005). Kappa-opioid receptor-mediated effects of the plant-derived hallucinogen, salvinorin $A$, on inverted screen performance in the mouse. Behavioural Pharmacology, 16(8), 627-633.

Fichna, J., Schicho, R., Janecka, A., Zjawiony, J. K., \& Storr, M. (2009). Selective natural kappa opioid and cannabinoid receptor agonists with a potential role in the treatment of gastrointestinal dysfunction. Drug News Perspect, 22(7), 383-392. doi: 10.1358/dnp.2009.22.7.1400219

Finnerup, N. B., \& Jensen, T. S. (2006). Mechanisms of Disease: mechanism-based classification of neuropathic pain[mdash]a critical analysis. Nat Clin Pract Neuro, 2(2), 107-115. 
Fishman, S. M. (2007). Recognizing pain management as a human right: a first step. Anesthesia \& Analgesia, 105(1), 8-9. doi: 10.1213/01.ane.0000267526.37663.41

Florez, J., McCarthy, L. E., \& Borison, H. L. (1968). A comparative study in the cat of the respiratory effects of morphine injected intravenously and into the cerebrospinal fluid. Journal of Pharmacology and Experimental Therapeutics, 163(2), 448-455.

Freye, E., Hartung, E., \& Schenk, G. K. (1983). Bremazocine: An Opiate That Induces Sedation and Analgesia without Respiratory Depression. Anesthesia \& Analgesia, 62(5), 483-488.

Gaskin, D. J., \& Richard, P. (2012). The Economic Costs of Pain in the United States. The Journal of Pain, 13(8), 715-724. doi: 10.1016/j.jpain.2012.03.009

Geffeney, S. L., \& Goodman, M. B. (2012). How we feel: ion channel partnerships that detect mechanical inputs and give rise to touch and pain perception. Neuron, 74(4), 609-619. doi: 10.1016/j.neuron.2012.04.023

Georgopoulos, A. P. (1976). Functional properties of primary afferent units probably related to pain mechanisms in primate glabrous skin. Journal of Neurophysiology, 39(1), 71-83.

Giroud, C., Felber, F., Augsburger, M., Horisberger, B., Rivier, L., \& Mangin, P. (2000). Salvia divinorum: an hallucinogenic mint which might become a new recreational drug in Switzerland. Forensic Science International, 112(2-3), 143-150.

Gold, M. S., \& Gebhart, G. F. (2010). Nociceptor sensitization in pain pathogenesis. Nature Medicine, 16(11), 1248-1257. doi: 10.1038/nm.2235

Goldberg, D., \& McGee, S. (2011). Pain as a global public health priority. BMC Public Health, 11(1), 770.

Gouardères, C., Cros, J., \& Quirion, R. (1985). Autoradiographic localization of mu, delta and kappa opioid receptor binding sites in rat and guinea pig spinal cord. Neuropeptides, 6(4), 331-342. doi: http://dx.doi.org/10.1016/0143-4179(85)90006-X

Grilli, M., Neri, E., Zappettini, S., Massa, F., Bisio, A., Romussi, G., . . Pittaluga, A. (2009). Salvinorin A exerts opposite presynaptic controls on neurotransmitter exocytosis from mouse brain nerve terminals. Neuropharmacology, 57(5-6), 523-530. doi:

10.1016/j.neuropharm.2009.07.023

Guida, F., Luongo, L., Aviello, G., Palazzo, E., Chiaro, M. D., Gatta, L., . . Maione, S. (2012). Salvinorin A reduces mechanical allodynia and spinal neuronal hyperexcitability induced by peripheral formalin injection. Molecular Pain, 8(1). doi: 10.1186/1744-8069-8-60

Gutstein, H. B., Mansour, A., Watson, S. J., Akil, H., \& Fields, H. L. (1998). Mu and kappa opioid receptors in periaqueductal gray and rostral ventromedial medulla. Neuroreport, 9(8), 17771781. 
Han, S. P., \& Xie, G. X. (1987). [Involvement of dynorphin in the antinociception induced by intrathecal injection of neurotensin in the rat]. Sheng Li Xue Bao, 39(1), 19-25.

Handler, C. M., Geller, E. B., \& Adler, M. W. (1992). Effect of $\mu-$, K-, and $\delta$-selective opioid agonists on thermoregulation in the rat. Pharmacology Biochemistry and Behavior, 43(4), 1209-1216. doi: http://dx.doi.org/10.1016/0091-3057(92)90504-9

Hartmann, B., Ahmadi, S., Heppenstall, P. A., Lewin, G. R., Schott, C., Borchardt, T., . . Kuner, R. (2004). The AMPA Receptor Subunits GluR-A and GluR-B Reciprocally Modulate Spinal Synaptic Plasticity and Inflammatory Pain. Neuron, 44(4), 637-650. doi: http://dx.doi.org/10.1016/i.neuron.2004.10.029

Hassan, A. H. S., Pzewłocki, R., Herz, A., \& Stein, C. (1992). Dynorphin, a preferential ligand for Kopioid receptors, is present in nerve fibers and immune cells within inflamed tissue of the rat. Neuroscience Letters, 140(1), 85-88. doi: http://dx.doi.org/10.1016/03043940(92)90688-4

Hassen, A. H., Feuerstein, G., \& Faden, A. I. (1984). Kappa opioid receptors modulate cardiorespiratory function in hindbrain nuclei of rat. Journal of Neuroscience, 4(9), 22132221.

Hayashi, F., Means, T. K., \& Luster, A. D. (2003). Toll-like receptors stimulate human neutrophil function (Vol. 102).

Hayes, A. G., Skingle, M., \& Tyers, M. B. (1983). Antinociceptive profile of dynorphin in the rat. Life Sciences, 33, Supplement 1(0), 657-660. doi: http://dx.doi.org/10.1016/00243205(83)90588-X

Hayes, A. G., Skingle, M., \& Tyers, M. B. (1985). Effect of $\beta$-funaltrexamine on opioid side-effects produced by morphine and U-50, 488H. Journal of Pharmacy and Pharmacology, 37(11), 841-843. doi: 10.1111/j.2042-7158.1985.tb04985.x

Ho, J., Mannes, A. J., Dubner, R., \& Caudle, R. M. (1997). Putative kappa-2 opioid agonists are antihyperalgesic in a rat model of inflammation. Journal of Pharmacology and Experimental Therapeutics, 281(1), 136-141.

Hong, Y., \& Abbott, F. V. (1995). Peripheral opioid modulation of pain and inflammation in the formalin test. European Journal of Pharmacology, 277(1), 21-28.

Horan, P., Taylor, J., Yamamura, H. I., \& Porreca, F. (1992). Extremely long-lasting antagonistic actions of nor-binaltorphimine (nor-BNI) in the mouse tail-flick test. Journal of Pharmacology and Experimental Therapeutics, 260(3), 1237-1243. 
Hunskaar, S., Berge, O.-G., \& Hole, K. (1986). A modified hot-plate test sensitivie to mild analgesics. Behavioural Brain Research, 21(2), 101-108. doi: http://dx.doi.org/10.1016/0166$\underline{4328(86) 90088-4}$

Hunskaar, S., \& Hole, K. (1987). The formalin test in mice: dissociation between inflammatory and non-inflammatory pain. Pain, 30(1), 103-114. doi: http://dx.doi.org/10.1016/03043959(87)90088-1

Hutchinson, M. R., Zhang, Y., Shridhar, M., Evans, J. H., Buchanan, M. M., Zhao, T. X., . . Watkins, L. R. (2010). Evidence that opioids may have toll-like receptor 4 and MD-2 effects. Brain, Behavior, and Immunity, 24(1), 83-95. doi: http://dx.doi.org/10.1016/i.bbi.2009.08.004 Huxtable, C. A., Roberts, L. J., Somogyi, A. A., \& MacIntyre, P. E. (2011). Acute pain management in opioid-tolerant patients: a growing challenge. Anaesthesia and Intensive Care, 39(5), 804823.

Idänpään-Heikkilä, J. J., Kalso, E. A., \& Seppälä, T. (1994). Antinociceptive actions of dexmedetomidine and the kappa-opioid agonist U-50,488H against noxious thermal, mechanical and inflammatory stimuli. Journal of Pharmacology and Experimental Therapeutics, 271(3), 1306-1313.

Imanshahidi, M., \& Hosseinzadeh, H. (2006). The pharmacological effects of Salvia species on the central nervous system. Phytotherapy Research, 20(6), 427-437. doi: 10.1002/ptr.1898

Inan, S., \& Cowan, A. (2004). Kappa opioid agonists suppress chloroquine-induced scratching in mice. European Journal of Pharmacology, 502(3), 233-237. doi: http://dx.doi.org/10.1016/j.ejphar.2004.09.010

Jerome, S. N., Akimitsu, T., \& Korthuis, R. J. (1994). Leukocyte adhesion, edema, and development of postischemic capillary no-reflow (Vol. 267).

Ji, R., Zhang, Q., Law, P., Low, H., Elde, R., \& Hokfelt, T. (1995). Expression of mu-, delta-, and kappaopioid receptor-like immunoreactivities in rat dorsal root ganglia after carrageenan-induced inflammation. The Journal of Neuroscience, 15(12), 8156-8166.

Jongkamonwiwat, N., Phansuwan-Pujito, P., Casalotti, S. O., Forge, A., Dodson, H., \& Govitrapong, P. (2006). The existence of opioid receptors in the cochlea of guinea pigs. European Journal of Neuroscience, 23(10), 2701-2711. doi: 10.1111/j.1460-9568.2006.04810.x

Jordan, B. A., \& Devi, L. A. (1999). G-protein-coupled receptor heterodimerization modulates receptor function. Nature, 399(6737), 697-700. doi: 10.1038/21441

Kalso, E., Smith, L., McQuay, H. J., \& Andrew Moore, R. (2002). No pain, no gain: clinical excellence and scientific rigour--lessons learned from IA morphine. Pain, 98(3), 269-275. 
Karjalainen, U., Paananen, M., Okuloff, A., Taimela, S., Auvinen, J., Mannikko, M., \& Karppinen, J. (2013). Role of environmental factors and history of low back pain in sciatica symptoms among Finnish adolescents. Spine (Phila Pa 1976), 38(13), 1105-1111. doi: 10.1097/BRS.0b013e318287fb3a

Kataoka, H., Kono, H., Patel, Z., \& Rock, K. L. (2014). Evaluation of the Contribution of Multiple DAMPs and DAMP Receptors in Cell Death-Induced Sterile Inflammatory Responses. PloS One, 9(8), e104741. doi: 10.1371/journal.pone.0104741

Kivell, B., \& Prisinzano, T. E. (2010). Kappa opioids and the modulation of pain. Psychopharmacology, 210(2), 109-119. doi: 10.1007/s00213-010-1819-6

Ko, M. C. H., Tuchman, J. E., Johnson, M. D., Wiesenauer, K., Woods, J. H., \& Woods, J. H. (2000). Local administration of mu or kappa opioid agonists attenuates capsaicin-induced thermal hyperalgesia via peripheral opioid receptors in rats. Psychopharmacology, 148(2), 180-185. doi: $10.1007 / \mathrm{s} 002130050040$

Kobayashi, K., Fukuoka, T., Obata, K., Yamanaka, H., Dai, Y., Tokunaga, A., \& Noguchi, K. (2005). Distinct expression of TRPM8, TRPA1, and TRPV1 mRNAs in rat primary afferent neurons

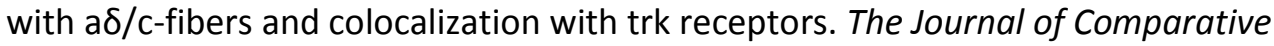
Neurology, 493(4), 596-606. doi: 10.1002/cne.20794

Kumagai, H., Ebata, T., Takamori, K., Muramatsu, T., Nakamoto, H., \& Suzuki, H. (2010). Effect of a novel kappa-receptor agonist, nalfurafine hydrochloride, on severe itch in 337 haemodialysis patients: a Phase III, randomized, double-blind, placebo-controlled study. Nephrology, Dialysis and Transplantation, 25(4), 1251-1257. doi: 10.1093/ndt/gfp588

Kumar, V., Guo, D., Cassel, J. A., Daubert, J. D., DeHaven, R. N., DeHaven-Hudkins, D. L., . . Maycock, A. L. (2005). Synthesis and evaluation of novel peripherally restricted $\mathrm{K}$-opioid receptor agonists. Bioorganic \& Medicinal Chemistry Letters, 15(4), 1091-1095. doi: 10.1016/j.bmcl.2004.12.018

Labuz, D., Mousa, S. A., Schäfer, M., Stein, C., \& Machelska, H. (2007). Relative contribution of peripheral versus central opioid receptors to antinociception. Brain Research, 1160, 30-38. doi: 10.1016/j.brainres.2007.05.049

Lahti, R. A., VonVoigtlander, P. F., \& Barsuhn, C. (1982). Properties of a selective kappa agonist, U50,488H. Life Sciences, 31(20-21), 2257-2260.

Lamb, K., Tidgewell, K., Simpson, D. S., Bohn, L. M., \& Prisinzano, T. E. (2012). Antinociceptive effects of herkinorin, a MOP receptor agonist derived from salvinorin A in the formalin test in rats: New concepts in mu opioid receptor pharmacology: From a symposium on new concepts in 
mu-opioid pharmacology. Drug and Alcohol Dependence, 121(3), 181-188. doi:

http://dx.doi.org/10.1016/i.drugalcdep.2011.10.026

LaMotte, R. H., \& Campbell, J. N. (1978). Comparison of responses of warm and nociceptive C-fiber afferents in monkey with human judgments of thermal pain (Vol. 41).

Lan, L. S., Ping, Y. J., Na, W. L., Miao, J., Cheng, Q. Q., Ni, M. Z., . . Wei, L. (2010). Down-regulation of Toll-like receptor 4 gene expression by short interfering RNA attenuates bone cancer pain in a rat model. Mol Pain, 6, 2. doi: 10.1186/1744-8069-6-2

Lawson, S. N. (2002). Phenotype and function of somatic primary afferent nociceptive neurones with C-, Adelta- or Aalpha/beta-fibres. Experimental Physiology, 87(2), 239-244.

Le Bars, D., Gozariu, M., \& Cadden, S. W. (2001). Animal models of nociception. Pharmacological Reviews, 53(4), 597-652.

Leak, J., Menétrey, D., \& De Pommery, J. (1988). Neuropeptides in long ascending spinal tract cells in the rat: Evidence for parallel processing of ascending information. Neuroscience, 24(1), 195207. doi: http://dx.doi.org/10.1016/0306-4522(88)90323-5

Levine, J. D., \& Alessandri-Haber, N. (2007). TRP channels: Targets for the relief of pain. Biochimica et Biophysica Acta (BBA) - Molecular Basis of Disease, 1772(8), 989-1003. doi: http://dx.doi.org/10.1016/j.bbadis.2007.01.008

Ling, W., Mooney, L., \& Hillhouse, M. (2011). Prescription opioid abuse, pain and addiction: Clinical issues and implications. Drug and Alcohol Review, 30(3), 300-305. doi: 10.1111/j.14653362.2010.00271.x

Liu, T., Gao, Y.-J., \& Ji, R.-R. (2012). Emerging role of Toll-like receptors in the control of pain and itch. Neuroscience Bulletin, 28(2), 131-144. doi: 10.1007/s12264-012-1219-5

Lutfy, K., Cai, S. X., Woodward, R. M., \& Eckard, W. (1997). Antinociceptive effects of NMDA and nonNMDA receptor antagonists in the tail flick test in mice. Pain, 70(1), 31-40. doi: http://dx.doi.org/10.1016/S0304-3959(96)03290-3

Madadi, P., Sistonen, J., Silverman, G., Gladdy, R., Ross, C. J., Carleton, B. C., . . Koren, G. (2013). Life-threatening adverse events following therapeutic opioid administration in adults: is pharmacogenetic analysis useful? Pain Res Manag, 18(3), 133-136.

Maier, S. F. (2003). Bi-directional immune-brain communication: Implications for understanding stress, pain, and cognition. Brain, Behavior, and Immunity, 17(2), 69-85.

Malmberg, A. B., \& Yaksh, T. L. (1993). Spinal nitric oxide synthesis inhibition blocks NMDA-induced thermal hyperalgesia and produces antinociception in the formalin test in rats. Pain, 54(3), 291-300. doi: http://dx.doi.org/10.1016/0304-3959(93)90028-N 
Mansour, A., Fox, C. A., Burke, S., Meng, F., Thompson, R. C., Akil, H., \& Watson, S. J. (1994). Mu, delta, and kappa opioid receptor mRNA expression in the rat CNS: an in situ hybridization study. Journal of Comparative Neurology, 350(3), 412-438. doi: 10.1002/cne.903500307

Marchand, S. (2008). The physiology of pain mechanisms: from the periphery to the brain. Rheumatic Disease Clinics of North America, 34(2), 285-309.

Marlier, L., Poulat, P., Rajaofetra, N., \& Privat, A. (1991). Modifications of serotonin-, substance Pand calcitonin gene-related peptide-like immunoreactivities in the dorsal horn of the spinal cord of arthritic rats: a quantitative immunocytochemical study. Experimental brain research. Experimentelle Hirnforschung. Expérimentation cérébrale, 85(3), 482-490.

Martin, W. J., Tsou, K., \& Walker, J. M. (1998). Cannabinoid receptor-mediated inhibition of the rat tail-flick reflex after microinjection into the rostral ventromedial medulla. Neuroscience Letters, 242(1), 33-36.

Mason, P. (1999). Central mechanisms of pain modulation. Current Opinion in Neurobiology, 9(4), 436-441. doi: http://dx.doi.org/10.1016/S0959-4388(99)80065-8

Matsumura, Y., \& Ananthaswamy, H. N. (2004). Toxic effects of ultraviolet radiation on the skin. Toxicology and Applied Pharmacology, 195(3), 298-308. doi: http://dx.doi.org/10.1016/j.taap.2003.08.019

McCarson, K. E. (1999). Central and peripheral expression of neurokinin-1 and neurokinin-3 receptor and substance P-encoding messenger RNAs: peripheral regulation during formalin-induced inflammation and lack of neurokinin receptor expression in primary afferent sensory neurons. Neuroscience, 93(1), 361-370.

McCurdy, C. R., Sufka, K. J., Smith, G. H., Warnick, J. E., \& Nieto, M. J. (2006). Antinociceptive profile of salvinorin A, a structurally unique kappa opioid receptor agonist. Pharmacology Biochemistry and Behavior, 83(1), 109-113. doi: 10.1016/j.pbb.2005.12.011

McCurdy, C. R., Sufka, K. J., Smith, G. H., Warnick, J. E., \& Nieto, M. J. (2006). Antinociceptive profile of salvinorin A, a structurally unique kappa opioid receptor agonist. Pharmacology Biochemistry and Behavior, 83(1), 109-113. doi: 10.1016/j.pbb.2005.12.011

McNamara, C. R., Mandel-Brehm, J., Bautista, D. M., Siemens, J., Deranian, K. L., Zhao, M., . . Fanger, C. M. (2007). TRPA1 mediates formalin-induced pain. Proceedings of the National Academy of Sciences, 104(33), 13525-13530. doi: 10.1073/pnas.0705924104

Merskey, H., \& Bogduk, N. (1994). Classification of chronic pain, IASP Task Force on Taxonomy. IASP Press, Seattle.

Morton, S. M., \& Bastian, A. J. (2004). Cerebellar Control of Balance and Locomotion. The Neuroscientist, 10(3), 247-259. doi: 10.1177/1073858404263517 
Mousa, S. A., Zhang, Q., Sitte, N., Ji, R.-R., \& Stein, C. (2001). $\beta$-Endorphin-containing memory-cells and $\mu$-opioid receptors undergo transport to peripheral inflamed tissue. Journal of Neuroimmunology, 115(1-2), 71-78. doi: http://dx.doi.org/10.1016/S0165-5728(01)00271-5

Murray, C. W., Porreca, F., \& Cowan, A. (1988). Methodological refinements to the mouse paw formalin test: An animal model of tonic pain. Journal of Pharmacological Methods, 20(2), 175-186. doi: http://dx.doi.org/10.1016/0160-5402(88)90078-2

Nagasako, E. M., Oaklander, A. L., \& Dworkin, R. H. (2003). Congenital insensitivity to pain: an update. Pain, 101(3), 213-219. doi: 10.1016/S0304-3959(02)00482-7

Negus, S. S., Schrode, K., \& Stevenson, G. W. (2008). Mu/kappa opioid interactions in rhesus monkeys: Implications for analgesia and abuse liability. Experimental and Clinical Psychopharmacology, 16(5), 386-399. doi: 10.1037/a0013088

Nelson, L. E., Guo, T. Z., Lu, J., Saper, C. B., Franks, N. P., \& Maze, M. (2002). The sedative component of anesthesia is mediated by $\mathrm{GABA}(\mathrm{A})$ receptors in an endogenous sleep pathway. Nature Neuroscience, 5(10), 979-984. doi: 10.1038/nn913

Nemmani, K. V., \& Mogil, J. S. (2003). Serotonin-GABA interactions in the modulation of mu- and kappa-opioid analgesia. Neuropharmacology, 44(3), 304-310.

Nestby, P., Schoffelmeer, A. N., Homberg, J. R., Wardeh, G., De Vries, T. J., Mulder, A. H., \& Vanderschuren, L. J. (1999). Bremazocine reduces unrestricted free-choice ethanol selfadministration in rats without affecting sucrose preference. Psychopharmacology, 142(3), 309-317.

Nicotra, L., Loram, L. C., Watkins, L. R., \& Hutchinson, M. R. (2012). Toll-like receptors in chronic pain. Experimental Neurology, 234(2), 316-329. doi: http://dx.doi.org/10.1016/j.expneurol.2011.09.038

O'Sullivan, P. B., \& Beales, D. J. (2007). Diagnosis and classification of pelvic girdle pain disorders-Part 1: a mechanism based approach within a biopsychosocial framework. Manual Therapy, 12(2), 86-97. doi: 10.1016/j.math.2007.02.001

Oldendorf, W. H., Hyman, S., Braun, L., \& Oldendorf, S. Z. (1972). Blood-brain barrier: penetration of morphine, codeine, heroin, and methadone after carotid injection. Science, 178(4064), 984986.

Ossipov, M. H., Kovelowski, C. J., Wheeler-Aceto, H., Cowan, A., Hunter, J. C., Lai, J., . . Porreca, F. (1996). Opioid antagonists and antisera to endogenous opioids increase the nociceptive response to formalin: demonstration of an opioid kappa and delta inhibitory tone. Journal of Pharmacology and Experimental Therapeutics, 277(2), 784-788. 
Ottosson, A., \& Edvinsson, L. (1997). Release of histamine from dural mast cells by substance P and calcitonin gene-related peptide. Cephalalgia: an international journal of headache, 17(3), 166-174.

Pelissier, T., Paeile, C., Soto-Moyano, R., Saavedra, H., \& Hernández, A. (1990). Analgesia produced by intrathecal administration of the k opioid agonist, $\mathrm{U}-50,488 \mathrm{H}$, on formalin-evoked cutaneous pain in the rat. European Journal of Pharmacology, 190(3), 287-293. doi: http://dx.doi.org/10.1016/0014-2999(90)94192-Z

Pert, C. B., \& Snyder, S. H. (1973). Opiate receptor: demonstration in nervous tissue. Science, 179(4077), 1011-1014.

Petrie, E. C., Tiffany, S. T., Baker, T. B., \& Dahl, J. L. (1982). Dynorphin (1-13): Analgesia, hypothermia, cross-tolerance with morphine and $\beta$-endorphin. Peptides, 3(1), 41-47. doi: http://dx.doi.org/10.1016/0196-9781(82)90140-1

Piercey, M. F., Lahti, R. A., Schroeder, L. A., Einspahr, F. J., \& Barsuhn, C. (1982a). U-50488H, a pure kappa receptor agonist with spinal analgesic loci in the mouse. Life Sciences, 31(12-13), 1197-1200. doi: http://dx.doi.org/10.1016/0024-3205(82)90341-1

Piercey, M. F., Lahti, R. A., Schroeder, L. A., Einspahr, F. J., \& Barsuhn, C. (1982b). U-50488H, a pure kappa receptor agonist with spinal analgesic loci in the mouse. Life Sciences, 31(12-13), 1197-1200.

Ploghaus, A., Tracey, I., Gati, J. S., Clare, S., Menon, R. S., Matthews, P. M., \& Rawlins, J. N. (1999). Dissociating pain from its anticipation in the human brain. Science, 284(5422), 1979-1981.

Pogozheva, I., Przydzial, M., \& Mosberg, H. (2008). Homology Modeling of Opioid Receptor-Ligand Complexes Using Experimental Constraints. In R. Rapaka \& W. Sadée (Eds.), Drug Addiction (pp. 559-584): Springer New York.

Porreca, F., Mosberg, H. I., Hurst, R., Hruby, V. J., \& Burks, T. F. (1984). Roles of mu, delta and kappa opioid receptors in spinal and supraspinal mediation of gastrointestinal transit effects and hot-plate analgesia in the mouse. Journal of Pharmacology and Experimental Therapeutics, 230(2), 341-348.

Porreca, F., Mosberg, H. I., Hurst, R., Hruby, V. J., \& Burks, T. F. (1984). Roles of mu, delta and kappa opioid receptors in spinal and supraspinal mediation of gastrointestinal transit effects and hot-plate analgesia in the mouse. Journal of Pharmacology and Experimental Therapeutics, 230(2), 341-348.

Porreca, F., Ossipov, M. H., \& Gebhart, G. F. (2002). Chronic pain and medullary descending facilitation. Trends in Neurosciences, 25(6), 319-325. 
Price, T. J., Cervero, F., Gold, M. S., Hammond, D. L., \& Prescott, S. A. (2009). Chloride regulation in the pain pathway. Brain Research Reviews, 60(1), 149-170. doi: 10.1016/j.brainresrev.2008.12.015

Radbruch, L., Nauck, F., \& European Association for Palliative, C. (2002). [Morphine and alternative opioids in cancer pain: the EAPC recommendations]. Schmerz, 16(3), 186-193. doi: $10.1007 / s 004820100104$

Randic, M., Cheng, G., \& Kojic, L. (1995). kappa-opioid receptor agonists modulate excitatory transmission in substantia gelatinosa neurons of the rat spinal cord. Journal of Neuroscience, 15(10), 6809-6826.

Rau, K. K., Jiang, N., Johnson, R. D., \& Cooper, B. Y. (2007). Heat Sensitization in Skin and Muscle Nociceptors Expressing Distinct Combinations of TRPV1 and TRPV2 Protein (Vol. 97).

Rawls, S. M., Ding, Z., Gray, A. M., \& Cowan, A. (2005). Peripheral kappa-opioid agonist, ICI 204448, evokes hypothermia in cold-exposed rats. Pharmacology, 74(2), 79-83. doi: $10.1159 / 000083704$

Rawls, S. M., Gomez, T., Ding, Z., \& Raffa, R. B. (2007). Differential behavioral effect of the TRPM8/TRPA1 channel agonist icilin (AG-3-5). European Journal of Pharmacology, 575(1-3), 103-104. doi: http://dx.doi.org/10.1016/j.ejphar.2007.07.060

Rives, M.-L., Rossillo, M., Liu-Chen, L.-Y., \& Javitch, J. A. (2012). 6'-Guanidinonaltrindole (6'-GNTI) Is a G Protein-biased k-Opioid Receptor Agonist That Inhibits Arrestin Recruitment. Journal of Biological Chemistry, 287(32), 27050-27054. doi: 10.1074/jbc.C112.387332

Riviere, P. J. (2004). Peripheral kappa-opioid agonists for visceral pain. British Journal of Pharmacology, 141(8), 1331-1334. doi: 10.1038/sj.bjp.0705763

Rivière, P. J. M. (2004). Peripheral kappa-opioid agonists for visceral pain. British Journal of Pharmacology, 141(8), 1331-1334. doi: 10.1038/sj.bjp.0705763

Rogers, H., Birch, P. J., Harrison, S. M., Palmer, E., Manchee, G. R., Judd, D. B., . . Hayes, A. G. (1992). GR94839, a k-opioid agonist with limited access to the central nervous system, has antinociceptive activity. British Journal of Pharmacology, 106(4), 783-789. doi: 10.1111/j.1476-5381.1992.tb14413.x

Schafer, A. G., Hall, T. M., Rolke, R., Treede, R. D., Ludtke, K., Mallwitz, J., \& Briffa, K. N. (2014). Low back related leg pain: An investigation of construct validity of a new classification system. Journal of Back and Musculoskeletal Rehabilitation. doi: 10.3233/BMR-140461

Schaible, H. G., Jarrott, B., Hope, P. J., \& Duggan, A. W. (1990). Release of immunoreactive substance $P$ in the spinal cord during development of acute arthritis in the knee joint of the cat: a study 
with antibody microprobes. Brain Research, 529(1-2), 214-223. doi: 10.1016/00068993(90)90830-5

Schmelz, M., Schmidt, R., Weidner, C., Hilliges, M., Torebjörk, H. E., \& Handwerker, H. O. (2003). Chemical Response Pattern of Different Classes of C-Nociceptors to Pruritogens and Algogens (Vol. 89).

Scholz, J., \& Woolf, C. J. (2007). The neuropathic pain triad: neurons, immune cells and glia. Nature Neuroscience, 10(11), 1361-1368. doi: 10.1038/nn1992

Schug, S., Zech, D., \& Grond, S. (1992). Adverse Effects of Systemic Opioid Analgesics. Drug Safety, 7(3), 200-213. doi: 10.2165/00002018-199207030-00005

Sessler, C. N., Gosnell, M. S., Grap, M. J., Brophy, G. M., O'Neal, P. V., Keane, K. A., . . Elswick, R. K. (2002). The Richmond Agitation-Sedation Scale: validity and reliability in adult intensive care unit patients. American Journal of Respiratory and Critical Care Medicine, 166(10), 13381344. doi: $10.1164 / \mathrm{rccm} .2107138$

Shapiro, A., Zohar, E., Zaslansky, R., Hoppenstein, D., Shabat, S., \& Fredman, B. (2005). The frequency and timing of respiratory depression in 1524 postoperative patients treated with systemic or neuraxial morphine. Journal of Clinical Anesthesia, 17(7), 537-542. doi:

10.1016/j.jclinane.2005.01.006

Shavit, Y., Fridel, K., \& Beilin, B. (2006). Postoperative pain management and proinflammatory cytokines: animal and human studies. Journal of Neuroimmune Pharmacology, 1(4), 443451. doi: 10.1007/s11481-006-9043-1

Shaw, J. S., Carroll, J. A., Alcock, P., \& Main, B. G. (1989). ICI 204448: a KP-opioid agonist with limited access to the CNS. British Journal of Pharmacology, 96(4), 986-992. doi: 10.1111/j.14765381.1989.tb11911.x

Shibata, M., Ohkubo, T., Takahashi, H., \& Inoki, R. (1989). Modified formalin test: characteristic biphasic pain response. Pain, 38(3), 347-352. doi: 10.1016/0304-3959(89)90222-4

Shir, Y., \& Seltzer, Z. e. (1990). A-fibers mediate mechanical hyperesthesia and allodynia and C-fibers mediate thermal hyperalgesia in a new model of causalgiform pain disorders in rats. Neuroscience Letters, 115(1), 62-67. doi: http://dx.doi.org/10.1016/0304-3940(90)90518-E

Shook, J. E., Lemcke, P. K., Gehrig, C. A., Hruby, V. J., \& Burks, T. F. (1989). Antidiarrheal properties of supraspinal mu and delta and peripheral mu, delta and kappa opioid receptors: inhibition of diarrhea without constipation. Journal of Pharmacology and Experimental Therapeutics, 249(1), 83-90.

Simonin, F., Valverde, O., Smadja, C., Slowe, S., Kitchen, I., Dierich, A., . . Kieffer, B. L. (1998). Disruption of the kappa-opioid receptor gene in mice enhances sensitivity to chemical 
visceral pain, impairs pharmacological actions of the selective kappa-agonist $\mathrm{U}-50,488 \mathrm{H}$ and attenuates morphine withdrawal. EMBO Journal, 17(4), 886-897. doi:

10.1093/emboj/17.4.886

Simonson, B., Morani, A. S., Ewald, A. W. M., Walker, L., Kumar, N., Simpson, D., . . Kivell, B. M. (2014). Pharmacology and anti-addiction effects of the novel $\mathrm{k}$ opioid receptor agonist Mesyl Sal B, a potent and long-acting analogue of salvinorin A. British Journal of Pharmacology, n/a-n/a. doi: 10.1111/bph.12692

Sora, I., Li, X.-F., Funada, M., Kinsey, S., \& R. Uhl, G. (1999). Visceral chemical nociception in mice lacking $\mu$-opioid receptors: effects of morphine, SNC80 and U-50,488. European Journal of Pharmacology, 366(2-3), R3-R5. doi: http://dx.doi.org/10.1016/S0014-2999(98)00933-9

Sorge, R. E., Martin, L. J., Isbester, K. A., Sotocinal, S. G., Rosen, S., Tuttle, A. H., . . Mogil, J. S. (2014). Olfactory exposure to males, including men, causes stress and related analgesia in rodents. Nat Meth, 11(6), 629-632. doi: 10.1038/nmeth.2935

http://www.nature.com/nmeth/journal/v11/n6/abs/nmeth.2935.html\#supplementary-information Spampinato, S., \& Candeletti, S. (1985). Characterization of dynorphin A-induced antinociception at spinal level. European Journal of Pharmacology, 110(1), 21-30. doi: http://dx.doi.org/10.1016/0014-2999(85)90024-X

Steeds, C. E. (2009). The anatomy and physiology of pain. Surgery (Oxford), 27(12), 507-511. doi: 10.1016/j.mpsur.2009.10.013

Stein, A., Yassouridis, A., Szopko, C., Helmke, K., \& Stein, C. (1999). Intraarticular morphine versus dexamethasone in chronic arthritis. Pain, 83(3), 525-532. doi: http://dx.doi.org/10.1016/S0304-3959(99)00156-6

Stein, C., Clark, J. D., Oh, U., Vasko, M. R., Wilcox, G. L., Overland, A. C., . . Spencer, R. H. (2009). Peripheral mechanisms of pain and analgesia. Brain Research Reviews, 60(1), 90-113. doi: http://dx.doi.org/10.1016/j.brainresrev.2008.12.017

Stein, C., \& Küchler, S. (2013). Targeting inflammation and wound healing by opioids. Trends in Pharmacological Sciences, 34(6), 303-312. doi: 10.1016/j.tips.2013.03.006

Stein, C., Millan, M. J., Shippenberg, T. S., Peter, K., \& Herz, A. (1989). Peripheral opioid receptors mediating antinociception in inflammation. Evidence for involvement of mu, delta and kappa receptors. Journal of Pharmacology and Experimental Therapeutics, 248(3), 1269-1275.

Stevens, C. W., \& Yaksh, T. L. (1986). Dynorphin A and related peptides administered intrathecally in the rat: a search for putative kappa opiate receptor activity. Journal of Pharmacology and Experimental Therapeutics, 238(3), 833-838. 
Tan-No, K., Taira, A., Sakurada, T., Inoue, M., Sakurada, S., Tadano, T., . . Kisara, K. (1996). Inhibition of dynorphin-converting enzymes prolongs the antinociceptive effect of intrathecally administered dynorphin in the mouse formalin test. European Journal of Pharmacology, 314(1-2), 61-67. doi: http://dx.doi.org/10.1016/S0014-2999(96)00518-3

Tjølsen, A., Berge, O.-G., Hunskaar, S., Rosland, J. H., \& Hole, K. (1992). The formalin test: an evaluation of the method. Pain, 51(1), 5-17. doi: 10.1016/0304-3959(92)90003-T

Torebjork, H. E., LaMotte, R. H., \& Robinson, C. J. (1984). Peripheral neural correlates of magnitude of cutaneous pain and hyperalgesia: simultaneous recordings in humans of sensory judgments of pain and evoked responses in nociceptors with C-fibers (Vol. 51).

Trigub, M. M., Bogdanova, N. G., Kolpakov, A. A., Bashkatova, V. G., \& Sudakov, S. K. (2014). Effect of Peripheral Opioid Receptor Agonists on Depressive Activity of Ethanol. Bulletin of Experimental Biology and Medicine, 156(6), 778-780. doi: 10.1007/s10517-014-2448-6

Tseng, L. F., \& Collins, K. A. (1991). Involvement of epsilon and kappa opioid receptors in inhibition of the tail-flick response induced by bremazocine in the mouse. Journal of Pharmacology and Experimental Therapeutics, 259(1), 330-336.

Tsuruoka, M., \& Willis Jr, W. D. (1996). Bilateral lesions in the area of the nucleus locus coeruleus affect the development of hyperalgesia during carrageenan-induced inflammation. Brain Research, 726(1-2), 233-236. doi: http://dx.doi.org/10.1016/0006-8993(96)00410-6

Ukai, M., Yamada, S., \& Kameyama, T. (1984). Naloxone reverses the inhibitory effects of dynorphin A on motor activity in the mouse. Pharmacology Biochemistry and Behavior, 20(5), 815-818. doi: http://dx.doi.org/10.1016/0091-3057(84)90206-5

Urban, M. O., \& Gebhart, G. F. (1999). CENTRAL MECHANISMS IN PAIN. Medical Clinics of North America, 83(3), 585-596. doi: http://dx.doi.org/10.1016/S0025-7125(05)70125-5

Villemure, C., Slotnick, B. M., \& Bushnell, M. C. (2003). Effects of odors on pain perception: deciphering the roles of emotion and attention. Pain, 106(1-2), 101-108.

Viscusi, E. R., Reynolds, L., Chung, F., Atkinson, L. E., \& Khanna, S. (2004). Patient-controlled transdermal fentanyl hydrochloride vs intravenous morphine pump for postoperative pain: A randomized controlled trial. JAMA, 291(11), 1333-1341. doi: 10.1001/jama.291.11.1333

Vonvoigtlander, P. F., Lahti, R. A., \& Ludens, J. H. (1983). U-50,488: a selective and structurally novel non-Mu (kappa) opioid agonist. Journal of Pharmacology and Experimental Therapeutics, 224(1), 7-12.

Vonvoigtlander, P. F., Lewis, R. A., \& Neff, G. L. (1984). Kappa opioid analgesia is dependent on serotonergic mechanisms. Journal of Pharmacology and Experimental Therapeutics, 231(2), 270-274. 
Wagner, R., Janjigian, M., \& Myers, R. R. (1998). Anti-inflammatory interleukin-10 therapy in CCl neuropathy decreases thermal hyperalgesia, macrophage recruitment, and endoneurial TNFalpha expression. Pain, 74(1), 35-42.

Wang, Y., Chen, Y., Xu, W., Lee, D. Y. W., Ma, Z., Rawls, S. M., . . L Liu-Chen, L.-Y. (2008). 2Methoxymethyl-Salvinorin B Is a Potent к Opioid Receptor Agonist with Longer Lasting Action in Vivo Than Salvinorin A. Journal of Pharmacology and Experimental Therapeutics, 324(3), 1073-1083. doi: 10.1124/jpet.107.132142

Warwick, R. O., \& Craig Schnell, R. (1976). Studies relating morphine hypothermia with serotonin reuptake in the rat hypothalamus. European Journal of Pharmacology, 38(2), 329-335. doi: http://dx.doi.org/10.1016/0014-2999(76)90336-8

Watanabe, M., Toma, S., Murakami, M., Shimoyama, I., Nakajima, Y., \& Moriya, H. (2002). Assessment of mechanical and thermal thresholds of human $\mathrm{C}$ nociceptors during increases in skin sympathetic nerve activity. Clinical Neurophysiology, 113(9), 1485-1490.

Werkheiser, J. L., Rawls, S. M., \& Cowan, A. (2007). Nalfurafine, the kappa opioid agonist, inhibits icilin-induced wet-dog shakes in rats and antagonizes glutamate release in the dorsal striatum. Neuropharmacology, 52(3), 925-930. doi: http://dx.doi.org/10.1016/j.neuropharm.2006.10.010

Werz, M. A., Grega, D. S., \& MacDonald, R. L. (1987). Actions of mu, delta and kappa opioid agonists and antagonists on mouse primary afferent neurons in culture. Journal of Pharmacology and Experimental Therapeutics, 243(1), 258-263.

Wheeler-Aceto, H., Porreca, F., \& Cowan, A. (1990). The rat paw formalin test: comparison of noxious agents. Pain, 40(2), 229-238. doi: http://dx.doi.org/10.1016/0304-3959(90)90073-M

Whiteside, G. T., Harrison, J. E., Pearson, M. S., Chen, Z., Fundytus, M. E., Rotshteyn, Y., . . Brogle, K. C. (2004). DiPOA ([8-(3,3-diphenyl-propyl)-4-oxo-1-phenyl-1,3,8-triazaspiro[4.5]dec-3-yl]acetic acid), a novel, systemically available, and peripherally restricted Mu opioid agonist with antihyperalgesic activity: II. In vivo pharmacological characterization in the rat. Journal of Pharmacology and Experimental Therapeutics, 310(2), 793-799. doi: 10.1124/jpet.103.063560

Wilder-Smith, O. H., \& Arendt-Nielsen, L. (2006). Postoperative hyperalgesia: its clinical importance and relevance. Anesthesiology, 104(3), 601-607.

Willis, W. D. (2001). Role of Neurotransmitters in Sensitization of Pain Responses. Annals of the New York Academy of Sciences, 933(1), 142-156. doi: 10.1111/j.1749-6632.2001.tb05821.x

Woolf, C. J. (2010). What is this thing called pain? Journal of Clinical Investigation, 120(11), 37423744. doi: $10.1172 / \mathrm{JCl} 45178$ 
Woolf, C. J., Bennett, G. J., Doherty, M., Dubner, R., Kidd, B., Koltzenburg, M., . . Torebjork, E. (1998). Towards a mechanism-based classification of pain? Pain, 77(3), 227-229.

Woolf, C. J., \& Fitzgerald, M. (1986). Somatotopic organization of cutaneous afferent terminals and dorsal horn neuronal receptive fields in the superficial and deep laminae of the rat lumbar spinal cord. The Journal of Comparative Neurology, 251(4), 517-531. doi: $10.1002 /$ cne. 902510407

Woolf, C. J., \& Ma, Q. (2007). Nociceptors--noxious stimulus detectors. Neuron, 55(3), 353-364. doi: 10.1016/j.neuron.2007.07.016

Xin, L., Geller, E. B., Liu-Chen, L. Y., Chen, C., \& Adler, M. W. (1997). Substance P release in the rat periaqueductal gray and preoptic anterior hypothalamus after noxious cold stimulation: effect of selective mu and kappa opioid agonists. Journal of Pharmacology and Experimental Therapeutics, 282(2), 1055-1063.

Yamamizu, K., Hamada, Y., \& Narita, M. (2014). kappa Opioid receptor ligands regulate angiogenesis in development and in tumours. British Journal of Pharmacology. doi: 10.1111/bph.12573

Young-McCaughan, S., \& Miaskowski, C. (2001). Definition of and mechanism for opioid-induced sedation. Pain Management Nursing, 2(3), 84-97. doi: http://dx.doi.org/10.1053/jpmn.2001.25012

Zeynalov, E., Nemoto, M., Hurn, P. D., Koehler, R. C., \& Bhardwaj, A. (2006). Neuroprotective effect of selective kappa opioid receptor agonist is gender specific and linked to reduced neuronal nitric oxide. Journal of Cerebral Blood Flow and Metabolism, 26(3), 414-420. doi: 10.1038/sj.jcbfm.9600196

Zhang, Y., Butelman, E. R., Schlussman, S. D., Ho, A., \& Kreek, M. J. (2005). Effects of the plantderived hallucinogen salvinorin A on basal dopamine levels in the caudate putamen and in a conditioned place aversion assay in mice: agonist actions at kappa opioid receptors. Psychopharmacology, 179(3), 551-558. doi: 10.1007/s00213-004-2087-0

Zhou, L., Lovell, K. M., Frankowski, K. J., Slauson, S. R., Phillips, A. M., Streicher, J. M., . . Bohn, L. M. (2013). Development of functionally selective, small molecule agonists at kappa opioid receptors. Journal of Biological Chemistry, 288(51), 36703-36716. doi: 10.1074/jbc.M113.504381 